University of Wollongong

Research Online

Faculty of Engineering and Information

Faculty of Engineering and Information

Sciences - Papers: Part A

Sciences

$1-1-2016$

\title{
A review on numerical solutions to self-heating of coal stockpile: Mechanism, theoretical basis, and variable study
}

Jian Zhang

University of Wollongong, jz164@uowmail.edu.au

Ting X. Ren

University of Wollongong, tren@uow.edu.au

Yuntao Liang

China Coal Research Institute, Shenyang

Zhongwei Wang

University of Wollongong, zhongwei@uow.edu.au

Follow this and additional works at: https://ro.uow.edu.au/eispapers

Part of the Engineering Commons, and the Science and Technology Studies Commons

Research Online is the open access institutional repository for the University of Wollongong. For further information contact the UOW Library: research-pubs@uow.edu.au 


\title{
A review on numerical solutions to self-heating of coal stockpile: Mechanism, theoretical basis, and variable study
}

\begin{abstract}
Self-heating or even spontaneous combustion of stockpiled coal, which is likely to outbreak under favourable circumstances during its transport, process, and storage, is a long-standing thermal dynamic hazard. This hazard is harmful in diverse aspects: causing loss of coal resource and caking property, raising safety concerns upon occurrence of open fire, and giving off noxious/greenhouse effect gases. Due to the complexity of involved physical process (e.g. heat and mass transport) and chemical process (e.g. coal oxidation), formulating an analytical solution to the problem with or even without a transient approach would be a daunting task and the problem is thus more often addressed numerically. So far many numerical models to self-heating of coal have been developed and to summarise these erratic findings, this work critically reviewed theses numerical solutions since the last four decades. Mechanism of self-heating on coal mass and low temperature coal oxidation especially kinetic modelling of coal oxidation is firstly investigated to clarify the involved physical and chemical processes. On basis of the mechanistic understanding, theoretical derivations and progressive advances on governing equations like energy, mass, and momentum conservation are reviewed and compiled in details. Through parametric studies or sensitivity check these models produced fruitful but slightly inconsistent findings. Therefore to provide industry more unbiased and comprehensive guides, the present work examined the influences of various contributors including wind flow, stockpile dimensions, coal particle size, moisture content, and packing porosity on the self-heating behaviour of stockpiled coal. Last not the least, major challenges and perspectives this subject may have are briefly discussed.
\end{abstract}

\section{Keywords}

theoretical, mechanism, stockpile, coal, study, review, variable, self, basis, heating, numerical, solutions

\section{Disciplines}

Engineering | Science and Technology Studies

\section{Publication Details}

Zhang, J., Ren, T., Liang, Y. \& Wang, Z. (2016). A review on numerical solutions to self-heating of coal stockpile: Mechanism, theoretical basis, and variable study. Fuel, 182 80-109. 


\title{
A review on numerical solutions to self-heating of coal stockpile:
} mechanism, theoretical basis, and variable study

\author{
Jian Zhang ${ }^{\mathrm{a}^{*}}$, Ting Ren ${ }^{\mathrm{a}}$, Yuntao Liang ${ }^{\mathrm{b}}$, Zhongwei Wang

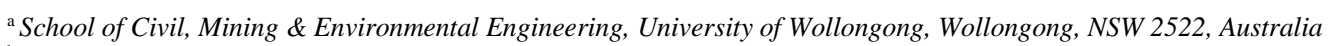 \\ ${ }^{\mathrm{b}}$ Shenyang Branch of China Coal Research Institute, Shenyang 110016, China
}

\section{Abstract}

Self-heating or even spontaneous combustion of stockpiled coal, which is likely to outbreak under favourable circumstances during its transport, process, and storage, is a long-standing thermal dynamic hazard. This hazard is harmful in diverse aspects: causing loss of coal resource and caking property, raising safety concerns upon occurrence of open fire, and giving off noxious/greenhouse effect gases. Due to the complexity of involved physical process (e.g. heat and mass transport) and chemical process (e.g. coal oxidation), formulating an analytical solution to the problem with or even without a transient approach would be a daunting task and the problem is thus more often addressed numerically. So far many numerical models to self-heating of coal have been developed and to summarise these erratic findings, this work critically reviewed theses numerical solutions since the last four decades. Mechanism of self-heating on coal mass and low temperature coal oxidation especially kinetic modelling of coal oxidation is firstly investigated to clarify the involved physical and chemical processes. On basis of the mechanistic understanding, theoretical derivations and progressive advances on essential terms like energy, mass, and momentum conservation are reviewed and compiled in details. Through parametric studies or sensitivity check these models produced fruitful but slightly inconsistent findings. Therefore to provide industry more unbiased and comprehensive guides, the present work examined the influences of various contributors including wind flow, stockpile dimensions, coal particle size, moisture content, and packing porosity on the self-heating behaviour of stockpiled coal. Last not the least, major challenges and perspectives this subject may have are briefly discussed.

\section{Keywords}

Self-heating, Coal stockpile, Numerical solution, Low-temperature oxidation 
2 Mechanism of self-heating of coal stockpile and coal oxidation kinetics. 
Nomenclature

\begin{tabular}{|c|c|c|}
\hline$A$ & Arrhenius pre-exponential factor & $\left(\mathrm{kmol} / \mathrm{m}^{3}\right)^{1-\mathrm{n}} \mathrm{s}^{-1}$ \\
\hline$a$ & Empirical constant in Elovich equation & \\
\hline$C$ & Gas concentration & $\mathrm{kmol} \mathrm{m}^{-3}$ \\
\hline$C_{\mathrm{p}}$ & Specific heat capacity & $\mathrm{J} \mathrm{kg}^{-1} \mathrm{~K}^{-1}$ \\
\hline$C_{P r}$ & Pressure coefficient & \\
\hline$D$ & Diffusion coefficient of specie in the gas phase & $\mathrm{m}^{2} \mathrm{~s}^{-1}$ \\
\hline $\mathrm{d}$ & Diameter of coal particle & $\mathrm{m}$ \\
\hline E & Apparent activation energy & $\mathrm{kJ} \mathrm{mol}^{-1}$ \\
\hline G & Specific porous media surface area & $\mathrm{m}^{-1}$ \\
\hline g & Gravitational acceleration & $\mathrm{m} \mathrm{s}^{-2}$ \\
\hline$h$ & Heat transfer coefficient & $\mathrm{W} \mathrm{m} \mathrm{m}^{-2} \mathrm{~K}^{-1}$ \\
\hline $\mathrm{k}$ & Permeability of the coal matrix & $\mathrm{m}^{-2}$ \\
\hline $\mathrm{n}$ & Apparent order of reaction & \\
\hline$P$ & Pressure & $\mathrm{Pa}$ \\
\hline$q$ & Amount of oxygen taken up per unit mass of coal & \\
\hline$R$ & Universe gas constant & $\mathrm{kJ} \mathrm{mol}^{-1} \mathrm{~K}$ \\
\hline$R a$ & Radius of coal particle & $\mathrm{m}$ \\
\hline $\mathrm{r}$ & Consumption rate of oxygen & $\mathrm{kmol} \mathrm{m}^{-3} \mathrm{~s}^{-1}$ \\
\hline $\mathrm{r}_{\mathrm{m}}$ & Rate of drying or wetting & $\mathrm{kmol} \mathrm{m}^{-3} \mathrm{~s}^{-1}$ \\
\hline$\check{\mathrm{r}}$ & Radial coordinate & $\mathrm{m}$ \\
\hline$S$ & Source term & \\
\hline$T$ & Temperature & $\mathrm{K}$ \\
\hline $\mathrm{t}$ & Time & s \\
\hline$U$ & Gas superficial velocity & $\mathrm{m} \mathrm{s}^{-1}$ \\
\hline $\mathrm{u}$ & Velocity component in $\mathrm{x}$ direction & $\mathrm{m} \mathrm{s}^{-1}$ \\
\hline$V$ & Free stream velocity & $\mathrm{m} \mathrm{s}^{-1}$ \\
\hline $\mathrm{v}$ & Velocity component in y direction & $\mathrm{m} \mathrm{s}^{-1}$ \\
\hline $\mathrm{w}$ & Velocity component in $\mathrm{z}$ direction & $\mathrm{m} \mathrm{s}^{-1}$ \\
\hline $\mathrm{x}$ & Longitudinal coordinate & $\mathrm{m}$ \\
\hline $\mathrm{y}$ & Transverse coordinate & $\mathrm{m}$ \\
\hline $\mathrm{z}$ & Axial coordinate & $\mathrm{m}$ \\
\hline \multicolumn{3}{|c|}{ Greek letters } \\
\hline$\alpha$ & Empirical constant in Elovich equation & \\
\hline$\beta$ & Thermal expansion coefficient & $\mathrm{K}^{-1}$ \\
\hline$\Delta H$ & Heat of coal oxidation & $\mathrm{kJ} \mathrm{mol}^{-1} \mathrm{O}_{2}$ \\
\hline$\Delta H_{m}$ & Heat of evaporation or condensation & $\mathrm{kJ} \mathrm{mol}^{-1}$ \\
\hline$\varepsilon$ & Porosity & \\
\hline$\lambda$ & Thermal conductivity & $\mathrm{W} \mathrm{m} \mathrm{m}^{-1} \mathrm{~K}^{-1}$ \\
\hline$\mu$ & Gas viscosity & $\mathrm{kg} \mathrm{m} \mathrm{s}^{-2}$ \\
\hline$\rho$ & Density & $\mathrm{kg} \mathrm{m}^{-3}$ \\
\hline$\psi$ & Stream function & $\mathrm{kg} \mathrm{m}^{-1} \mathrm{~s}^{-1}$ \\
\hline \multicolumn{3}{|c|}{ Subscripts } \\
\hline am & Ambient & \\
\hline $\mathrm{b}$ & Bulk coal & \\
\hline $\mathrm{c}$ & Coal & \\
\hline $\mathrm{e}$ & Effective & \\
\hline g & Gas & \\
\hline $\mathrm{m}$ & Moisture & \\
\hline o & Oxygen & \\
\hline $\mathrm{r}$ & Reference & \\
\hline
\end{tabular}




\section{Introduction}

68 Coal in all ranks, as a carbonaceous material, is able to be oxidised at low temperature with presence of oxygen rich air 69 [1-19]. The interaction of coal with oxygen at low temperature is exothermic as a whole although some reaction sequences could be endothermic $[15,20]$. It is widely recognised that low temperature oxidation is the main source of heat leading to spontaneous ignition of stockpiled coal. Other exothermic processes like microbial metabolism, interaction of coal with water, and oxidation of pyrite can also contribute to self-heating of coal mass [21]. Among them an important one is that heat evolves as moisture in both gas and liquid phase physically bonds with dry coal particles in which the process is termed as heat of "wetting" in some literatures [21-23]. Phenomenon of self-heating on a coal stockpile is likely to outbreak if the heat generated by coal oxidation and other mechanisms is not adequately dissipated to the surroundings via conduction, convection, and radiation. The excessive heat is, to a considerable extent, stored in the coal by virtue of its poor thermal conductivity and results in a net increment of temperature and meanwhile, very possibly, the reaction rate of coal oxidation. Once the temperature of a coal mass reaches a critical value at which thermal runaway occurs, a fire ensues if not averted with appropriate remedies [24-26]. The hazard of self-heating of coal stockpile is likely to take place in long term storage of thermal power station, in waste surface coal mining spoil piles, and transportation in cargo ship or train over large distances [26-30]. Spontaneous ignition and smouldering of coal stockpile burns the valuable fossil asset and poses a great threat to coal producers and users. In addition, serious and extensive oxidation of coal can also cause loss of its calorific value and coking property [31-33]. More recently, the liberation of large amounts of greenhouse-relevant gases and toxic gases, such as $\mathrm{CO}$ and $\mathrm{NO}_{\mathrm{x}}$, and hazardous substances, such as arsenic, selenium, mercury, and lead contributed from spontaneous combustion and low temperature oxidation of large-scale coal matrix has raised considerable concerns from global communities lately [34-38]. Figure 1 provides some of the photographic views of stockpiled coal fire collected from the worldwide.

Considering all of the raised concerns and the annoying fact that self-heating of coal stockpile is a long-standing problem, the hazard needs to be controlled. Although this imperative has long been acknowledged, it has also been accepted that the physical and chemical processes responsible for this problem is extremely complicated [28]. The problem was mitigated by practical means long before the scientific accounts emerged. However the theoretical research is in equal importance, on a quantitative basis, in assisting with the assessment and prediction of self-heating hazard and design of procedures and countermeasures to reduce this risk. Early efforts have been devoted to self-heating problem of bulky solids by thermal explosion theory, which laid firm foundation of the theoretical solution to the problem [39-42]. 
97 [43-53]. Although thermal explosion theory is able to determine criticality of a porous body with diffusion-controlled oxygen consumption $[45,49,50,53]$, it still has difficulties to directly apply this solution to self-heating problem of coal stockpile as more of the factors affecting self-heating are taken into account [28]. Additionally what raised much of the concern to coal operator is the induction period of a coal stockpile before catching a fire. The increasing demand of transient solutions poses significant challenges to the subject. Derivation of an analytical solution with less approximation to such a transient problem which might involves fluid dynamics, heat transfer, and chemical reaction kinetics would be a daunting or even impossible task so the problem is more often addressed numerically with increasing availability to high-performance computers. The main scope of this work is to review the numerical solutions to self-

To predict the self-heating behaviour of porous coal mass with progressively consumed gas species like oxygen and vapour, prior to the availability of high-performance commercial fluid dynamics simulation code, several rudimentary mathematical studies with many assumptions and simplifications though were conducted [23, 54-70]. Among these works, Sondreal and Ellman [23] calculated the material and energy balances for a stockpiled lignite in which heat is transferred only by conduction. Nordon [54] proposed a one-dimensional unsteady state model consisting of the differential equations for mass and energy conservation and for the reaction rate of coal oxidation. Schmal et al. [55] developed another one-dimensional model which included thermal impacts exhibited by evaporation/condensation of coal moisture. Both models analysed forced convection through the packed bed by varying the air flow velocity as a system parameter. Brooks and co-workers [56-59] differed from previous treatments in that natural convection was taken into account as an important mechanism for oxygen transport that is responsible for the occurrence of self-heating without the need to assume the existence of a pressure gradient over the coal bed. Young et al. [60] proposed a twodimensional natural convection and conduction model in a packed bed containing a hot spot (i.e. coal stockpile, nuclear reactor) and this work reconfirmed natural convection is a feasible mechanism for oxygen transport into a coal pile where sufficient reaction may occur to sustain a hot spot. To predict the development of localized spontaneous heating within a porous coal matrix that is subjected to forced convection or in an otherwise quiescent environment in which buoyancy flow dominates, the Bureau of Mines developed three time-dependent mathematical models, which were used to calculate the temperature increase associated with chemisorption of oxygen by the coal [67]. Bradshaw et al. [61] studied the effect of natural convection on ignition in a laterally-unbounded coal pile and stable three-dimensional flow planforms for the model were predicted. Arisoy and Akgün [65] developed a one-dimensional non-equilibrium thermal model consisting of conservation equations for oxygen, water vapour, moisture of coal, and energy for both gaseous and 
solid phases. Salinger and co-authors [69] critically reviewed the mathematical analysis of coupled reaction and transport

128 in chemical reactors and analysed spontaneous heating of coal stockpiles by considering the nonlinear interactions of 129 chemical reaction, heat transfer, and buoyancy-driven flows within and around the stockpile. Krishnaswamy and coworkers $[8,62]$ developed a reaction-diffusion model for low-temperature oxidation of coal and this model was incorporated in a two-dimensional model for spontaneous heating of open coal stockpiles where the influence of moisture migration can be negligible. Hull et al. $[63,68]$ developed a theoretical model for a confined space context where stockpile is sealed on all sides except the top which provides free surface and channels for oxygen diffusion. Monazam et

al. [70] formulated a transient one-dimensional spontaneous heating model to describe the self-heating process at relatively low temperatures. Akgün and Essenhigh [64] proposed a two dimension transient model of self-heating of coal stockpile and found height and time are two primary factors in determining if a stockpile is unconditionally safe. Although the predictions of temperature ramping profile and incubation period are very likely beyond engineering providing subsequent researchers valuable insights to the problem and offering initial guidance to assist coal operators to stack stockpile more safely. No doubt the fundamental understanding of self-heating in coal stockpile has advanced but yet lacks clarification and summary especially for the period after the Carras and Young's review work [28]. Therefore the first intent of this work is to investigate more details of the mechanism of self-heating and heat \& mass transfer process in coal matrix and on basis of this mechanistic understanding, core constituents and main features of these

More recently with the advance and development of more sophisticated numerical solutions, especially the availability of cutting-edge Computational Fluid Dynamics (CFD) modelling techniques and their increasing applications in coal and related industries [71], predictable interpretation of transient self-heating of coal mass with less restrictions and within tolerated engineering accuracy becomes possible [24, 26, 30, 31, 72-80]. Among these works, Moghtaderi et al. [30] studied the effects of wind driven flow field on self-heating behaviour of typical coal stockpiles and found wind flow plays a critical part in dynamics of flow field inside the pile and thereby affects the heating process. Krajčiová et al. [78] innovated a model including radiation energy balance of the coal stockpile surface and indicated solar radiation has a strong influence on the temperature ramping profile of stockpile. Yuan and Smith [75] studied effects of coal properties on self-heating problem in underground coal mine goaf areas by a CFD model. Yuan and Smith [24] further developed a three-dimensional equilibrium thermal CFD model to simulate spontaneous heating in a large-scale testing chamber with a forced ventilation system. Ejlali et al. [77] improved preceding models by employing a local thermal non-equilibrium 
approach and stated the required time to vaporize the water content and the maximum temperature is a function of porosity of porous pile, moisture content and Darcy number. Taraba and Michalec [73] numerically investigated the effects of longwall advance rate on spontaneous heating in goaf areas by a CFD model. Kim and Sohn [72] numerically validated a novel method (air blowing from bottom of stockpile and/or instalment of dual barrier) to suppress spontaneous ignition of coal stockpiles in a coal storage yard. Zhu et al. [26] developed a theoretical model to predict the self-ignition time and locations of coal stockpiles with relatively large diameter of coal particle. Taraba et al. [74] developed a CFD model to study the influences of wind on the spontaneous heating process of a coal stockpile. Yang et al. [31] proposed a two-dimensional model to investigate the effects of coating the bottom of coal stockpile with fine particles to control self-heating hazard. Xia et al. [79] also used the CFD code to simulate the self-heating process of residual coal in longwall goaf. Zhang et al. [80] studied the low-temperature self-heating behaviour of multiple coal stockpiles under different prevailing wind conditions. Not only above works can eliminate more restrictions to enhance the applicability of numerical solutions to coal self-heating problems, considerable variable studies have also been conducted and many parametric findings have been reported. These key findings are however not strictly consistent so the applicability of these valuable suggestions to industry is somehow hindered. Hence to deliver more unbiased and and the parametric study which provides much more information and understanding of the problem. Therefore the present work mainly reviewed previous numerical models of self-heating of coal stockpile from above perspectives. Lastly some challenges the subject faces and possible improvements are discussed.

\section{Mechanism of self-heating of coal stockpile and coal oxidation kinetics}

\section{$178 \quad 2.1$ Mechanistic understanding of the hazard}

Analogous to many other biological and chemical porous reactors, a coal stockpile is essentially a coal mass consisting of heterogeneous distribution of porous coal particles and gases like oxygen, water vapour, and gaseous product liberated by oxidation reaction transporting in the inter-particle channels and the microstructures of coal particles [81, 82]. Figure 3 provides a schematic illustration of the process and main features of coal stockpile self-heating. Very briefly, phenomenon of self-heating could occur if the heat generated by coal oxidation and other exothermic processes exceed the heat dissipated to the surroundings by conduction, convection, and radiation. The air inside of stockpile can be constantly replaced and replenished through advective motion caused by forced or natural convection caused by presence of pressure gradient and diffusive motion caused by oxygen consumption of coal which results concentration of oxygen 
187 in stockpile is lower than that of ambient atmosphere. The heat can be continuously produced if air supply is not

eliminated. Interaction of coal with oxygen including coal oxidation and oxygen adsorption at low temperature is exothermic as a whole although it could be endothermic at some steps [15, 20]. The thermal effect of moisture might not be ignored at the initial stage of coal self-heating but heat generated by coal oxidation will dominate with progressive drying of coal. Therefore it is safe to argue that the major heat generation mechanism responsible for self-heating is still coal oxidation [28]. The heat of reaction during oxidation of lignite increased from approximately $313 \mathrm{~kJ}$ per mole oxygen absorbed at $20^{\circ} \mathrm{C}$ to $376 \mathrm{~kJ}$ per mole oxygen at $90^{\circ} \mathrm{C} \mathrm{[23].} \mathrm{Kaji} \mathrm{et} \mathrm{al.} \mathrm{[7]} \mathrm{measured} \mathrm{the} \mathrm{rates} \mathrm{of} \mathrm{heat} \mathrm{liberation} \mathrm{and}$ oxygen consumption due to coal oxidation in the temperature range $20-170^{\circ} \mathrm{C}$ using coals ranging from subbituminous to anthracite and 75-90kcal (i.e. 300-379kJ) heat evolved per mole of oxygen at steady state was reported. The generated heat is transported out of the stockpile by conduction through coal mass, convection through wind, and radiation. If the rate of heat generation is greater than the rate at which heat can be dissipated to the external environment, the excessive heat will be stored in coal matrix and results in a temperature rise. The higher temperature would cause a more drastic reaction taking place, and if no controls are exercised, a fire is very likely to outbreak. Considering the factors that weathering coal particles at surface of coal stockpile are relatively inert in terms of oxidative reaction with long period of exposure to the ambient atmosphere and convective and conductive heat dissipation is stronger than heat production at coal for a given coal water content $[28,66,83,84]$. Moisture has an impact on the process through both chemical and physical ways albeit the effects exhibited in chemical ways have not been fully grasped. More specific accounts of

To be more realistic to describe heat interaction inside a coal stockpile, heat transfer between coal particles should be treated in a non-equilibrium thermal approach because temperature differentials between air transported from ambient and coal particles could be substantially high. In other words, a stockpile should not be treated as a non-porous body and convective heat loss which takes place in the interior of stockpile ought to be featured. If the temperature differential between the solid coal particle and gas is important in the thermal behaviour, it is necessary to represent the energy stored in each individual phase as well as the exchange of thermal energy between them [85, 86]. Figure 4 is a close-up 
to-gas, gas-to-coal, and coal-to-coal where effective solid conductance is introduced because of narrow clearance existing between coal particles which further reduce the thermal conductivity of coal. It is assumed that the porous coal stockpile may be treated as homogeneous so that conduction can be modelled by a single effective thermal conductivity [60]. Effective thermal conductivity $\lambda_{\mathrm{e}}$ is often given by equation $1[24,26,75,82]$, other solutions for effective thermal conductivity can be found in the literatures $[67,70,72]$,

$$
\lambda_{e}=\varepsilon \lambda_{g}+(1-\varepsilon) \lambda_{c}
$$

223 The low thermal conductivity of coal is the main reason why thermal energy can be well contained in the deep stockpile.

224 Heat convection occurs between gas to coal and the efficiency of heat convection is mainly determined by velocity of gas advection stream within narrow connected channels between coal particles. Whilst heat radiation could be a major contributor in the surface of stockpile because of solar energy it absorbed but in deep stockpile heat radiation can be negligible [78]. Another efficient heat transfer mechanism is interaction of coal with moisture in which the vaporisation and diffusion of water from a hot region, followed by condensation in a cooler region, is accompanied by a considerably higher effective rate of heat transfer than that which can occur by conduction alone [50]. The interaction of coal with water proceeds much quicker than with oxygen molecule and that leads to the conclusion that interaction of coal with moisture is an efficient heat transfer mechanism especially at temperature range $80 \sim 90^{\circ} \mathrm{C}$. Air transported into coal stockpile via convection and diffusion. Convective flow in both natural and forced ways is pressure-driven flow and diffusive motion is caused by gas concentration gradients because neither oxygen is consumed nor gaseous products are produced at an equal rate everywhere. Convective flow is the primary driver in micro-scale flow, even very small pressure gradients will cause larger flux than flux generated by very steep concentration gradients [87]. Air convection mainly occurs in inter-particle channels and diffusion mainly occurs in inner pores of coal particle and in deep region of coal stockpile where convection is very weak. Irrespective of complex pore structure of coal, many numerical solutions adopted a global surface reaction mechanism so detailed transport mechanism like gas diffusion into inner pores is normally disregarded.

\subsection{A brief study of coal oxidation kinetics}

241 To define oxygen consumption rate of coal on a quantitative basis for numerical solution, the nature and chemical 242 kinetics of low temperature coal oxidation must be well studied. Mechanism of low-temperature coal oxidation has been investigated by many studies but complete understanding has never been obtained because of very complex pore structure and chemical composition of coal $[4,9,15-18,20,28,33,88-103]$. Despite of the incomplete understanding of the mechanism and kinetics of coal oxidation, overall reaction paths have reached a general consensus. Very briefly two parallel interaction sequences exist: direct burn-off and adsorption sequence. The burn-off reaction resembles direct 
combustion of solid fuels which is strongly dependent on temperature and the reaction sequence is likely to occur at specific sites in a coal's aromatic or aliphatic structure, resulting in the direct formation of gaseous products including $\mathrm{CO}, \mathrm{CO}_{2}$, and $\mathrm{H}_{2} \mathrm{O}[8,9,15,95,100,104]$. The adsorption sequence includes: (i) reversible physical adsorption; (ii) irreversible chemisorption of oxygen on the surfaces of pores and the formation of intermediate coal-oxygen complexes including peroxygen, hydroperoxide and hydroxyl species; (iii) the degradation of unstable solid coal-oxygen complexes to gaseous products and formation of stable solid compounds, e.g. carbonyl or carboxyl containing species; (iv) the decomposition of stable compounds and the exposure of new active sites for oxidation [15, 90], refer Figure 5 which is a very representative chart of interaction of coal with oxygen at low temperature. More kinetic models were summarized by Wang et al. [15], the compilation is further cited in this work to give a clearer picture of kinetic models, refer Table 1.

It is noticeable, at low temperature range, the number of the active sites for oxygen adsorption usually decays exponentially, which often correlates to exhibition of the Elovich effect. At present it is, however, unlikely to describe the burn-off reaction sequence in fundamental steps due to the lack of understanding and therefore, to a quantitative basis, many authors attempted to use the Elovich dependence (or partially) to describe the progressive decrease of the rate of sorption reaction regime with increasing uptake of active sites at a constant temperature $[1,15,54,90,98,105,106]$. The Elovich equation was often written as,

$$
\frac{\mathrm{d} q}{\mathrm{~d} t}=a \exp (-\alpha q)
$$

264 Although the Elovich equation is often taken as a purely empirical term, it can be effectively applied to explain the rate of oxygen consumption with time, namely the "ageing" effect $[1,54,107]$. Whilst in reality temperature in stockpile is elevating as a result of heat accumulation and further due to the existence of burn-off reaction sequence which is highly dependent on temperature so consumption rate of oxygen is more frequently expressed in Arrhenius form with a given temperature and oxygen concentration $[24,26,74,75,79]$, which was written,

$$
r=A\left[C_{0}\right]^{\mathrm{n}} \exp (-E / R T)
$$

270 Authentic Arrhenius equation has its origin in gas phase reaction regime $[108,109]$. An equation of the same form as 271 Equation 3 has also found wide application to the oxidation of coal. However usually there is no mechanistic interpretation of A and E, simply an observed temperature dependence of rate that fits an equation of this form [110]. But some other studies indicated the activation energy, E, may be regarded as a measure of the energy barrier to reaction, while the pre-exponential factor, $A$, correlates to the available surface area for oxidation [111]. Thus, the pre-exponential factor depends heavily on the coal's pore structure and fine particles tend to have a larger pre-exponential factor [112]. Irrespective this dispute, it can be observed, from Equation 3, that coal oxidation rate is simply determined by the 
reaction order and two Arrhenius constants at a given temperature and partial pressure of oxygen. It is assumed that oxygen can penetrate throughout the coal without any diffusional resistance and the reaction rate between gaseous oxygen and solid coal particle is expressed as if it is a homogenous gas phase reaction [1]. To consider the diffusional restriction into the interior of coal particle, many studies introduced an effectiveness factor, which is conventionally defined as the ratio of the reaction rate under diffusional limitations to the rate which would be observed in the chemical control regime in the absence of transport or diffusional effect [96]. Detailed interpretation of the effectiveness factor can be found in the literatures $[8,63,65,96]$. The value of the reaction order in low temperature oxidation of coal and other carbonaceous materials has been indicated to vary from 0.5 to $1[28,50]$. More specific values of reaction order have been published are: $\mathrm{n}=1[23,73,113], \mathrm{n}=0.61[24,114], \mathrm{n}=0.52[115]$, and $\mathrm{n}=0.7[55,116]$. In the case of the spontaneous combustion of coal, temperatures are extremely low and chemical kinetics play the main role on reaction rate [1]. The kinetic constants are affected by unique coal properties such as pore structure, mineral matter, volatile content, and coal rank so they varies from coal to coal. Even for a same coal the parameters can be affected by different particle sizes [112] and heating stages [2]. The value of apparent activation energy, $E$, of different coals can vary between 12 and $95 \mathrm{~kJ} / \mathrm{mol}$ and more values of activation energy for low temperature coal oxidation can be found in the review work conducted by Wang et al. [15]. Taraba and Michalec [73] discussed the pre-exponential factor is of the greatest uncertainty giving ordinarily values differing over several orders and another study also indicated the pre-exponential factor has a typical value between 1 and $7 \times 10^{5} / \mathrm{s}[24,75]$. As a result, the Arrhenius constants for a given coal oxidation context must be determined experimentally. These experimental methods may include adiabatic testing method, heat

Self-heating of coal starts with low temperature oxidation stage at which adsorption reaction sequence might manifest so the reaction rate of a coal could display a non-Arrhenius behaviour curve (more likely, a Elovich curve). In a study of the oxidation rate of coal and coal char [107], it was shown that the oxidation rate of a coal char exhibits both an Arrhenius and Elovich kinetics from 50 100 ${ }^{\circ} \mathrm{C}$. As can be seen in Figure 6(a), Jones and Newman [110] reported a non-Arrhenius behaviour of a Chinese bituminous coal in a micro-calorimeter experiment at temperatures in the range 311 338K. More recently an adiabatic testing figure of a high volatile bituminous coal from Hunter Valley coalfield of Australia indicated that an Arrhenius dependence curve above $70^{\circ} \mathrm{C}$ can be found and below this temperature a straight line is impossible to be fitted at the $\ln (\mathrm{dT} / \mathrm{dt})$ versus $(1 / \mathrm{T})$ plot, refer Figure 6(b) [1]. A possible explanation is adsorption reaction sequence proceeds at a high rate initially and manifests itself by driving reaction rate to a non-Arrhenius behaviour curve. With the 
lead to the extent reaction rate starts to follow the Arrhenius-like dependence. Many numerical solutions adopted a simple Arrhenius approach with or without an effectiveness factor to mathematically deal with consumption rate of oxygen within a stockpile $[24,26,31,55,58,62,64,65,72-75]$. The conjunctive effects brought by the Elovich mechanism and Arrhenius equation at low temperature coal oxidation may introduce a new dimension for numerical simulation of self-heating behaviour on a coal mass although the need of numerical assessment of Elovich parameters was called long ago [54]. Another glance at the Equation 3 it can be known partial pressure of oxygen also plays a role in the rate of coal oxidation at a given temperature and Arrhenius constants. It is plausible to approximate that any solid coal-oxygen complex produced during low-temperature coal oxidation would not affect the rate of oxidation if Arrhenius reaction mechanism is presumed. Gaseous products (e.g. $\mathrm{CO}, \mathrm{CO}_{2}$, and $\mathrm{H}_{2} \mathrm{O}$ ) liberated by direct burn-off reaction and decomposition of solid complex would, however, disperse into the gas mixture and affect the concentration of oxygen although the amount of gaseous product is much less appreciable than that of consumed oxygen [95]. Early numerical works only considered the consumption of oxygen and some recent works started to incorporate effect of gaseous products with very simplified stoichiometric schemes though [24, 72-75], refer Table 2 which summaries the main features such as transport mechanism and spatial dimension, and important parameters like physical properties and reaction kinetics of present numerical solutions to self-heating of coal mass.

\section{Theoretical basis}

323 On formulating a theoretical model for a numerical solution to self-heating of coal stockpile one is very likely to shed curiosity, to a mathematical sense, into how the heat is generated and transferred, how the oxygen is transported as being consuming by coal, how the gas flux flows inside stockpile, and how the moisture migrates from one site to another site. The mechanistic understanding of self-heating of coal matrix has been comprehensively discussed in the last section and having the fundamental knowledge in mind, core constituents of the mathematical model should include terms on heat and species (e.g. oxygen and/or water vapour) conservation, momentum balance and continuity equations for fluid flow in a porous matrix. This section will serve to discuss and record the progressive formulation and development of theoretical models. To keep the straightforwardness and simplicity of the discussion, energy term of heat radiation is not be included.

\subsection{Energy conservation}

\subsubsection{Absence of moisture}

334 The energy description starts with Sondreal and Ellman [23] who assumed heat is only dissipated by conduction of a coal mass, which yields,

$$
\rho_{\mathrm{b}} C_{\mathrm{pb}} \frac{\partial T}{\partial t}=\lambda_{e} \nabla^{2} T+S
$$


The successive terms denote the storage of internal energy which manifest itself as a transient temperature rise of bulky coal, heat diffusion and energy source which denotes liberation of reaction heat. Later, Hull et al. and Young et al. [60, 63] also used conduction as a sole heat transport mechanism when levelled stockpiles of coal are transported in a confined space like barges or rail cars, which gives,

$$
(1-\varepsilon) \rho_{\mathrm{c}} C_{\mathrm{pc}} \frac{\partial T}{\partial t}=\lambda_{e} \frac{\partial^{2} T}{\partial x^{2}}+(1-\varepsilon) r \Delta H
$$

In Schmal's one dimensional model [55], heat dissipated by convection (the second term in equation 5) was included in the heat balance equation, which results,

$$
(1-\varepsilon) \rho_{\mathrm{c}} C_{\mathrm{pc}} \frac{\partial T}{\partial t}+\rho_{\mathrm{g}} C_{\mathrm{pg}} u \frac{\partial T}{\partial x}=\lambda_{\mathrm{e}} \frac{\partial^{2} T}{\partial x^{2}}+(1-\varepsilon) r \Delta H
$$

Brooks et al. [56-58] also incorporated convective heat term in heat balance but presuming a pseudo steady state, which produces,

$$
\lambda_{\mathrm{e}} \frac{\partial^{2} T}{\partial x^{2}}-\rho_{\mathrm{g}} C_{\mathrm{pg}} u \frac{\partial T}{\partial x}+r \Delta H=0
$$

In the forced convection model of Edwards's work [67], a non-equilibrium thermal state between gas and coal was considered and the thermal transport equation was written in cylindrical coordinates, which yields,

$$
\varepsilon \rho_{\mathrm{g}} C_{\mathrm{pg}} \frac{\partial T_{\mathrm{g}}}{\partial t}+(1-\varepsilon) \rho_{\mathrm{c}} C_{\mathrm{pc}} \frac{\partial T_{\mathrm{c}}}{\partial t}+\rho_{\mathrm{g}} C_{\mathrm{pg}} U_{\check{\mathrm{r}}} \frac{\partial T_{\mathrm{g}}}{\partial x}+\rho_{\mathrm{g}} C_{\mathrm{pg}} w \frac{\partial T_{\mathrm{g}}}{\partial x}=\lambda_{\mathrm{e}} \frac{\partial^{2} T}{\partial \mathrm{z}^{2}}+\lambda_{\mathrm{e}}\left(\frac{\partial^{2} T}{\partial \check{\mathrm{r}}^{2}}+\frac{1}{\check{\mathrm{r}}} \frac{\partial T}{\partial \check{\mathrm{r}}}\right)+r \Delta H
$$

And thermal transfer between the solid coal and the gas is governed by,

$$
\rho_{\mathrm{c}} C_{\mathrm{pc}} \frac{\partial T_{\mathrm{c}}}{\partial t}=\frac{3 h}{R}\left(T_{\mathrm{g}}-T_{\mathrm{c}}\right)
$$

While in the wind-driven convection model, the gas and solid coal were, for a conservative estimate of induction period, assumed to be in thermal equilibrium. The energy transport equation was therefore written as,

$$
\left[\varepsilon \rho_{\mathrm{g}} C_{\mathrm{pg}}+(1-\varepsilon) \rho_{\mathrm{c}} C_{\mathrm{pc}}\right] \frac{\partial T}{\partial t}+\rho_{\mathrm{g}} C_{\mathrm{pg}} u \frac{\partial T}{\partial x}=\lambda_{\mathrm{e}} \frac{\partial^{2} T}{\partial x^{2}}+r \Delta H
$$

Krishnaswamy et al. [62] extended the heat conservation equation to two dimensions in Cartesian coordinate system, which yields,

$$
(1-\varepsilon) \rho_{\mathrm{c}} C_{\mathrm{pc}} \frac{\partial T}{\partial t}+\rho_{\mathrm{g}} C_{\mathrm{pg}}\left(u \frac{\partial T}{\partial x}+v \frac{\partial T}{\partial y}\right)=\lambda_{\mathrm{e}}\left(\frac{\partial^{2} T}{\partial x^{2}}+\frac{\partial^{2} T}{\partial y^{2}}\right)+r \Delta H
$$

To date commercial CFD code is capable of solving 3D problem in (non-)equilibrium thermal approach. Zhu and coworkers [26] used the code established a 2D energy conservation in thermal equilibrium, the equation is written as,

$$
\left[\varepsilon \rho_{\mathrm{g}} C_{\mathrm{pg}}+(1-\varepsilon) \rho_{\mathrm{c}} C_{\mathrm{pc}}\right] \frac{\partial T}{\partial t}+\rho_{\mathrm{g}} C_{\mathrm{pg}}\left(u \frac{\partial T}{\partial x}+v \frac{\partial T}{\partial y}\right)=\lambda_{\mathrm{e}}\left(\frac{\partial^{2} T}{\partial x^{2}}+\frac{\partial^{2} T}{\partial y^{2}}\right)+(1-\varepsilon) r \Delta H
$$

Yuan and Smith $[24,75]$ used CFD code to develop a three-dimensional equilibrium thermal model for self-heating of coalbed in a testing chamber, which produces, 


$$
\left[\varepsilon \rho_{g} C_{p g}+(1-\varepsilon) \rho_{c} C_{p c}\right] \frac{\partial T}{\partial t}+\rho_{g} C_{p g}\left(u \frac{\partial T}{\partial x}+v \frac{\partial T}{\partial y}+w \frac{\partial T}{\partial z}\right)=\lambda_{\mathrm{e}}\left(\frac{\partial^{2} T}{\partial x^{2}}+\frac{\partial^{2} T}{\partial y^{2}}+\frac{\partial^{2} T}{\partial z^{2}}\right)+r \Delta H
$$

The most recently, Xia and co-workers [79] developed a non-equilibrium thermal model for self-heating of a longwall goaf, hence two separate energy equations are required,

For solid phase

$$
(1-\varepsilon) \rho_{\mathrm{c}} C_{\mathrm{pc}} \frac{\partial T_{\mathrm{c}}}{\partial t}-(1-\varepsilon) \nabla\left(\lambda_{\mathrm{c}} \nabla T_{\mathrm{c}}\right)=S+h G\left(T_{\mathrm{g}}-T_{\mathrm{c}}\right)
$$

For gas phase

$$
\varepsilon \rho_{\mathrm{g}} C_{\mathrm{pg}} \frac{\partial T_{\mathrm{g}}}{\partial t}+\rho_{\mathrm{g}} C_{\mathrm{pg}} U_{\mathrm{g}} \nabla T_{\mathrm{g}}-\varepsilon \nabla\left(\lambda_{\mathrm{g}} \nabla T_{\mathrm{g}}\right)=-h G\left(T_{\mathrm{g}}-T_{\mathrm{c}}\right)
$$

\subsubsection{Presence of moisture}

Although some fresh stockpiles are very dry due to low inherent water content of coal, they are likely to become moist with presence of rain, snow, and/or moist ambient air. In practice most coal stockpiles are moist especially some low rank coals with presence of high inherent water content and thereby heat exchanged via transition of water phase should be incorporated in the model. In Schmal's model, additional energy conservation was proposed for a moist coal pile [55]. To adjust the model, two extra terms were incorporated in Equation (6): one for evaporation (or, with the opposite sign for condensation, first term) and another one for convective heat transfer by water vapour (second term).

$$
\Delta H_{m} \frac{\partial\left(U C_{\mathrm{m}}\right)}{\partial x}+U_{\mathrm{m}} \rho_{\mathrm{m}} C_{\mathrm{pm}} \frac{\partial T}{\partial t}+(1-\varepsilon) \rho_{\mathrm{c}} C_{\mathrm{pc}} \frac{\partial T}{\partial t}+\rho_{\mathrm{g}} C_{\mathrm{pg}} u \frac{\partial T}{\partial x}=\lambda_{\mathrm{e}} \frac{\partial^{2} T}{\partial x^{2}}+(1-\varepsilon) r \Delta H
$$

By ignoring the convective heat transfer by water vapour, Monazam et al. [70] proposed another equation for energy balance of a damp coal mass,

$$
(1-\varepsilon) \rho_{\mathrm{c}} C_{\mathrm{pc}} \frac{\partial T}{\partial t}=\lambda_{\mathrm{e}} \frac{\partial^{2} T}{\partial x^{2}}-\rho_{\mathrm{g}} C_{\mathrm{pg}} u \frac{\partial T}{\partial x}+r \Delta H(1-\varepsilon)+(1-\varepsilon) \Delta H_{m} r_{m}
$$

Arisoy and Akgun [65] improved Schmal's model by adopting a non-equilibrium thermal model to study the effect of moisture, which gives,

For solid phase:

$$
(1-\varepsilon) \rho_{\mathrm{c}} C_{\mathrm{pc}} \frac{\partial T_{\mathrm{c}}}{\partial t}=\lambda_{\mathrm{c}} \frac{\partial^{2} T_{\mathrm{c}}}{\partial x^{2}}+(1-\varepsilon) \frac{3}{R a} h\left(T_{\mathrm{g}}-T_{\mathrm{c}}\right)-(1-\varepsilon) \Delta H_{m} r_{m}+(1-\varepsilon) r \Delta H
$$

For gas phase:

$$
\varepsilon \frac{\partial}{\partial t}\left(\rho_{\mathrm{g}} C_{\mathrm{pg}}+\rho_{\mathrm{m}} C_{\mathrm{pm}}\right) T_{\mathrm{g}}+u \frac{\partial}{\partial x}\left(\rho_{\mathrm{g}} C_{\mathrm{pg}}+\rho_{\mathrm{m}} C_{\mathrm{pm}}\right) T_{\mathrm{g}}=\varepsilon \lambda_{\mathrm{g}} \frac{\partial^{2} T_{\mathrm{g}}}{\partial x^{2}}-(1-\varepsilon) \frac{3}{R a} h\left(T_{\mathrm{g}}-T_{\mathrm{c}}\right)
$$

Later Akgun and Essenhigh [64] extended the one-dimensional non-equilibrium thermal model into two dimensions, which yields,

\section{For solid phase:}

$$
(1-\varepsilon) \rho_{\mathrm{c}} C_{\mathrm{pc}} \frac{\partial T_{\mathrm{c}}}{\partial t}=\lambda_{\mathrm{c}}\left(\frac{\partial^{2} T_{\mathrm{c}}}{\partial x^{2}}+\frac{\partial^{2} T_{\mathrm{c}}}{\partial y^{2}}\right)+(1-\varepsilon) \frac{3}{R a} h\left(T_{\mathrm{g}}-T_{\mathrm{c}}\right)+(1-\varepsilon) r \Delta H-(1-\varepsilon) r_{\mathrm{m}} \Delta H_{\mathrm{m}}
$$


For gas phase:

$$
\varepsilon \frac{\partial T_{\mathrm{g}}}{\partial t} \rho_{\mathrm{g}} C_{\mathrm{pg}}+\rho_{\mathrm{g}} C_{\mathrm{pg}}\left[\frac{\partial}{\partial x}\left(u T_{\mathrm{g}}\right)+\frac{\partial}{\partial y}\left(v T_{\mathrm{g}}\right)\right]=\lambda_{\mathrm{g}}\left(\frac{\partial^{2} T_{\mathrm{g}}}{\partial x^{2}}+\frac{\partial^{2} T_{\mathrm{g}}}{\partial y^{2}}\right)-(1-\varepsilon) \frac{3}{R a} h\left(T_{\mathrm{g}}-T_{\mathrm{c}}\right)
$$

\subsection{Mass conservation}

Most models assumed mass of solid coal particle remains unchanged prior to ignition and therefore mass conservation study was focused on oxygen conservation and water vapour conservation (for a moist coal stockpile). Schmal et al. [55] proposed a one dimensional mass balance model for both oxygen and moisture, which yields,

For oxygen:

$$
\varepsilon \frac{\partial C_{\mathrm{o}}}{\partial t}+u \frac{\partial C_{\mathrm{o}}}{\partial x}-\varepsilon D_{\mathrm{o}} \frac{\partial^{2} C_{\mathrm{o}}}{\partial x^{2}}+(1-\varepsilon) r=0
$$

In which the successive terms represent the local accumulation of oxygen, the convective transport of oxygen, the diffusion of oxygen, and the consumption of oxygen due to coal oxidation.

For moisture:

$$
\frac{\partial c_{\mathrm{m}}}{\partial t}-\frac{\partial\left(U C_{\mathrm{m}}\right)}{\partial x}=0
$$

The successive terms represent the transient accumulation of moisture at the coal particle and the rate of evaporation (or condensation). Hull et al. [63] also used a one dimensional model to study the role of the diffusion of oxygen in a confined storage by eliminating volumetric convective component, which gives,

$$
\varepsilon \frac{\partial C_{0}}{\partial t}=\varepsilon D_{\mathrm{o}} \frac{\partial^{2} C_{\mathrm{o}}}{\partial x^{2}}-(1-\varepsilon) r
$$

Krishnaswamy et al. [62] developed the oxygen balance equation to two dimensions but molecular diffusion is ignored and a pseudo steady state is assumed, and these assumptions produce,

$$
u \frac{\partial C_{\mathrm{o}}}{\partial x}+v \frac{\partial C_{\mathrm{o}}}{\partial y}=-r
$$

Arisoy and Akgun [65] developed another one-dimensional conservation model for both oxygen and moisture, with similar form of Schmal's model,

For oxygen:

$$
\varepsilon \frac{\partial \rho_{\mathrm{o}}}{\partial t}+u \frac{\partial \rho_{\mathrm{o}}}{\partial x}=\varepsilon D_{\mathrm{o}} \frac{\partial^{2} \rho_{\mathrm{o}}}{\partial x^{2}}-(1-\varepsilon) r
$$

For moisture:

$$
\varepsilon \frac{\partial \rho_{\mathrm{m}}}{\partial t}+u \frac{\partial \rho_{\mathrm{m}}}{\partial x}=\varepsilon D_{\mathrm{m}} \frac{\partial^{2} \rho_{\mathrm{m}}}{\partial x^{2}}+(1-\varepsilon) r_{\mathrm{m}}
$$

Akgun and Essenhigh [64] developed a more complete mass conservation model for both oxygen and moisture in two dimensions, which produces, 
For oxygen:

$$
\varepsilon \frac{\partial \rho_{\mathrm{o}}}{\partial t}+\left(u \frac{\partial \rho_{\mathrm{o}}}{\partial x}+v \frac{\partial \rho_{\mathrm{o}}}{\partial y}\right)=\varepsilon D_{\mathrm{o}}\left(\frac{\partial^{2} \rho_{\mathrm{o}}}{\partial x^{2}}+\frac{\partial^{2} \rho_{\mathrm{o}}}{\partial y^{2}}\right)-(1-\varepsilon) r
$$

421

423

For moisture:

$$
\varepsilon \frac{\partial \rho_{\mathrm{m}}}{\partial t}+\left(u \frac{\partial \rho_{\mathrm{m}}}{\partial x}+v \frac{\partial \rho_{\mathrm{m}}}{\partial y}\right)=\varepsilon D_{\mathrm{m}}\left(\frac{\partial^{2} \rho_{\mathrm{m}}}{\partial x^{2}}+\frac{\partial^{2} \rho_{\mathrm{m}}}{\partial y^{2}}\right)-(1-\varepsilon) r_{\mathrm{m}}
$$

Carras and Young [28] summarised a general form of mass balance which can be applied in both oxygen and water vapour, the general form was written as,

$$
\varepsilon \frac{\partial C}{\partial t}+\varepsilon U \nabla C-D \nabla^{2} C+S=0
$$

Yuan and Smith $[24,75]$ developed a generic mass transfer equation in three dimensions by ignoring localized accumulation of gaseous species, which gives,

$$
\rho u \frac{\partial C_{\mathrm{o}}}{\partial x}+\rho v \frac{\partial C_{\mathrm{o}}}{\partial y}+\rho w \frac{\partial C_{\mathrm{o}}}{\partial z}=\rho D_{\mathrm{o}} \frac{\partial^{2} C_{\mathrm{o}}}{\partial x^{2}}+\rho D_{\mathrm{o}} \frac{\partial^{2} C_{\mathrm{o}}}{\partial y^{2}}+\rho D_{\mathrm{o}} \frac{\partial^{2} C_{\mathrm{o}}}{\partial z^{2}}+S
$$

More recently the oxygen conservation equation proposed by Zhu et al. [26] and Xia et al. [79] has the same form as the generalised description of Equation (30),

$$
\begin{gathered}
\text { Zhu's model } \rightarrow \varepsilon \frac{\partial C}{\partial t}+\left(u \frac{\partial C}{\partial x}+v \frac{\partial C}{\partial y}\right)=D\left(\frac{\partial^{2} C}{\partial x^{2}}+\frac{\partial^{2} C}{\partial y^{2}}\right)-(1-\varepsilon) r \\
\text { Xia's model } \rightarrow \varepsilon \frac{\partial C_{\mathrm{o}}}{\partial t}+\nabla\left(-\varepsilon D \nabla C_{\mathrm{o}}\right)+U \nabla C_{\mathrm{o}}=r
\end{gathered}
$$

\subsection{Momentum balance}

By making the Boussinesq approximation which essentially states that the temperature variation of the fluid properties can be ignored except for the density, and that the density dependence is only considered when it gives rise to buoyancy convection [121] and using Darcy's model to replace the shear stress tensor, Young et al. [60] proposed the motion equation in porous coal pile,

$$
-\nabla P-\frac{\rho_{\mathrm{am} g}}{k} U+\rho_{\mathrm{g}} g=0
$$

Later in buoyance-driven model of Edwards's work [67], a similar manner was used to develop the motion equation into two components, which shows,

$$
\left\{\begin{array}{c}
\frac{\partial P}{\partial x}=-\frac{\mu}{k} u \\
\frac{\partial P}{\partial y}=-\frac{\mu}{k} v+\rho_{\mathrm{am}} g\left(1-\frac{T_{\mathrm{am}}}{T_{g}}\right)
\end{array}\right.
$$

The permeability $k$ of coal matrix is approximated by the Blake-Kozeny equation for laminar flow in packed beds [24, $26,62,67,72,75,77,122]$, which gives, 


$$
k=\frac{\varepsilon^{3} d^{2}}{150(1-\varepsilon)^{2}}
$$

445 Many other works also used Darcy's law to describe flow in porous stockpile and additionally incorporates buoyancy convection as a possible mechanism of flow in porous medium as formulated by Edwards's work $[30,62,64,69]$. The equation was generalised by Carras [28] and the universal form is written as,

$$
U=\frac{k}{\varepsilon \mu}(-\nabla P+\rho g)
$$

The first term in Equation (37) describes flow due to a pressure gradient while the second term describes the buoyancy due to gas density changes with temperature. For a very coarse coal stockpile $(3 \sim 20 \mathrm{~cm})$, Zhu et al. [26] argued it is more appropriate to describe flow in Brinkman's law because of high Darcy number and Reynolds number [123], and motion of gas flow should be written as,

$$
\left\{\begin{array}{c}
\frac{\partial P}{\partial x}=\mu \frac{\partial^{2} U}{\partial x^{2}}-\frac{\mu}{k} u \\
\frac{\partial P}{\partial y}=\mu \frac{\partial^{2} U}{\partial y^{2}}-\frac{\mu}{k} v+\rho_{\mathrm{g}} g\left(1-\frac{T_{\mathrm{am}}}{T_{\mathrm{g}}}\right)
\end{array}\right.
$$

454

Nevertheless above models yields a steady flow field, to date, commercial CFD code is capable of handling a transient flow field which can be given by [82],

$$
\rho_{\mathrm{g}}\left(\frac{\partial U}{\partial t}+U \nabla U\right)=-\nabla P-\varepsilon U \frac{\mu}{k}+\mu \nabla^{2} U-\rho_{\mathrm{g}} g \beta\left(T_{\mathrm{g}}-T_{\mathrm{am}}\right)
$$

In which the successive terms represent the transient momentum response, advection of momentum, pressure gradient, Darcy force, Brinkman effects and buoyant force.

\subsection{Continuity}

The continuity equation also assumes the validity of the Boussinesq approximation, which gives rise to the continuity equation $[28,60,62,69]$,

$$
\nabla U=0
$$

In a quasi steady-state approximation for the gas flow, the mass flux can be defined in terms of a stream function [60, 64, 67],

$$
\left\{\begin{array}{c}
\rho_{\mathrm{g}} u=-\frac{\partial \psi}{\partial \mathrm{y}} \\
\rho_{\mathrm{g}} v=\frac{\partial \psi}{\partial \mathrm{x}}
\end{array}\right.
$$

With CFD code, Kim and Sohn [72] proposed a three dimensional transient continuity equation with absence of the Boussinesq approximation, which yield,

$$
\frac{\partial \rho}{\partial t}+\frac{\partial \rho u}{\partial x}+\frac{\partial \rho v}{\partial y}+\frac{\partial \rho w}{\partial z}=0
$$


If given appropriate initial and boundary conditions, quantitative information on self-heating phenomena can be produced. It should be noted, as a review study, any validation and analysis of mathematical model is not a task of present work. These theoretical terms are organised for general knowledge purpose so they might be modified or reworked when it comes to a numerical solution to a given context of self-heating of stockpiled coal.

\section{Variable study}

474 The last section compiles the theoretical basis of numerical solutions, one apparent point, as can be observed from these terms, is that self-heating behaviour of a coal stockpiles is governed by various variables, like coal reactivity which correlates to rate of coal oxidation and heat generation, moisture content which have an impact on heat transfer process, and geometry of stockpile which is likely to affect the distribution of wind induced pressure gradients around it. Considerable parametric studies based on these base models have been conducted to provide fruitful information to industry yet these valuable results are not strictly consistent. Therefore the aim of this section is to critically investigate and examine the impacts of different variables on the thermal behaviour of coal stockpile, and to clarify these findings and hopefully, shed light on practical industry operations. The main contributors to the self-heating of coal stockpile and the values they have been assigned are tabulated and attached in Appendix A. It can be seen some of the variables received intensive attentions and therefore the conduction of variable analysis is limited to those parameters, namely coal reactivity, particle diameter, compaction degree, moisture, wind, stockpile height and slope.

\subsection{Coal reactivity}

Two studies $[124,125]$ reviewed the factors affecting the susceptibility of coal to spontaneous combustion and the factors include: (1) Coal rank and petrographic composition, (2) Moisture content and volatile matter content; (3) Mineral matter type and pyrite content; (4) Particle size and physical properties; (5) Oxidation history and weathering. Among them one important intrinsic factor is rank of coal and coal rank is a measure of the extent of organic metamorphism of a coal, ranging from low-rank peat to high-rank anthracite [126]. It has reached a general consensus that low-rank coals are more liable to spontaneous heating than high-rank ones. Coal reactivity is a multi-factor driven parameter and it is difficult to determine their relative effects by varying one factor while retaining the others unchanged. As a result it appears impossible to develop a mathematical sense to consider all the factors in a numerical solution so the normal procedure is to manipulate the Arrhenius constants to denote different reactivity of different coals. This is plausible because the Arrhenius empirical constants are derived via real experimental data which might, to some extent, reflect the true nature of coal. Many studies have adopted this approach to investigate the influence of coal reactivity on self-heating behaviour of coal stockpile but what caused the variation of coal reactivity or Arrhenius parameters was not clearly stated. It is suspected the variation may attribute to some intrinsic factors of coal (e.g. coal rank, maceral or 
physical composition) rather than some extrinsic ones (e.g. moisture content or coal particle size) because the external factors would have effects on both coal reactivity and other properties of coal and coal matrix. Schmal et al. [55] examined the effect of reactivity of coal by assigning different values of pre-exponential factor, refer Figure 7. The lower value of frequency factor stands for a less reactive coal, while the intermediate value represents a normal coal and the higher value signifies a more reactive coal. It is very noticeable the maximum temperature rise most rapidly for a more reactive coal due to faster coal oxidation which accompanies with more heat generation. A striking trend is that maximum temperature rise more slowly than that of a plain coal for a long run. A possible elucidation is that the hot spot of a more reactive coal stockpile move towards to the surface due to the depletion of oxygen. While the heat transferred by conduction is more efficient near surface, which results a pseudo steady state for a long run. However, the situation is very unlikely to occur because long before that the coal would become very inert. Brooks and Glasser [58] also studied coal reactivity by using different Arrhenius constants, refer Figure 8 . In the model coal particle size was considered as an independent factor while maximum temperature was a dependent variable. It was found that pre-exponential factor is a more critical parameter than activation energy because safe particle size range varies more significantly with pre-

Krishnaswamy et al. [62] investigated the effect of coal reactivity by using three values of pre-exponential factor for coal beds with various porosities, refer Figure 9. It was found from Figure 9(a) that decreasing the reactivity tenfold has little impact on the susceptibility of a coal stockpile to thermal runaway occurrence but the time required would be considerably extended. The reactivity of coal does not impact the self-ignitibility for a long run and it appeared to depend primarily on the amount of oxygen within the stockpile. Krajčiová et al. [78] studied the effects of coal reactivity by choosing four different coals among which Wyoming coal and Talcher coal are two extreme types with high preexponential factor $\left(8.83 \times 10^{6} / \mathrm{s}\right)$ and low activation energy $(26 \mathrm{~kJ} / \mathrm{mol})$ respectively. It took approximately 10 days and 20 days to reach critical coal temperature for Wyoming coal and Talcher coal respectively. Therefore it might be summarised that more reactive coals (smaller value of activation energy and larger value of pre-exponential factor) could considerably decrease induction period for a coal stockpile to reach the critical temperature and for less reactive coals, thermal runaway is still possible to occur but would take longer.

The reactivity of coal also often correlates to the deterioration effect (also the Elovich effect) as more and more active sites attached to the surface area of coal are consumed with elapsing of time. Nordon and co-workers [54, 107] incorporated Elovich constants in the oxidation rate equation (Equation 43) to examine the deterioration effect of a 
supercritical bed, as can be seen in Figure 10(a), the occurrence of thermal runaway totally changes with or without presence of Elovich constans. Schmal et al. [55] employed two rate reduction approaches (i.e. linear reduction and exponential reduction) to mimic the loss of reactivity, it was found that, unlike Nordon's result, it would not affect the occurrence of thermal runaway but the induction time is appreciably extended, refer Figure 10(b). Hence more numerical assessments are required to justify the influences of reactivity loss with time. The converged effects brought by the Elovich mechanism and Arrhenius mechanism at low temperature coal oxidation may introduce a new dimension for numerical simulation of self-heating behaviour on a coal mass although it may make the estimation of induction period less conservative.

$$
\frac{\mathrm{d} q}{\mathrm{~d} t}=r_{r} \exp [-(E+\alpha R T q) / R T]
$$

\section{$538 \quad 4.2$ Coal particle size}

Increasing (or decreasing) coal particle diameter has two independent impacts on self-heating behaviour of a coal stockpile. One effect is to decrease (or increase) reaction rate of coal oxidation due to less (or more) exposure of inner surface of coal and another impact is to enhance (or reduce) permeability of coal mass. For coal particle sizes ranging from a few hundred microns to a few centimetres, it is widely reported that the rate of oxidation increases with a decrease in particle size because more internal surface area is exposed and most of the coal reaction surface is within the coal particle rather than on the exterior surface.[15, 23, 28, 65, 67, 95, 112, 113, 127]. The oxidation rate is widely reported to be inversely proportional to $0.1 \sim 0.7$ power of particle size $[15,73,95,113,127,128]$. However it has also been found the rate is independent of particle size if particle diameter is below a critical value. The values of critical diameter of coal particle were reported to be $2.31 \mathrm{~mm}$ [116], $1 \mathrm{~mm}$ [7], $5 \mathrm{~mm}$ [23], and $0.05 \mathrm{~mm}$ [127]. The difference of these values may attribute to coals with varying porosities and different testing configurations. To understand the physical and chemical connotation of the critical particle size, an illustration which divides the oxidation of a coal particle into three reaction regimes is given. As is well known, solid (coal)-gas (oxygen) reaction falls into three regimes, namely (a) kinetically dominated (b) kinetically and pore-diffusionally controlled (c) external mass transfer governed $[16,112,116]$, refer Figure 11. Regime (a) often occurs in a very porous coal particle where overall oxidation rate is dominated by intrinsic chemistry of coal, oxygen molecule will diffuse deeply into the coal and the internal oxygen concentration (or concentration in pores) is equal to the bulk oxygen concentration. In the chemically-controlled regime, the gas transport restriction imposed by pore diffusion is eliminated and chemical composition and/or the number of reactive sites on the coal surfaces may be able to greatly influence reactivity. The reaction rate would be independent of coal particle size 
large diameter of coal particle. Reactions in regime (b) are characterized by less porous coal with higher effective diffusivities for molecular oxygen. The chemical reaction is slower than diffusion, allowing gaseous oxygen to diffuse into the coal particle before reacting. Oxygen concentration near the external surface approaches bulk concentration and a concentration profile within the pore is expected. In this case the overall reaction rate is controlled by the combined effects of chemical reaction and oxygen diffusion and is influenced by coal particle size. An extreme case may occur (regime c) for a nonporous coal particle or a coal with strong internal diffusion limitations where the oxidation mostly occurs on the superficial surface without any external diffusion resistance. Chemical reaction is fast relative to mass transfer and therefore, oxygen concentrations on the external surface are close to zero. In this case reaction rate is considered to be inversely proportional to the particle size. This regime occurs mainly in combustion at high temperatures and is not the subject of low temperature oxidation [112]. The implication of critical value of coal particle diameter is at which the oxygen diffused in internal and external surface equals to the maximum capacity of oxygen consumption for low-temperature coal oxidation. Below the critical diameter the reaction of oxygen with coal falls into fully chemical dominated regime (regime a) and any further reduction in coal particle size will not promote the reaction

To examine the effect of particle size on the rate of oxidation in a large coal stockpile, Akgun and Arisoy [112] conducted a series of tests in a large testing cylinder by using four ranges of diameters (i.e. $2-5 \mathrm{~mm}, 5-10 \mathrm{~mm}, 15-20 \mathrm{~mm}$, and 20-50mm) of a Turkish coal. The reported kinetic parameters of four coal samples are summarised in Figure 12. As can be observed, a noticeable trend is both activation energy and pre-exponential factor drop with increasing diameters and the variance of pre-exponential factor is more obvious than that of activation energy. The reduction of preexponential factor correlates to less availability to surface reaction area and more restrictions for oxygen to diffuse into interior of coal particle. The physical meaning of this reduction in activation energies is that the overall rate of oxidation becomes less sensitive to temperature as particle size increases which may imply the transition of reaction regime from (b) to (c). This is due to mass transfer regime might be dominated in large and intact particles and mass transfer is less sensitive to temperature rise. Karnser and Perlmutter [116] and Kam et al. [100] also reported the reduction of activation energy with larger diameter of coal particle. It was also indicated the apparent activation energy is approximately 20 $\mathrm{kJ} / \mathrm{mol}$ if reaction rate is limited by external mass transfer and $63 \mathrm{~kJ} / \mathrm{mol}$ for a very porous coal of which reaction rate is governed by intrinsic chemical reaction [116]. While for coal reaction rated by combined effect of chemically and diffusion control the value of activation energy is in the between [100]. It appears the reaction regime of four coal particle size in Figure 12 falls into reaction regime (b) and further calculation reconfirmed this finding [112]. 
589 As the oxidation rate of most coals might be restricted by internal diffusion and therefore, for most cases reaction rate of 590 coal increases with decreasing diameter. It ought to note that a decrease in diameter can decease the permeability of coal mass (reduce particle size by twofold reduces the permeability by fourfold, Equation 36) and thus decrease the availability of oxygen within coal stockpile as well. To examine the net effect, Edwards [67] scaled the value of preexponential factor with direct ratio of particle diameter, which implies the reaction rate is governed by external mass transfer. Three sizes of coal particles $(0.05625 \mathrm{~mm}, 0.1125 \mathrm{~mm}$, and $0.225 \mathrm{~mm})$ were studied in a wind-driven convection model and the result is illustrated in Figure 13(a). The result shows a reduction in coal particle diameter, as a net effect, leads to a greater increase in the maximum coalbed temperature and the hot spot moves towards surface of coalbed due to starvation of and more difficulty to transport oxygen. As can be observed from Figure 13(b), Arisoy and Akgun reported a similar finding that an increase in particle dimeter cause less temperature rise but hot spot transports towards deeper region of coalbed. In this study the reaction regime was considered to be chemically and pore-diffusion controlled oxidation and the dependence of the reaction rate on particle diameter was described by defining an effectiveness factor

Krishnaswamy et al. [62] indicated the effect of particle size on bed permeability is more pronounced than its effect on reaction rate in which an effectiveness factor was also introduced. In comparison of three sub-figures of Figure 14, it is not hard to observe decreasing particle size is tending to catch an occurrence of thermal runaway more readily and rapidly. It has also been noticed for low porosity (0.06) of coal stockpile with small particle, the thermal runaway would not occur due to extreme transport restrictions of oxygen. However for a large particle, the fire incident is still likely to outbreak for a long run, refer Figure 14(c). Thus the influence of particle size on pile permeability is deemed more critical than that of global reaction rate. In consideration of the good limitation of oxygen ingress to a fine particle stockpile, Yang et al. [31] demonstrated using fine particle coal coating coal stockpile could significantly decrease the temperature rising rate. In practice, a possible strategy would be: (i) If a coal is very porous and the critical size of the coal is quite large which implies coal reaction regime is chemically controlled, it is favourable to stack stockpile with fine particle to restrict oxygen ingress because particle size has limited effect on reaction rate; (ii) whilst if a coal is less porous and its critical size is very small which means the reaction is governed by oxygen diffusion and/or external mass transfer, it is possibly safer to pack stockpile with large particles to slow down coal oxidation rate. However, it requires more numerical assessment and field demonstration prior to any implementation with due consideration of alleviating the self-heating hazard by changing particle size. 
619 Porosity represents the degree of compaction of a coal stockpile and its value has been generally categorised into three ranges to stand for three compaction scenarios [30,55], refer Table 3. Porosity is a parameter which can be varied in practice by means of compaction and it has been a routine procedure for coal handlers to compact coal stockpile periodically due to more restriction of oxygen ingress for a more compacted pile [58, 64]. A detailed examination indicates an increase in porosity of a coal stockpile could affect self-heating behaviour in four aspects: (i) attract more airflow into stockpile and thus enhance availability of oxygen; (ii) provide more convective flow within pile and hence increase heat dissipation via convection in a non-equilibrium thermal model [64]; (iii) incur more difficulty to transfer heat via conduction due to more inter-particle clearance [55, 115]; (iv) has less reactive material per unit volume of pile. It has been showed that limitation of oxygen transport due to more compaction has an overwhelming effect on the selfheating process in many models $[26,55,62,67,78,115]$ and some of the representatives results are given in Figure 9 , Figure 14, and Figure 15. It is obvious that at low porosities (0.06 for Krishnaswamy's model, 0.05 for Schmal's model, 0.165 for Edwards's model, and 0.1 for Fierro's model), the incident of thermal runaway is less likely to occur. While an exceptional result is given in Figure 15(d) which shows thermal runaway still outbreaks at low porosity of 0.1 for a stockpile composed of coarse particles (diameter $>20 \mathrm{~mm}$ ). The similar finding has also been previously reported by Figure 14(c) with $9.6 \mathrm{~mm}$ coal particle. This might attribute to only the large particle size has secured sufficient permeability as indicated by Equation 36 regardless the value of porosity.

635 stockpile is able to prolong induction time but unable to make a stockpile unconditionally safe. The value of porosity is suggested to be below 0.2 for long time storage and extra pre-cautions needs to be taken upon compaction of a coarse stockpile. 


\subsection{Moisture}

649 There have been many instances of combustible materials like linen stacks and grain-dust stockpiles being ignited by moisture and this has been attributed to the latent heat of condensation, heat of adsorption (wetting) in the case of direct addition of liquid, or indeed both $[129,130]$. Coal, however, unlike other combustible material, exerts much more complex processes interacted with moisture. It has been reported water is present in coal particles as many forms and a generalised classification is bulk, capillary, multilayer, and monolayer water [131-133]. Bulk water dwells at the external surface of coal particles or in the inter-particle voids and water condensed in a coal pore structure is usually denoted as capillary water. Multilayer water, occurring in thin layers next to the walls of coal pores (a few molecular diameters in depth), is weakly bonded to hydrogen atoms in coal aliphatic or aromatic structure, while monolayer water is strongly hydrogen bonded to oxygen-containing functional groups at the pore surface [131]. More classifications of water in coal can be derived in a review work conducted by $\mathrm{Yu}$ and co-workers [134]. The fact that water exists in many forms implies the complex nature of coal-water interactions. Besides the mentioned physical interaction of coal with water, moisture can also be a crucial part in chemical oxidation. The overall effect of moisture can be divided into two aspects, namely (i) the effect of moisture transfer (evaporation, condensation, diffusion and convection) on the overall heat balance; (ii) the effect of moisture (at equilibrium or during drying or wetting) on the rate of coal oxidation [135]. Moisture plays an important part in determining the nature, rate and extent of self-heating in the stockpiled coal. It is widely reported water in a coal may chemically and physically promote or inhibit coal oxidation and self-heating behaviour of coal. These effects are briefly generalised and tabulated in Table 4 in which whether these effects were included in a numerical solution is also discussed. The interactions between water vapour and coal can either exothermic or endothermic, mostly depending on whether water condenses or evaporates. The equilibrium moisture content of coal is determined by the difference between the humidity level of the surrounding air and the inherent moisture content [28]. It is thus necessary to consider both of them simultaneously to study the effects of the moisture on the coal self-heating process. For example, dry air flowing over moist coal stockpile will adsorb the moisture and leads in temperature decrease due to evaporation; while moist air flowing over dry coal pile will condense the water vapour to coal surface and results in temperature rise because of heat gain from condensation and wetting.

As inherent water plays a contradictory role in impacting consumption rate of oxygen, theoretically a critical moisture range for a specific coal exists below or above which oxygen consumption rate is likely to be reduced. The implication of the critical water content is that if water content is higher than this critical value, extra water forms multilayer at the surface of coal pores increasing diffusion resistance for oxygen into interior of coal; whilst below this value, only a 
677 portion of the active sites have access to the monolayer water molecules and this slows down the chemisorption reactions

$678[15,131]$. It has been suspected that the value of critical water content equals to the amount of water being adsorbed in

679 monolayer. Table 5 summaries some of the critical water contents for different coals. Due to existence of critical water content and other complex interaction mechanisms of coal with water, extra precautions needs to be taken upon preventing coal self-heating by spraying water.

The complex nature of the above effects hindered a comprehensive mathematical modelling as well as practical applications. Consequently, many researchers only considered its physical effects by adding extra terms on energy equations and mass equations in numerical solutions, refer Table 4. The heat of wetting is also not included because it has been shown its value accounts for only $10 \%$ of the heat of evaporation [55] although it has been accepted combustible material could be ignited by heat of "wetting". As can be seen from Figure 17(a), moisture exhibits little difference up to temperature $340 \mathrm{~K}$. However at higher temperature, the maximum temperature profile levels off at $350 \mathrm{~K}$ for a long period of time for a coal pile with $8 \%$ moisture content. This temperature rises again till the coal becomes locally dry. At the pseudo steady state, it is postulated heat liberation due to oxidation approximately equals to heat dissipation due to evaporation. This temperature level is maintained or slightly increased until the coal becomes totally dry and then temperature may take off again. Not only the temperature rising rate is affected, the profile with distance from surface of coal bed also has considerable difference, refer Figure 17(b). For a normal dry self-heating body, generally the temperature profile across the body itself is roughly parabolic in shape with a peak at the hot spot [136], like the result of dry coal. However the maximum temperature for moist coal becomes deeper and extended over a much longer distance than for dry coal. Both phenomena are caused by the "heat pipe" effect, which is a very efficient heat transfer mechanism and leads to a levelling of temperatures in a stockpile. The "heat pipe" effect appears even more efficient at higher gas velocity as can be observed from Figure 17(c). The drying time is much shorter for a higher velocity air stream. The calculations also implies the moisture can only serve to delay the onset spontaneous heating of coal rather than a cure to this problem suggesting that safety of long-term storage of a coal stockpiles is independent of moisture.

More calculations regarding effects of moisture for various airflow velocities were presented in Figure 18. Figure 18(a) is the maximum temperature rising rate for both moist coal and dry coal with various airflow velocities. It can be seen moisture has a great impact on self-heating behaviour and the levelling effect also manifest at high temperatures. There are basically no differences between the heating rates of dry and damp coal initially because evaporation is very slow at very low temperature. It can be also noticed the rate of temperature rise is greater at higher for dry coal for the entire 
process and for moist coal only up to $330 \mathrm{~K}$. Upon the temperature the "heat pipe" effect governs the self-heating behaviour and the rate of temperature rise reduces owing to the more efficient water migration rate at higher velocities.

The extended length of hot spot of wet coal was also reported, refer Figure 18(b). As the airflow velocity increases, the maximum temperature gradually drops and the length of the hot spot along the coalbed increases due to higher convective heat transport.

Figure 19 illustrates the influence of moisture on maximum temperature of a stockpile sourced from Akgun's model [64]. In Figure 19(a) moisture levels of coal samples A, B, C are 16.8\%, 1.8\% and 35.4\%, respectively. For coal B which is almost totally dry, the maximum temperature increases steadily with time as a normal case. For coal C which is very wet, temperature increases rapidly at the beginning and then evaporation becomes more effective and the temperature levels off. For coal A, the temperature rising profile resembles that of coal C but the steady state is much shorter than that of coal C probably because of quicker drying of coal A. However, Akgun's calculation was running with a limitation that the chemical and physical compositions of the three coal samples are not identical and therefore it remains unclear whether moisture is the sole factor which causes the difference in the temperature ramping profiles of the three coal samples. One decade later Ejlali et al. claimed a similar finding in temperature rising profile for a wet stockpile [77]. Temperature rising profile of a wet coal underwent three stages: (i) slow rise due to self-heating, (ii) levelling effect due to energy exchange from alteration of water phase, and (iii) rapid rise due to drastic oxidation of dry coal at a relatively high temperature. Clearly numerical assessments on influences of moisture require to be substantially reinforced especially heat of "wetting" and how the moisture content affects coal oxidation kinetics need to be incorporated into the numerical model.

More recently intensive attentions have been drawn to study the complex effects of wind as more and more commercial CFD codes become available [26, 30, 72, 74]. Wind, as a kind of forced convection, plays a contradictory role in selfheating behaviour of a stockpiled coal. On one hand, the forced convection cools down the stockpile by taking more heat away; on the other hand, the wind is very likely to supply more oxygen into pile and generate more heat. Many studies used a constant velocity profile to mimic the wild wind $[26,62,67,115]$, to date a varying profile of incoming wind can be established either by power low [74] or log low [30] with the assistance of CFD code, refer Figure 20(a). Taraba et al. [74] further considered real changes in the velocity and direction of wind over time as deduced from meteorological data, refer Figure 20(b). It was also reported that the wind flow induces a wake region downstream from the pile and, consequently, creates an asymmetric pressure distribution, refer Figure 21. 
To understand how air is transported into stockpile, the main requirement is a knowledge of the distribution of the pressure around the pile. When wind confronts coal stockpile, locally higher velocity region is induced and higher stockpile is more likely to result in even greater local velocity. Have another glance of momentum conservation equation (Equations 37 and 39) it is not hard to notice that higher local velocity will contribute to more significant pressure drop. Therefore lower pressure region where wind meets a higher obstacle, stockpile in this case, will be created and this lower pressure region will draw air in. This quantity of pressure drop is conveniently presented in non-dimensional term using the concept of a pressure coefficient [137]. The pressure coefficient, $C_{\mathrm{Pr}}$, is defined via

$$
C_{\mathrm{Pr}}=\frac{2\left(P-P_{0}\right)}{\rho_{\mathrm{am}} V^{2}}
$$

Both Moghtaderi et al. [30] and Taraba et al. [74] reported the highest pressure is exerted at the front bottom of the pile where the air flow is brought to rest (i.e. local velocity approaches zero) and pressure drops substantially at the top of the pile before tailing off, refer Figure 22.

Moghtaderi et al. [30] and Akgun and Essenhigh [64] agreed that at initiation of oxidation, the resultant self-heating rapidly becomes non-uniform throughout the pile and two local hot spot with maximum temperature will be created at either side of the pile symmetrically when there is no wind. However it would be a totally different story with presence of wind. Given that the equilibrium of symmetric mass transport and heat transfer is broken due to the wind, the distribution of the hot spot is supposed to be asymmetric and indeed, almost all literatures agree this but the location of the hot spot differs based on different models. Many models $[30,62,74,115]$ indicated that the hot spot always locates on the windward side, while Zhu et al. [26] stated the location of the hot spot will move to the leeward for a coarse particle stockpile with the increase of the velocity of wind. A possible reason is that more space and inter-particle channels can be generated in a coarse coal stockpile and a stronger forced convection is induced at the windward side of the pile. When wind becomes stronger, heat dissipated by the forced convection exceeds that generated by the oxidation and as a result the hot spot moves to the deeper side or even the leeward side of the pile. Besides the lateral motion of hot spot, Taraba et al. [74] further reported a vertical movement of the hot spot in the stockpile, refer Figure 23. At the initial stage of self-heating (346K) the hot spot locates at top corner of windward side, it gradually moves to the bottom as selfheating develops to an advanced stage (>397K). The buoyancy effects were deemed as a possible reason for the vertical motion of the hot spot. Naturally convective airflow driven by buoyancy evidently promotes dissipation of the oxidation heat in a hot spot located in the upper part of the pile and as a result, heat accumulation optimally commence to be 
was demonstrated by field observation of another study [31], refer Figure 23. It can be seen the smoke and smouldering fire locates at bottom of the stockpile and hence and coating stockpile bottom with fine particle coal can significantly alleviate the hazard due to reduced ingress of oxygen into bottom zone.

Many studies also confirmed that the maximum temperature in the hot spot increases with the increased wind velocity and some of the representative results are given in Figure 25. It appears the effects of more oxygen drawn into stockpile promoting heat generation outweigh the effects of more heat dissipation via convection of higher wind velocity. It can be also observed heat loss due to more wind convection has very limited effects especially at low temperature range, refer Figure 25(d). Therefore installing artificial wind barriers confronting wind prevailing direction could be a possible control to prevent self-heating and spontaneous combustion of the coal stocked [72, 138].

\section{$777 \quad 4.6$ Stockpile height}

For a specific spatial shape of stockpile decreasing pile height is widely reported to be capable of prolonging induction period $[26,32,64]$. An apparent reason is heat for a lower stockpile can more readily be dissipated by conduction. Figure 26 shows influences of stockpile height on self-heating behaviour of stockpiled coals. A general trend is decreasing stockpile height can make a safer stockpile. Thus the risk of spontaneous combustion on coal stockpile can be reduced by stacking low pile. In addition, Akgun and Essenhigh [64], Zhu et al. [26], both agreed that a specific pile has a critical value of pile height ( $1 \mathrm{~m}$ in Akgun's model, 3m in Zhu's model) below which the stockpile becomes intrinsically safe or can be safely stored for a very extended period of time. Each coal stockpile has a unique critical height and the critical height is affected by many other factors like coal reactivity and moisture content. It is also found that the maximum temperature rises of different coal piles have different sensitivities to pile height. If coal is very reactive and dry, maximum temperature rise is very sensitive to the pile height. While if coal is very moist the occurrence of thermal runaway exhibit independence of stockpile height, refer Figure 26(c). In practical coal storage and handling operation, the pile height and storage capacity must be considered simultaneously because of the limitation of area of storage yard. If a critical height of a reactive coal pile is less than $1 \mathrm{~m}$, it is obviously not suitable to stack that low pile in practical operations. Figure 27 plots the loading capacity of a single stockpile in varied pile heights and slopes. Here a standard truncated pyramid pile is assumed to be $100 \mathrm{~m}$ long and $50 \mathrm{~m}$ wide, and density of bulk coal is roughly $1.12 \mathrm{t} / \mathrm{m}^{3}$ considering porosity of 0.2 . It can be clearly seen from Figure 27(a), storage capacity of a single pile is becoming increasingly insensitive to pile height and this insensitivity becomes more manifest at a gentle slope. For a very reactive and gentle slope coal stockpile, decreasing pile height will considerably improve safe storage time and incur less loss of 
the storage capacity. For a less reactive or very moist coal, increasing pile height will improve the storage capacity of pile and have less impact on self-heating behaviour.

\section{$798 \quad 4.7$ Stockpile slope}

799 Slope angel influences the self-heating process through wind-induced pressure gradient distribution. In the case of stockpiles with gentle slopes, the wind-induced pressure driving force for convective flow is smaller than for steep slopes. Two extreme situations are exemplified. If the wind attacks a very gentle or nearly flat pile, the variation on wind velocity will be negligible and therefore the effects on pressure variation can be ignored as well. If the airway is partial blocked by a nearly vertical porous pile, the local wind velocity will significantly rise and result in huge pressure coefficient drop. Therefore more air flows into the stockpile with a steeper slope and more oxygen can be supplied for coal oxidation. Figure 28 gives some of representative results of the effects of varying slopes on self-heating process of coal stockpile. Krishnaswamy et al. [62] indicated for a gentle slope, most porosities of stockpile is safe except for porosities above 0.3 , while for a steeper slope, most porosities are not safe except for extremely low porosity of 0.06 . Akgun and Essenhigh [64] also found that the self-heating behaviour is very sensitive to the side slope. As the slope decreases, the period of time when thermal runaway occurs considerably increases. However when it comes to a coarse particle stockpile (particle diameter>20mm), the pile slope has a very limited effect on self-heating behaviour [26]. A possible reason is big diameter of coal has secured enough permeability of oxygen ingress so slope has limited influence. It can be seen from Figure 27(b) the storage capacity of single pile is less dependent of side slope at lower heights. Thus for a low stockpile $(<10 \mathrm{~m})$, a gentle slope can be employed to slow down self-heating process with less loss to the

\section{$815 \quad 5$ Challenges and perspectives}

816 As discussed self-heating of coal stockpile is a result of several complex processes and therefore most numerical models 817 were developed with excessive assumptions and simplifications. The consequence of it is accuracy of the numerical outcome is questioned and even unable to meet engineering demand. Due to the lack of knowledge of coal oxidation mechanism, the mathematical description of oxygen consumption rate and heat generation rate would be a major dilemma. As indicated many investigators employed a simple Arrhenius dependence in defining coal oxidation rate and

821 heat release rate in numerical models. This might be acceptable after coal thermal runaway occurs but the accuracy could be beyond engineering demand at low temperature as the time dependent term (i.e. the Elovich effect) is most effective at the beginning of the reaction [1]. The combination of Arrhenius and Elovich dependence could be a solution [1, 54] or utilization of two sets of Arrhenius parameters before and after thermal runaway could be an alternative [73, 74]. 
equally worthy of exploring. As previously discussed many studies introduced an effectiveness factor to describe the dependence of coal oxidation rate on particle size. The nature of this approach is to mathematically manipulate the oxygen transport limitation with the effectiveness factor upon changing particle size but the Arrhenius parameters remains constants. In fact Arrhenius parameters changes with particle size especially the pre-exponential factor varies considerably with particle size [112]. Therefore more tests are required to be undertaken to define the dependence of Arrhenius parameters on particle diameter. This approach may deal with effects of particle size on coal reaction rate more properly and the reaction rate is more conveniently to be described in a numerical model. Moisture affects self-heating behaviour of coal in many aspects but the previous models mainly considered heat transport arise from evaporation and recondensation. There are two effects of moisture should be worthy of more inspections: inclusion of heat of "wetting" and how oxidation rate varies with moisture contents owing to more/less exposure of oxidation surface. The inclusion of heat due to adsorption of moisture could be simulated by an increment of initial temperature. However the magnitude must be considered carefully because it is affected by the inherent moisture content of coal and humidity level of environment coal is stored [22] and more critically, the influence of initial temperature on self-heating behaviour of coal stockpile could be enormous [55]. How the moisture influences the coal oxidation rate is troublesome as dewatering or wetting of coal might be a highly dynamic process. The testing method in literature [139] might be a solution to define the reaction constants for different moisture contents of coal. How to enhance applicability of numerical models is also a major obstacle. To maintain simplicity and save computation load, most models were developed in one or two dimensions. Whilst a three dimensional model is in need as it is capable of providing a more clear picture of self-heating behaviour of a coal stockpile. To achieve that validation of the model would be paramount as many extrinsic factors would be functioning. A possible validation method would be the erection of wind, rain, solar radiation, and varying ambient temperature profiles accompanied with scattered temperature monitoring points inside stockpile. In addition more numerical assessments should be conducted to evaluate the control measures like wind shield, coating stockpile with inert and fine substances, and spraying coal particle with chemical inhibitor because research in this direction is

\section{Summary remark}

851 The phenomenon of self-heating of coal stockpile is a result of complex physical processes (e.g. airflow in porous coal stockpile, heat and mass transfer) and chemical processes (e.g. coal oxidation accompanied with heat liberation, interaction of coal with moisture). This hazard can be harmful in various aspects and be very persistent due to capability of coal oxidation at low-temperature. Equally important to practical mitigations, theoretical solutions draw immense attentions especially for prediction and management of the hazard. As an advanced tool numerical modelling has been 
widely applied in investigating the transient self-heating behaviour of coal mass since last four decades. No doubt substantial developments have been acquired but many findings needs to be critically reviewed and examined with aiming to provide more comprehensive guidance to industry and to give inspiration of future works. This work firstly investigated the mechanisms of self-heating of coal mass including interaction of coal with oxygen and characteristic behaviour of heat and mass transfer at coal particle scale. The hazard is possible to take place if heat generated from coal oxidation outweighs its dissipation via conduction and convection. On basis of the mechanistic understanding, derivation and development of key theoretical terms of previous models were reviewed and compiled. It has also been recognised the hazard is dependent on many factors like coal property, geometric feature of a stockpile, particle size and associated compaction. To gain deep insights of the problem and deliver more objective guides to industry, variable analyses were undertaken and several meaningful findings are listed:

a) Reactive coals are more readily to catch an occurrence of thermal runaway but less reactive coals are never unconditionally safe. Pre-exponential factor appears to be a more critical parameter than activation energy if Arrhenius reaction mechanism is employed;

b) Effect of coal particle size still remains a puzzle and requires further study. A possible strategy is: (i) If the critical size of a specific coal is quite large, it is favourable to stack stockpile with smaller particle or coating it with fine particles to restrict oxygen ingress; (ii) whilst if critical size is very small it is possibly safer to pack stockpile with large particles to slow down coal oxidation rate;

c) Periodical compaction of stockpile can increase the induction period but need to keep porosity less than 0.2. Extremely low porosity could make a stockpile intrinsically safe and extra precautions requires to be taken upon compacting a coarse stockpile;

d) Temperature rise of a moist coal may undergo three stages: (i) slow rise due to self-heating, (ii) levelling effect due to energy exchange from alteration of water phase, and (iii) rapid rise due to fast oxidation of dry coal. Extra precautions are also required if control a heating hazard of stockpile by spraying water due to the existence of critical water content;

e) Self-heating accelerates with increasing incoming wind velocity; both horizontal and vertical motion of hot spot was observed with stronger wind;

f) Lower and gentle stockpile is safer in terms of prolonging incubation period but will compromise the loading capacity of single stockpile. For a low stockpile $(<10 \mathrm{~m})$, a gentle slope can be employed to slow down selfheating process with less loss to the storage capacity.

Due to the complex nature of this problem, numerical models were often developed with too many assumptions and simplifications. This subject faces two major challenges: one is the lack of a more reliable kinetic modelling of coal oxidation especially at low temperature and another one is how to enhance its applicability. A new dimension is introduced if more numerical assessments are conducted with due consideration of combined Arrhenius and Elovich effect although this may make the result less conservative. More studies of effects of particle size are in need especially how the Arrhenius parameters differ with different ranges of particle size. Heat of moisture adsorption and how coal 
reactivity evolves with progressive drying of coal are two factors worthy of exploring upon considering effects of moisture on self-heating of coal stockpile. To enhance practical significance of this subject, a validated solution in three dimensions is in need. Erection of profiles of several internal temperature monitoring points with more considerations of local meteorological conditions like rainfall, varying ambient temperature, and gusty wind may facilitate the validation. spraying chemical inhibitor are also inspiring as studies in this directions are rare.

\section{Acknowledgement}

The authors wish to acknowledge the financial support of the scholarship from University of Wollongong (4390490) and the Shenhua Group Innovative Technology Research Fund (SHGF-13-07). We acknowledge the authors of the references cited in this paper and the researchers committing themselves to address self-heating hazards on stockpiled coal and making contributions to the progress of such a complicated subject.

\section{Reference list}

1. $\quad$ Arisoy, A. and B. Beamish, Reaction kinetics of coal oxidation at low temperatures. Fuel, 2015. 159: p. 412-417.

2. Banerjee, S.C., B.D. Banerjee, and R.N. Chakravorty, Rate studies of aerial oxidation of coal at low temperatures (30$\left.170{ }^{\circ} \mathrm{C}\right)$. Fuel, 1970. 49(3): p. 324-331.

3. $\quad$ Baris, K., S. Kizgut, and V. Didari, Low-temperature oxidation of some Turkish coals. Fuel, 2012. 93: p. $423-432$.

4. Clemens, A.H., T.W. Matheson, and D.E. Rogers, Low temperature oxidation studies of dried New Zealand coals. Fuel, 1991. 70(2): p. 215-221.

5. Itay, M., C.R. Hill, and D. Glasser, A study of the low temperature oxidation of coal. Fuel Processing Technology, 1989. 21(2): p. 81-97.

6. Kaji, R., Y. Hishinuma, and Y. Nakamura, Low temperature oxidation of coals: Effects of pore structure and coal composition. Fuel, 1985. 64(3): p. 297-302.

7. Kaji, R., Y. Hishinuma, and Y. Nakamura, Low temperature oxidation of coals-a calorimetric study. Fuel, 1987. 66(2): p. 154-157.

8. Krishnaswamy, S., S. Bhat, R.D. Gunn, and P.K. Agarwal, Low-temperature oxidation of coal. 1. A single-particle reactiondiffusion model. Fuel, 1996. 75(3): p. 333-343.

9. Krishnaswamy, S., R.D. Gunn, and P.K. Agarwal, Low-temperature oxidation of coal. 2. An experimental and modelling investigation using a fixed-bed isothermal flow reactor. Fuel, 1996. 75(3): p. 344-352.

10. Nugroho, Y.S., A.C. McIntosh, and B.M. Gibbs, Low-temperature oxidation of single and blended coals. Fuel, 2000. 79(15): p. 1951-1961.

11. Petit, J.C., A calorimetric investigation of the low temperature oxidation of coal and activated carbon. Fuel, 1990. 69(7): p. 861-866.

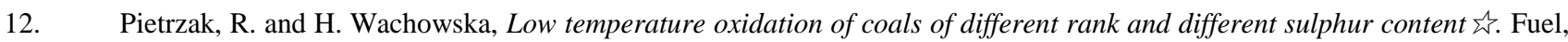
2003. 82(6): p. 705-713.

13. Polat, S. and I.J. Harris, Low-temperature oxidation of Victorian brown coal. Fuel, 1984. 63(5): p. 669-672.

14. van der Plaats, G., H. Soons, and H.A.G. Chermin, Low-temperature oxidation of coal. Thermochimica Acta, 1984. 82(1): p. $131-136$.

15. Wang, H., B.Z. Dlugogorski, and E.M. Kennedy, Coal oxidation at low temperatures: oxygen consumption, oxidation products, reaction mechanism and kinetic modelling. Progress in Energy and Combustion Science, 2003. 29(6): p. 487-513.

16. Zhang, Y., J. Wu, L. Chang, J. Wang, and Z. Li, Changes in the reaction regime during low-temperature oxidation of coal in confined spaces. Journal of Loss Prevention in the Process Industries, 2013. 26(6): p. 1221-1229.

17. Zhang, Y., J. Wu, L. Chang, J. Wang, S. Xue, and Z. Li, Kinetic and thermodynamic studies on the mechanism of lowtemperature oxidation of coal: A case study of Shendong coal (China). International Journal of Coal Geology, 2013. 120: p. 41-49.

18. Wang, H., B.Z. Dlugogorski, and E.M. Kennedy, Low-temperature oxidation of coal at elevated pressures. Journal of Loss Prevention in the Process Industries, 1998. 11(6): p. 373-381.

19. Yuan, L. and A.C. Smith, Experimental study on $\mathrm{CO}$ and $\mathrm{CO} 2$ emissions from spontaneous heating of coals at varying temperatures and O2 concentrations. Journal of Loss Prevention in the Process Industries, 2013. 26(6): p. 1321-1327.

20. Shi, T., X. Wang, J. Deng, and Z. Wen, The mechanism at the initial stage of the room-temperature oxidation of coal. Combustion and Flame, 2005. 140(4): p. 332-345.

21. Bhat, S. and P.K. Agarwal, The effect of moisture condensation on the spontaneous combustibility of coal. Fuel, 1996. 75(13): p. 1523-1532. 
22. Nordon, P. and N.W. Bainbridge, Heat of wetting of a bituminous coal. Fuel, 1983. 62(5): p. 619-621. simulation of spontaneous heating. 1974, Bureau of Mines, Grand Forks, N. Dak.(USA). Grand Forks Energy Research Lab.
Yuan, L. and A.C. Smith, CFD modeling of spontaneous heating in a large-scale coal chamber. Journal of Loss Prevention in the Process Industries, 2009. 22(4): p. 426-433.

25. Song, Z. and C. Kuenzer, Coal fires in China over the last decade: A comprehensive review. International Journal of Coal Geology, 2014. 133: p. 72-99.

26. Zhu, H.-q., Z.-y. Song, B. Tan, and Y.-z. Hao, Numerical investigation and theoretical prediction of self-ignition characteristics of coarse coal stockpiles. Journal of Loss Prevention in the Process Industries, 2013. 26(1): p. 236-244.

27. Carras, J.N., S. Day, A. Saghafi, and O.C. Roberts, Spontaneous Combustion in Open Cut Coal Mines -- Recent Australian Research. 2005: Research Online.

28. Carras, J.N. and B.C. Young, Self-heating of coal and related materials: Models, application and test methods. Progress in Energy and Combustion Science, 1994. 20(1): p. 1-15.

29. Carres, J.N. and A. Saghafi, Predicting spontaneous combustion in spoil piles from open cut coal mines. 1998 : Research Online.

30. Moghtaderi, B., B.Z. Dlugogorski, and E.M. Kennedy, Effects of Wind Flow on Self-Heating Characteristics of Coal Stockpiles. Process Safety and Environmental Protection, 2000. 78(6): p. 445-453.

31. Yang, Y., Z. Li, Y. Tang, Z. Liu, and H. Ji, Fine coal covering for preventing spontaneous combustion of coal pile. Natural Hazards, 2014. 74(2): p. 603-622.

32. Arisoy, A. and F. Akgün, Effect of Pile Height on Spontaneous Heating of Coal Stockpiles. Combustion Science and Technology, 2000. 153(1): p. 157-168.

33. Swann, P.D., D.J. Allardice, and D.G. Evans, Low-temperature oxidation of brown coal. 1. Changes in internal surface due to oxidation. Fuel, 1974. 53(2): p. 85-87.

34. Carras, J.N., S.J. Day, A. Saghafi, and D.J. Williams, Greenhouse gas emissions from low-temperature oxidation and spontaneous combustion at open-cut coal mines in Australia. International Journal of Coal Geology, 2009. 78(2): p. 161-168.

35. Day, S., J. Carras, R. Fry, and D. Williams, Greenhouse gas emissions from Australian open-cut coal mines: contribution from spontaneous combustion and low-temperature oxidation. Environmental Monitoring \& Assessment, 2010. 166(1-4): p. 529-541.

36. Kuenzer, C. and G.B. Stracher, Geomorphology of coal seam fires. Geomorphology, 2012. 138(1): p. $209-222$.

37. Chen, G., X. Ma, M. Lin, X. Peng, and Z. Yu, Pollutant emission characteristics and interaction during low-temperature oxidation of blended coal. Journal of the Energy Institute, 2016. 89(1): p. 40-47.

38. Liang, Y., H. Liang, and S. Zhu, Mercury emission from coal seam fire at Wuda, Inner Mongolia, China. Atmospheric Environment, 2014. 83: p. 176-184.

39. Semenov, N.N. and I.I. Frenkel', Chemical kinetics and chain reactions. 1935, Oxford: Clarendon Press.

40. Semenov, N.N., Thermal Theory of Combustion and Explosion. 3; Theory of Normal Flame Propagation. 1942.

41. Frank-Kamenetskii, D.A., Diffusion and heat exchange in chemical kinetics. 1955: Princeton University Press.

42. Hoff, J.H.v.t., Etudes de dynamique chimique. Landmarks of science. 1884, Amsterdam: Frederik Muller.

43. Thomas, P., On the thermal conduction equation for self-heating materials with surface cooling. Transactions of the Faraday Society, 1958. 54: p. 60-65.

44. Thomas, P., Some approximations in the theory of self-heating and thermal explosion. Trans. Faraday Soc., 1960. 56: p. 833839.

45. Thomas, P. Effect of reactant consumption on the induction period and critical condition for a thermal explosion. in Proceedings of the Royal Society of London A: Mathematical, Physical and Engineering Sciences. 1961: The Royal Society.

46. Thomas, P., Self-heating and thermal ignition-a guide to its theory and application. Ignition, Heat Release and Noncombustibility of Materials, ASTM STP, 1972. 502: p. p56.

47. Thomas, P. and P. Bowes, Some aspects of the self-heating and ignition of solid cellulosic materials. British Journal of Applied Physics, 1961. 12(5): p. 222.

48. $\quad$ Bowes, P.C., Thermal ignition in two-component systems, theoretical model. Combustion and Flame, 1969. 13(5): p. 521530 .

49. Bowes, P.C. and P.H. Thomas, Ignition and extinction phenomena accompanying oxygen-dependent self-heating of porous bodies. Combustion and Flame, 1966. 10(3): p. 221-230.

50. Bowes, P.C., Self-heating : evaluating and controlling the hazards. 1984, Dept. of the Environment, Building Research Establishment ;: Garston, Merseyside :.

51. Gray, B. and S. Scott, The influence of initial temperature-excess on critical conditions for thermal explosion. Combustion and Flame, 1985. 61(3): p. 227-236.

52. Gray, B. and G. Wake, On the determination of critical ambient temperatures and critical initial temperatures for thermal ignition. Combustion and Flame, 1988. 71(1): p. 101-104.

53. Adler, J. and J.W. Enig, The critical conditions in thermal explosion theory with reactant consumption. Combustion and Flame, 1964. 8(2): p. 97-103.

54. $\quad$ Nordon, P., A model for the self-heating reaction of coal and char. Fuel, 1979. 58(6): p. $456-464$.

55. Schmal, D., J.H. Duyzer, and J.W. van Heuven, A model for the spontaneous heating of coal. Fuel, 1985. 64(7): p. 963-972.

56. Brooks, K., V. Balakotaiah, and D. Luss, Effect of natural convection on spontaneous combustion of coal stockpiles. AIChE Journal, 1988. 34(3): p. 353-365.

57. Brooks, K., S. Bradshaw, and D. Glasser, Spontaneous combustion of coal stockpiles - an unusual chemical reaction engineering problem. Chemical Engineering Science, 1988. 43(8): p. 2139-2145.

58. Brooks, K. and D. Glasser, A simplified model of spontaneous combustion in coal stockpiles. Fuel, 1986. 65(8): p. 10351041. 
59. Brooks, K., N. Svanas, and D. Glasser, Evaluating the risk of spontaneous combustion in coal stockpiles. Fuel, 1988. 67(5): p. 651-656.

60. Young, B.D., D.F. Williams, and A.W. Bryson, Two-dimensional natural convection and conduction in a packed bed containing a hot spot and its relevance to the transport of air in a coal dump. International Journal of Heat and Mass Transfer, 1986. 29(2): p. 331-336.

61. Bradshaw, S., D. Glasser, and K. Brooks, Self-ignition and convection patterns in an infinite coal layer. Chemical Engineering Communications, 1991. 105(1): p. 255-278.

62. Krishnaswamy, S., P.K. Agarwal, and R.D. Gunn, Low-temperature oxidation of coal. 3. Modelling spontaneous combustion in coal stockpiles. Fuel, 1996. 75(3): p. 353-362.

63. Hull, A., J.L. Lanthier, and P.K. Agarwal, The role of the diffusion of oxygen in the ignition of a coal stockpile in confined storage. Fuel, 1997. 76(10): p. 975-983.

64. Akgun, F. and R.H. Essenhigh, Self-ignition characteristics of coal stockpiles: theoretical prediction from a two-dimensional unsteady-state model. Fuel, 2001. 80(3): p. 409-415.

65. Arisoy, A. and F. Akgün, Modelling of spontaneous combustion of coal with moisture content included. Fuel, 1994. 73(2): p. 281-286.

66. Chen, X.D., On the mathematical modeling of the transient process of spontaneous heating in a moist coal stockpile. Combustion and Flame, 1992. 90(2): p. 114-120.

67. Edwards, J.C., Mathematical modeling of spontaneous heating of a coalbed. Report of investigations (United States. Bureau of Mines) ; 9296., ed. M. United States. Bureau of. 1990, Washington, D.C. : U.S. Dept. of the Interior, Bureau of Mines.

68. Hull, A.S., J.L. Lanthier, Z. Chen, and P.K. Agarwal, The role of the diffusion of oxygen and radiation on the spontaneous combustibility of a coal pile in confined storage. Combustion and Flame, 1997. 110(4): p. 479-493.

69. Salinger, A.G., R. Aris, and J.J. Derby, Modeling the spontaneous ignition of coal stockpiles. AIChE Journal, 1994. 40(6): p. 991-1004.

70. Monazam, E.R., L.J. Shadle, and A. Shamsi, Spontaneous combustion of char stockpiles. Energy \& fuels, 1998. 12(6): p. 1305-1312.

71. Ren, T. and R. Balusu, The use of CFD modelling as a tool for solving mining health and safety problems. 2010: Research Online.

72. Kim, C.J. and C.H. Sohn, A novel method to suppress spontaneous ignition of coal stockpiles in a coal storage yard. Fuel Processing Technology, 2012. 100: p. 73-83.

73. Taraba, B. and Z. Michalec, Effect of longwall face advance rate on spontaneous heating process in the gob area - CFD modelling. Fuel, 2011. 90(8): p. 2790-2797.

74. Taraba, B., Z. Michalec, V. Michalcová, T. Blejchař, M. Bojko, and M. Kozubková, CFD simulations of the effect of wind on the spontaneous heating of coal stockpiles. Fuel, 2014. 118: p. 107-112.

75. Yuan, L. and A.C. Smith, Numerical study on effects of coal properties on spontaneous heating in longwall gob areas. Fuel, 2008. 87(15-16): p. 3409-3419.

76. Ejlali, A. and K. Hooman, Buoyancy Effects on Cooling a Heat Generating Porous Medium: Coal Stockpile. Transport in Porous Media, 2011. 88(2): p. 235-248.

77. Ejlali, A., D.J. Mee, K. Hooman, and B.B. Beamish, Numerical modelling of the self-heating process of a wet porous medium. International Journal of Heat and Mass Transfer, 2011. 54(25-26): p. 5200-5206.

78. Krajčiová, M., L. Jelemenský, M. Kiša, and J. Markoš, Model predictions on self-heating and prevention of stockpiled coals. Journal of Loss Prevention in the Process Industries, 2004. 17(3): p. 205-216.

79. Xia, T., X. Wang, F. Zhou, J. Kang, J. Liu, and F. Gao, Evolution of coal self-heating processes in longwall gob areas. International Journal of Heat and Mass Transfer, 2015. 86: p. 861-868.

80. Zhang, J., Y. Liang, T. Ren, Z. Wang, and G. Wang, Transient CFD modelling of low-temperature spontaneous heating behaviour in multiple coal stockpiles with wind forced convection. Fuel Processing Technology, 2016. 149: p. 55-74.

81. Zambra, C.E., N.O. Moraga, and M. Escudey, Heat and mass transfer in unsaturated porous media: Moisture effects in compost piles self-heating. International Journal of Heat and Mass Transfer, 2011. 54(13-14): p. 2801-2810.

82. Aganetti, R., A. Lamorlette, E. Guilbert, D. Morvan, and G.R. Thorpe, Advection and the self-heating of organic porous media. International Journal of Heat and Mass Transfer, 2016. 93: p. 1150-1158.

83. Lohrer, C., U. Krause, and J. Steinbach, Self-Ignition of Combustible Bulk Materials Under Various Ambient Conditions. Process Safety and Environmental Protection, 2005. 83(2): p. 145-150.

84. Lohrer, C., M. Schmidt, and U. Krause, A study on the influence of liquid water and water vapour on the self-ignition of lignite coal-experiments and numerical simulations. Journal of Loss Prevention in the Process Industries, 2005. 18(3): p. 167-177.

85. Gómez, M.A., D. Patiño, R. Comesaña, J. Porteiro, M.A. Álvarez Feijoo, and J.L. Míguez, CFD simulation of a solar radiation absorber. International Journal of Heat and Mass Transfer, 2013. 57(1): p. 231-240.

86. Ashwin, T.R., G.S.V.L. Narasimham, and S. Jacob, CFD analysis of high frequency miniature pulse tube refrigerators for space applications with thermal non-equilibrium model. Applied Thermal Engineering, 2010. 30(2-3): p. 152-166.

87. Wang, G., T. Ren, K. Wang, and A. Zhou, Improved apparent permeability models of gas flow in coal with Klinkenberg effect. Fuel, 2014. 128: p. 53-61.

88. Wang, H., B.Z. Dlugogorski, and E.M. Kennedy, Theoretical analysis of reaction regimes in low-temperature oxidation of coal. Fuel, 1999. 78(9): p. 1073-1081.

89. Wang, H., B.Z. Dlugogorski, and E.M. Kennedy, Thermal decomposition of solid oxygenated complexes formed by coal oxidation at low temperatures. Fuel, 2002. 81(15): p. 1913-1923.

90. Wang, H., B.Z. Dlugogorski, and E.M. Kennedy, Kinetic modeling of low-temperature oxidation of coal. Combustion and Flame, 2002. 131(4): p. 452-464. 
91. Wang, H., B.Z. Dlugogorski, and E.M. Kennedy, Analysis of the mechanism of the low-temperature oxidation of coal Combustion and Flame, 2003. 134(1-2): p. 107-117.

92. Wang, H., B.Z. Dlugogorski, and E.M. Kennedy, Pathways for production of CO2 and CO in low-temperature oxidation of coal. Energy \& fuels, 2003. 17(1): p. 150-158.

93. Wang, D.-m., H.-h. Xin, X.-y. Qi, G.-1. Dou, G.-s. Qi, and L.-y. Ma, Reaction pathway of coal oxidation at low temperatures: a model of cyclic chain reactions and kinetic characteristics. Combustion and Flame, 2016. 163: p. 447-460.

94. Wang, H., B.Z. Dlugogorski, and E.M. Kennedy, Experimental study on low-temperature oxidation of an Australian coal. Energy \& fuels, 1999. 13(6): p. 1173-1179.

95. Karsner, G.G. and D.D. Perlmutter, Model for coal oxidation kinetics. 1. Reaction under chemical control. Fuel, 1982. 61(1): p. 29-34.

96. Karsner, G.G. and D.D. Perlmutter, Model for coal oxidation kinetics. 2. An effectiveness factor interpretation. Fuel, 1982. 61(1): p. 35-43.

97. Swann, P.D. and D.G. Evans, Low-temperature oxidation of brown coal. 3. Reaction with molecular oxygen at temperatures close to ambient. Fuel, 1979. 58(4): p. 276-280.

98. Harris, J.A. and D.G. Evans, Low-temperature oxidation of brown coal. 2. Elovich adsorption kinetics and porous materials. Fuel, 1975. 54(4): p. 276-278.

99. Kam, A., A. Hixson, and D. Perlmutter, The oxidation of bituminous coal—I Development of a mathematical model. Chemical Engineering Science, 1976. 31(9): p. 815-819.

100. Kam, A., A. Hixson, and D. Perlmutter, The oxidation of bituminous coal-II experimental kinetics and interpretation. Chemical Engineering Science, 1976. 31(9): p. 821-834.

101. Gethner, J.S., Kinetic study of the oxidation of Illinois No. 6 coal at low temperatures. Fuel, 1987. 66(8): p. 1091-1096.

102. Gethner, J.S., Thermal and oxidation chemistry of coal at low temperatures. Fuel, 1985. 64(10): p. 1443-1446.

103. Nelson, C.R., Chemistry of coal weathering. 1989, Amsterdam; New York; New York, N.Y., U.S.A.: Elsevier ; Distributors for the U.S. and Canada, Elsevier Science Pub. Co.

104. Jensen, E., N. Melnyk, J. Wood, and N. Berkowitz, The dry oxidation of subbituminous coal. 1966.

105. Khan, M.R., C.E. Everitt, and A.P. Lui, Modeling of oxygen chemisorption kinetics on coal char. Combustion and Flame, 1990. 80(1): p. 83-93.

106. McLintock, I., The Elovich equation in chemisorption kinetics. Nature, 1967. 216: p. 1204-1205.

107. Nordon, P., B.C. Young, and N.W. Bainbridge, The rate of oxidation of char and coal in relation to their tendency to selfheat. Fuel, 1979. 58(6): p. 443-449.

108. Moore, W.J., Physical chemistry. 1963, London: Longman.

109. Peleg, M., M.D. Normand, and M.G. Corradini, The Arrhenius equation revisited. Critical reviews in food science and nutrition, 2012. 52(9): p. 830-851.

110. Jones, J.C. and S.C. Newman, Non-Arrhenius behaviour in the oxidation of two carbonaceous substrates. Journal of Loss Prevention in the Process Industries, 2003. 16(3): p. 223-225.

111. Nugroho, Y.S., A.C. McIntosh, and B.M. Gibbs, On the prediction of thermal runaway of coal piles of differing dimension by using a correlation between heat release and activation energy. Proceedings of the Combustion Institute, 2000. 28(2): $\mathrm{p}$. 2321-2327.

112. Akgun, F. and A. Arisoy, Effect of particle size on the spontaneous heating of a coal stockpile. Combustion and Flame, 1994. 99(1): p. 137-146.

113. Taraba, B., Reversible and irreversible interaction of oxygen with coal using pulse flow calorimetry. Fuel, 1990. 69(9): $\mathrm{p}$. 1191-1199.

114. Schmidt, L. and J. Elder, Atmospheric oxidation of coal at moderate temperatures. Industrial \& Engineering Chemistry, 1940. 32(2): p. 249-256.

115. Fierro, V., J.L. Miranda, C. Romero, J.M. Andrés, A. Arriaga, and D. Schmal, Model predictions and experimental results on self-heating prevention of stockpiled coals. Fuel, 2001. 80(1): p. 125-134.

116. Karsner, G. and D. Perlmutter, Reaction regimes in coal oxidation. AIChE Journal, 1981. 27(6): p. 920-927.

117. Gouws, M., G. Gibbon, L. Wade, and H. Phillips, An adiabatic apparatus to establish the spontaneous combustion propensity of coal. Mining Science and Technology, 1991. 13(3): p. 417-422.

118. Ertunc, G. and M.V. Kok, Determination of kinetic parameters of different origin coals using software. Journal of Thermal Analysis and Calorimetry, 2015. 119(2): p. 1407-1413.

119. Li, B., G. Chen, H. Zhang, and C. Sheng, Development of non-isothermal TGA-DSC for kinetics analysis of low temperature coal oxidation prior to ignition. Fuel, 2014. 118: p. 385-391.

120. Jones, J.C., P.S. Chiz, R. Koh, and J. Matthew, Kinetic parameters of oxidation of bituminous coals from heat-release rate measurements. Fuel, 1996. 75(15): p. 1755-1757.

121. Turner, J.S., Buoyancy effects in fluids. 1979: Cambridge University Press.

122. Bird, R.B., W.E. Stewart, and E.N. Lightfoot, Transport phenomena, John Wiley and Sons, Inc., New York (1960). .

123. Brinkman, H., A calculation of the viscous force exerted by a flowing fluid on a dense swarm of particles. Applied Scientific Research, 1949. 1(1): p. 27-34.

124. Kaymakçi, E. and V. Didari, Relations between coal properties and spontaneous combustion parameters. Turkish Journal of Engineering and Environmental Sciences, 2001. 26(1): p. 59-64.

125. Morris, R. and T. Atkinson, Seam factor and the spontaneous heating of coal. Mining Science and Technology, 1988. 7(2): $\mathrm{p}$. 149-159.

126. Finkelman, R.B. and G.B. Stracher, Coal and Peat Fires: A Global Perspective. 2011, By Glenn B. Stracher, Anupma Prakash, and Ellina V. Sokol. Amsterdam: Elsevier.

127. Palmer, A., M. Cheng, J.-C. Goulet, and E. Furimsky, Relation between particle size and properties of some bituminous coals. Fuel, 1990. 69(2): p. 183-188. 
1143 128. Avison, N., R. Winters, and D. Perlmutter, On the kinetics of coal oxidation. AIChE Journal, 1979. 25(5): p. 773-781.

129. Gray, B.F. and G.C. Wake, The ignition of hygroscopic combustible materials by water. Combustion and Flame, 1990. 79(1): p. 2-6.

130. Gray, B.F., M.J. Sexton, B. Halliburton, and C. Macaskill, Wetting-induced ignition in cellulosic materials. Fire Safety Journal, 2002. 37(5): p. 465-479.

131. Wang, H., B.Z. Dlugogorski, and E.M. Kennedy, Role of inherent water in low-temperature oxidation of coal. Combustion Science and Technology, 2003. 175(2): p. 253-270.

132. Allardice, D. and D. Evans, The brown-coal/water system: Part 1, The effect of temperature on the evolution of water from brown coal. Fuel, 1971. 50(2): p. 201-210.

133. Allardice, D. and D. Evans, The-brown coal/water system: Part 2. Water sorption isotherms on bed-moist Yallourn brown coal. Fuel, 1971. 50(3): p. 236-253.

134. Yu, J., A. Tahmasebi, Y. Han, F. Yin, and X. Li, A review on water in low rank coals: The existence, interaction with coal structure and effects on coal utilization. Fuel Processing Technology, 2013. 106: p. 9-20.

135. Vance, W.E., X.D. Chen, and S.C. Scott, The rate of temperature rise of a subbituminous coal during spontaneous combustion in an adiabatic device: The effect of moisture content and drying methods. Combustion and Flame, 1996. 106(3): p. 261-270.

136. Hurley, M.J., D.T. Gottuk, J.R. Hall Jr, K. Harada, E.D. Kuligowski, M. Puchovsky, J.M. Watts Jr, and C.J. Wieczorek, SFPE handbook of fire protection engineering. 2015: Springer.

137. McCaughey, M. and D.F. Fletcher, Calculations of the wind-induced pressure distribution on a model building. Fire Safety Journal, 1993. 21(3): p. 189-205.

138. Fierro, V., J. Miranda, C. Romero, J. Andres, A. Arriaga, D. Schmal, and G. Visser, Prevention of spontaneous combustion in coal stockpiles: experimental results in coal storage yard. Fuel Processing Technology, 1999. 59(1): p. 23-34.

139. Beamish, B.B. and G.R. Hamilton, Effect of moisture content on the R70 self-heating rate of Callide coal. International Journal of Coal Geology, 2005. 64(1-2): p. 133-138.

140. IEA CLEAN COAL CENTER. Quantifying emissions from spontaneous combustion. 2013; Available from: http://www.iea-coal.org.uk/site/2010/publications-section/newsletter-information/current-newsletter-4/quantifyingemissions-from-spontaneous-combustion.

141. van Genderen, J., Coal and peat fires: a global perspective: Volume 1: Coal-geology and combustion. International Journal of Digital Earth, 2012. 5(5): p. 458-459.

142. MINING MAYHEM. Stacker Fire. 2013; Available from: http://www.miningmayhem.com/2013/04/stacker-fire.html.

143. Rosema, A., H. Guan, and H. Veld, Simulation of spontaneous combustion, to study the causes of coal fires in the Rujigou Basin. Fuel, 2001. 80(1): p. 7-16.

144. Stott, J., Influence of moisture on the spontaneous heating of coal. 1960.

145. Clemens, A.H. and T.W. Matheson, The role of moisture in the self-heating of low-rank coals. Fuel, 1996. 75(7): p. 891-895.

146. Chen, X.D. and J.B. Stott, The effect of moisture content on the oxidation rate of coal during near-equilibrium drying and wetting at $50^{\circ} \mathrm{C}$. Fuel, 1993. 72(6): p. 787-792.

147. Carr, R.M., H. Kumagai, B.M. Peake, B.H. Robinson, A.H. Clemens, and T.W. Matheson, Formation of free radicals during drying and oxidation of a lignite and a bituminous coal. Fuel, 1995. 74(3): p. 389-394.

148. Banerjee, S.C., Spontaneous combustion of coal and mine fires. 1985: Balkema Rotterdam.

149. Suuberg, E.M., Y. Otake, Y. Yun, and S.C. Deevi, Role of moisture in coal structure and the effects of drying upon the accessibility of coal structure. Energy \& fuels, 1993. 7(3): p. 384-392.

150. Deevi, S. and E. Suuberg, Physical changes accompanying drying of western US lignites. Fuel, 1987. 66(4): p. 454-460.

151. Nelson, C.R., Chemistry of coal weathering. 1989. 

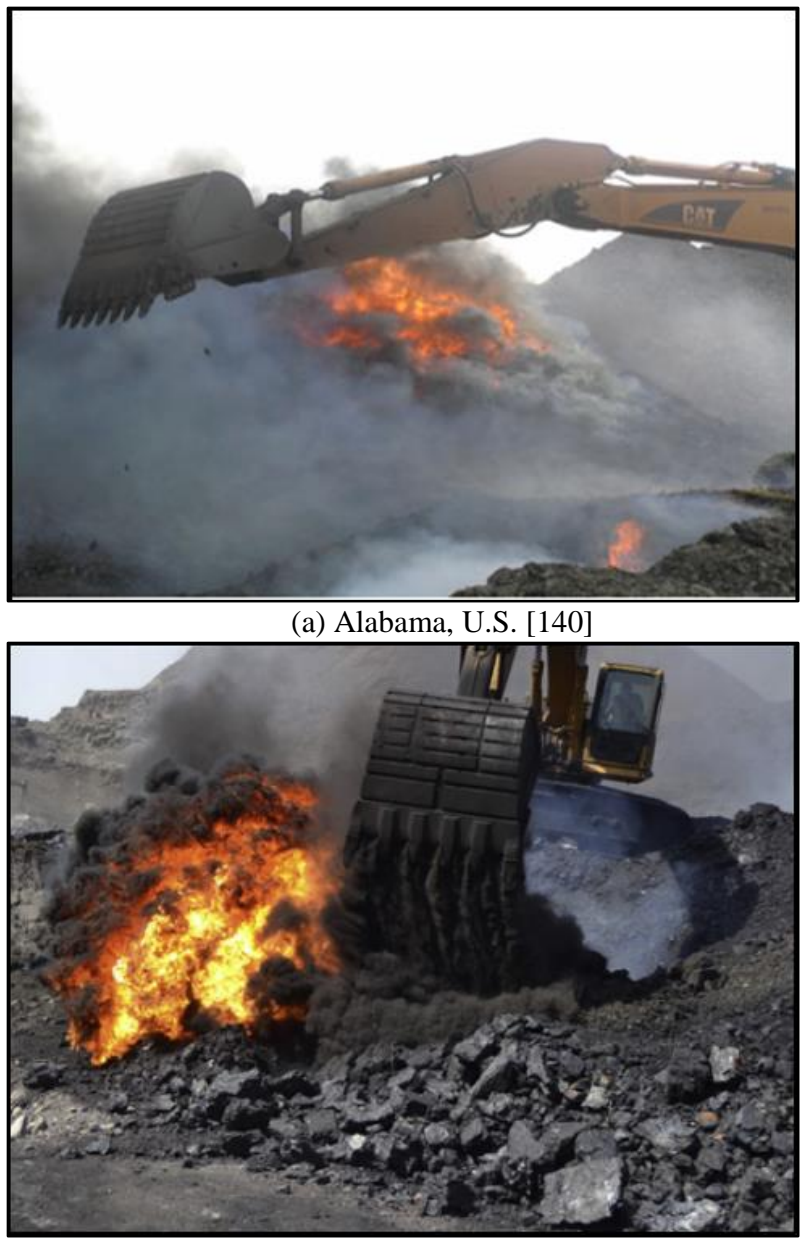

(c) Wuda coalfield, China [25]

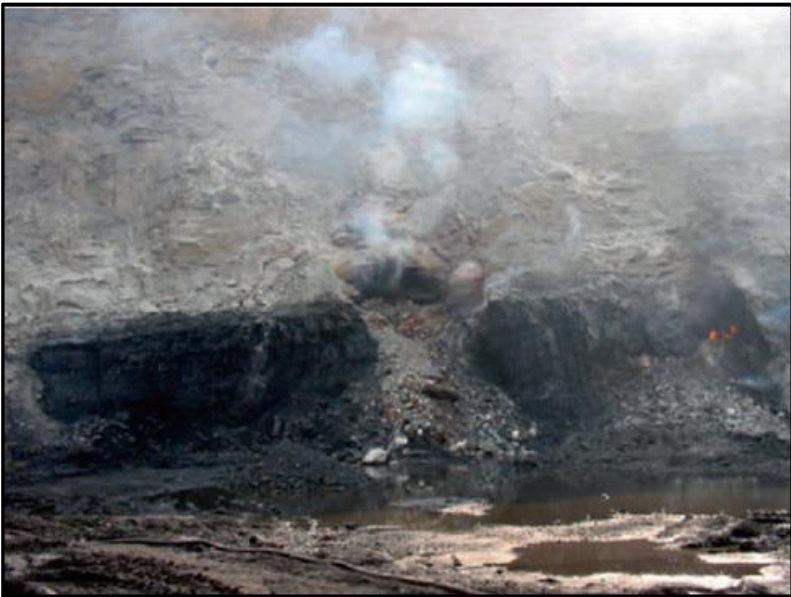

(b) Jharia coalfield, India [141]

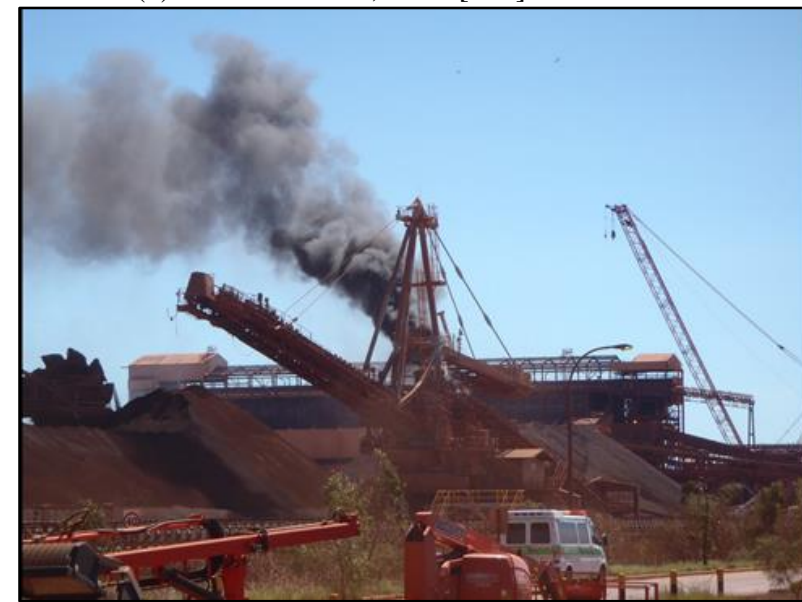

(d) Hedland port stacker fire, Australia [142]

\section{Figure 1 Photographic views of fire of stockpiled coal from the worldwide}

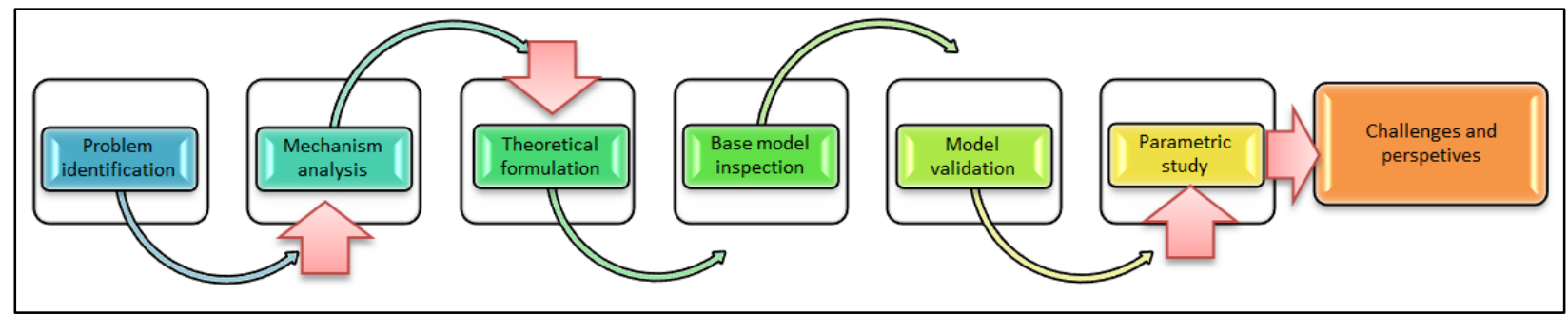

Figure 2 Illustration of major steps for a numerical solution and work scope of this study 


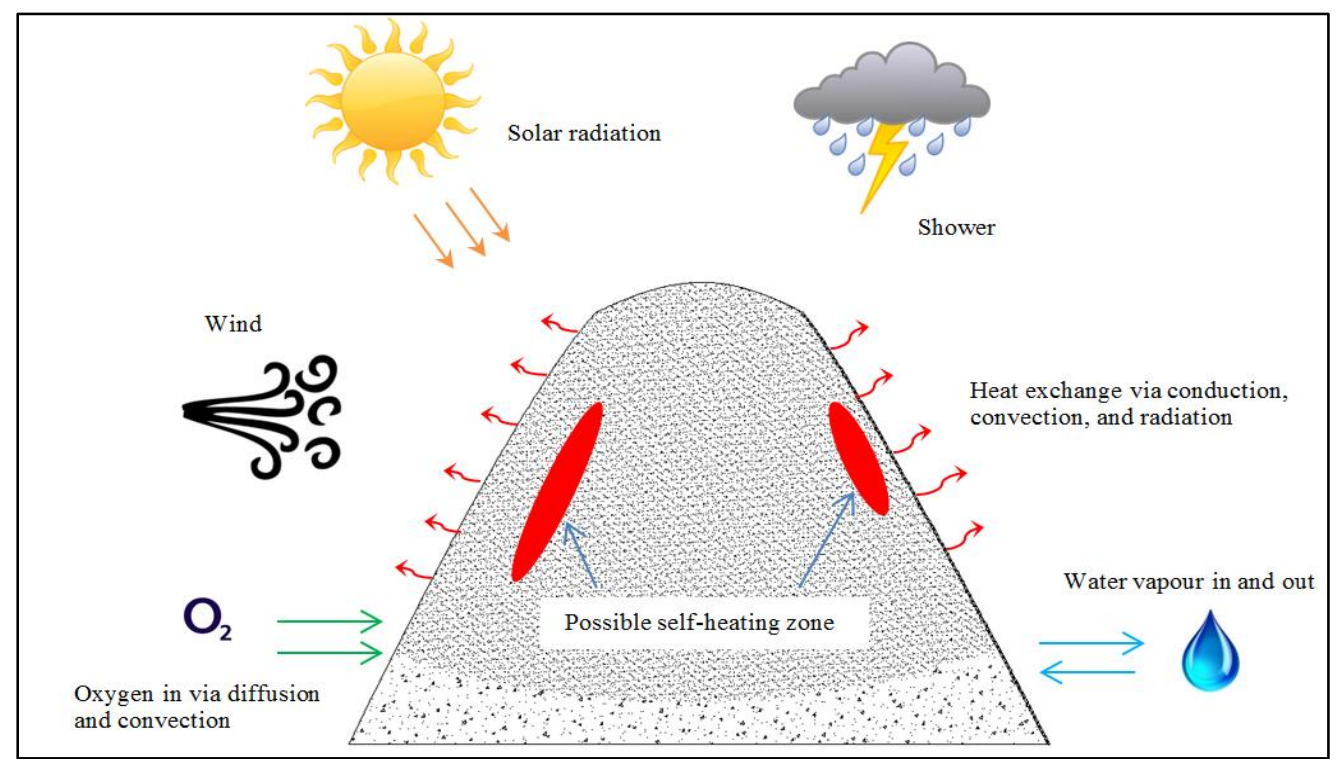

Figure 3 Schematic process and main feature of coal stockpile self-heating

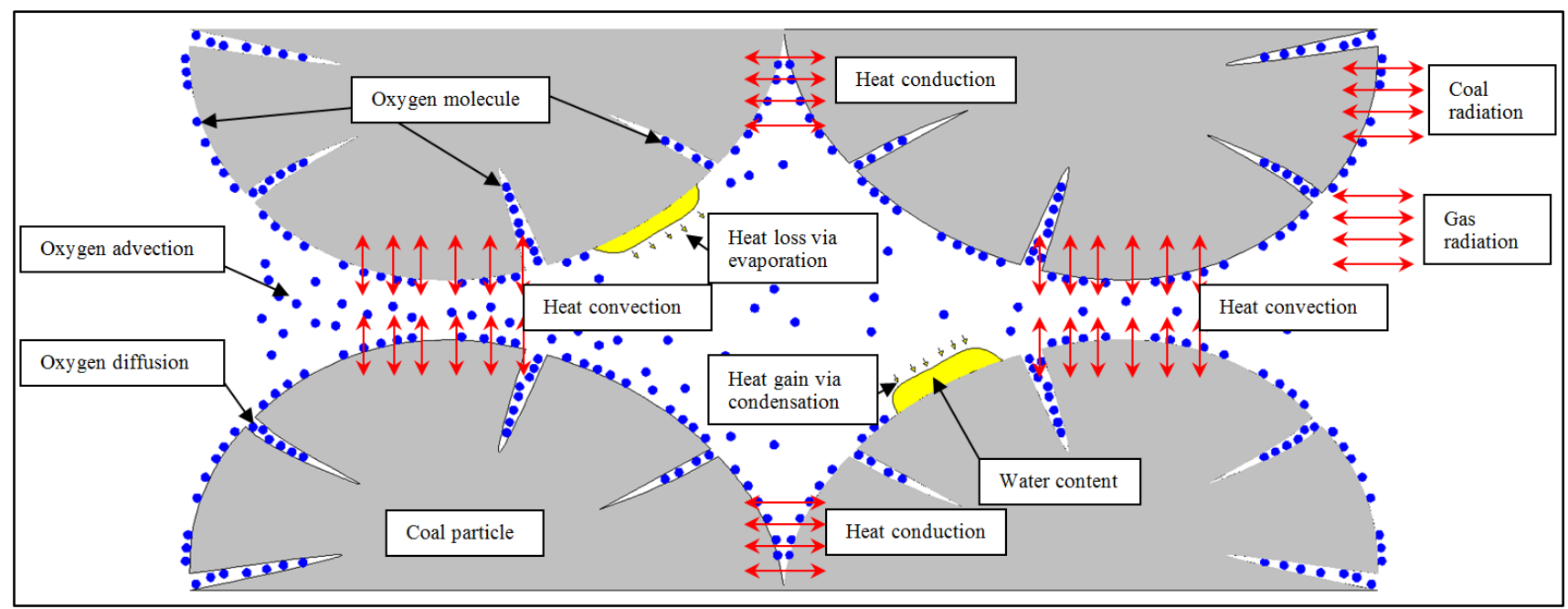

Figure 4 A schematic view of heat and mass transfer between coal particles

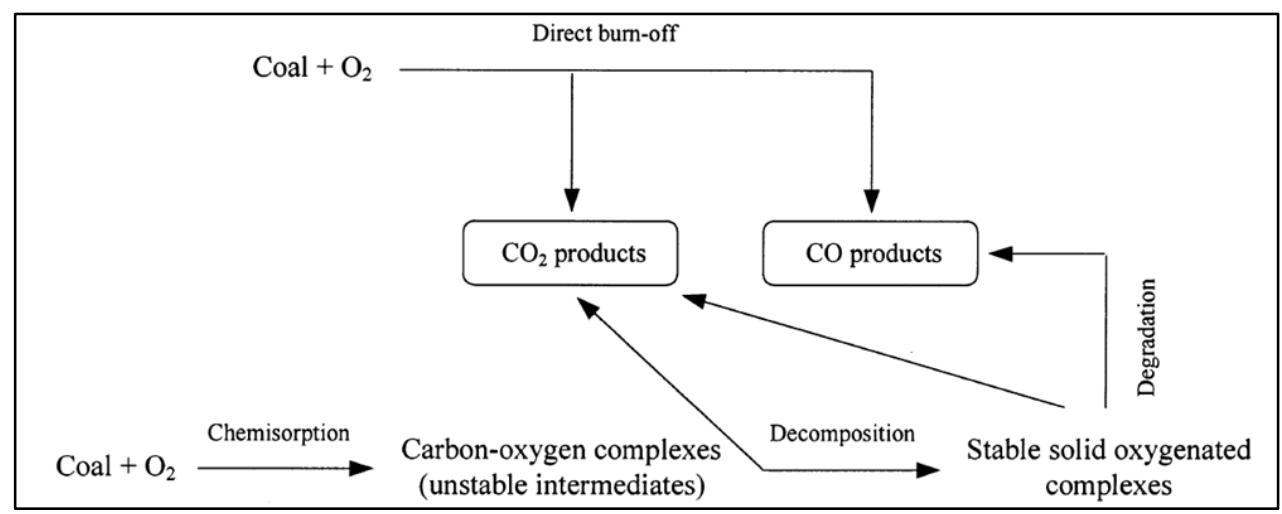



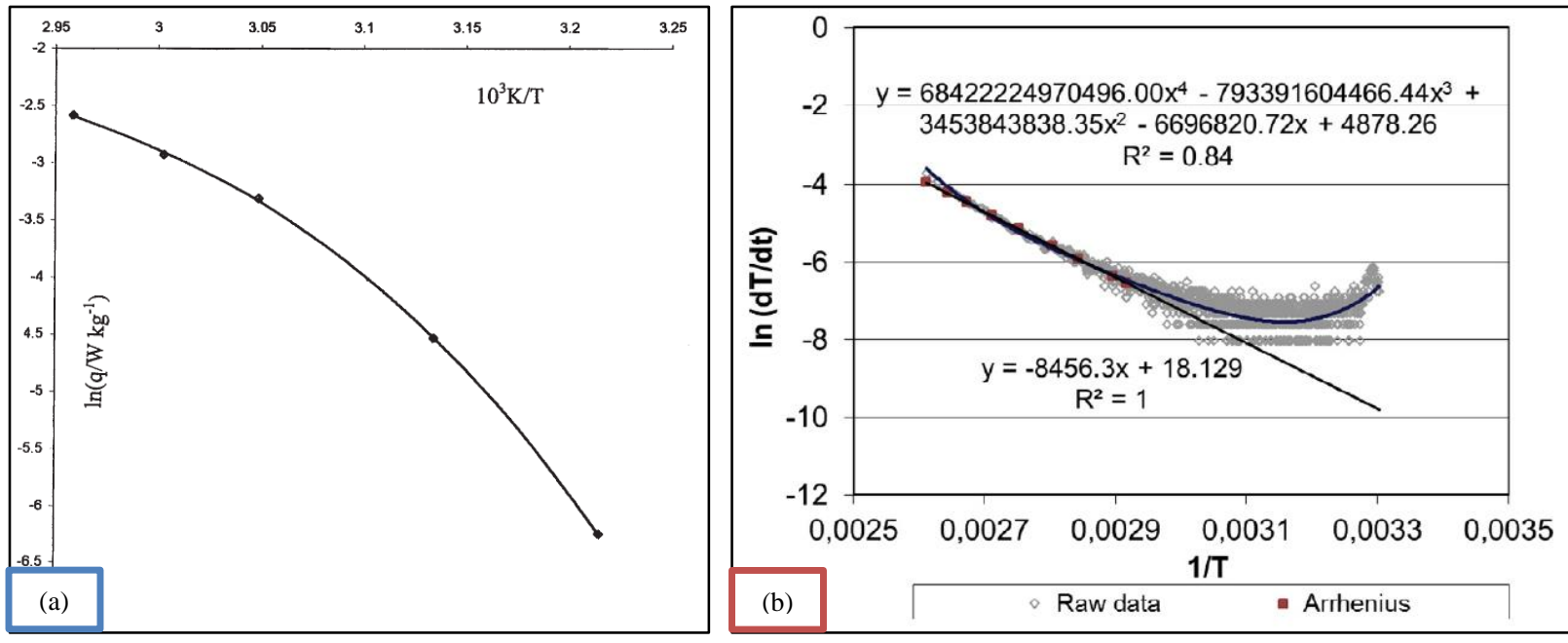

Figure 6 Two examples of non-Arrhenius behaviour of coal oxidation rate at low temperature (a) Plot of $\ln$ (heat release) against 1/T for a China coal [110] (b) Plot of $\ln (\mathrm{dT} / \mathrm{dt}$ ) against 1/T for an Australia coal [1]
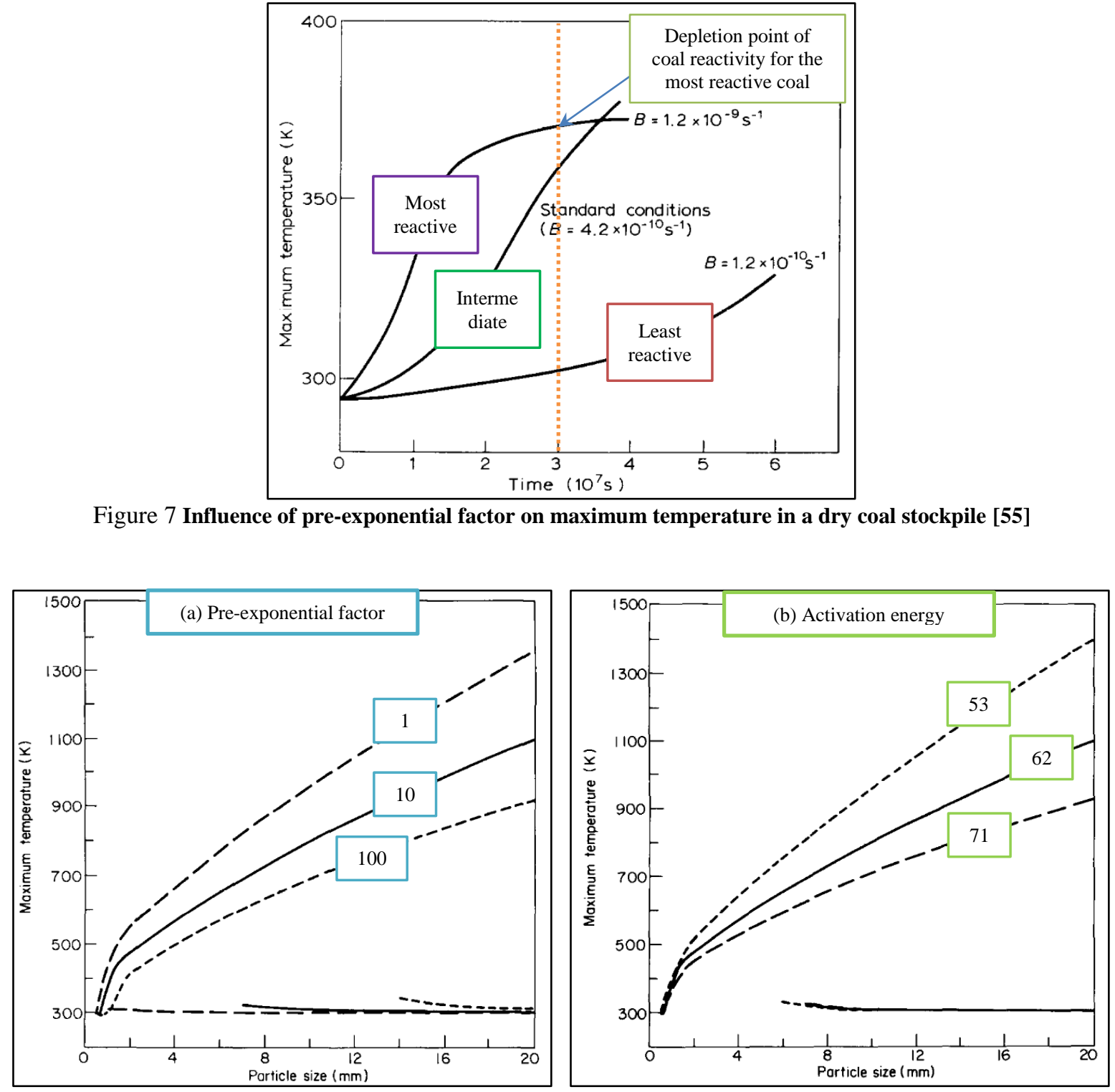

Figure 8 Influence of reactivity on maximum temperature of a coalbed [58] 

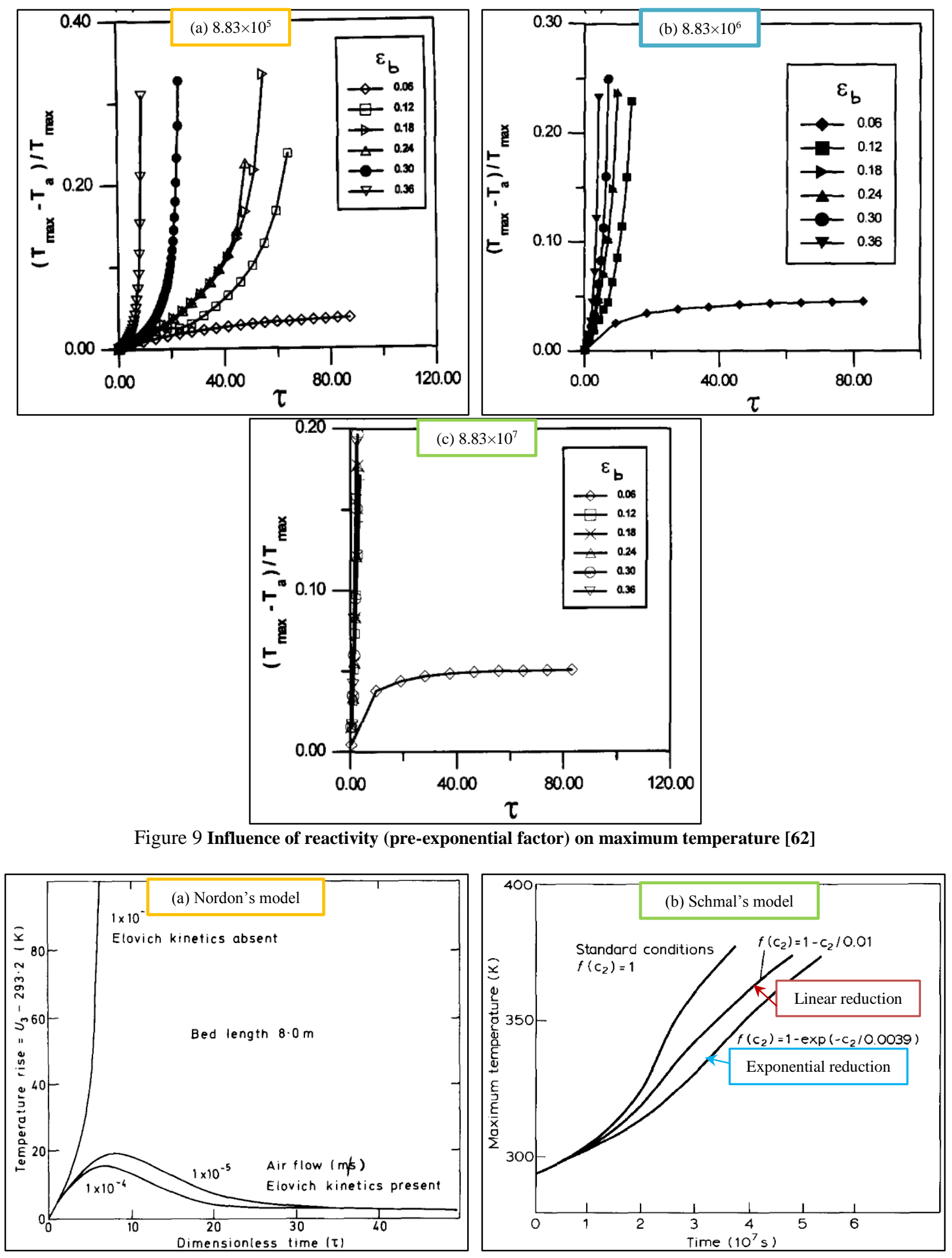


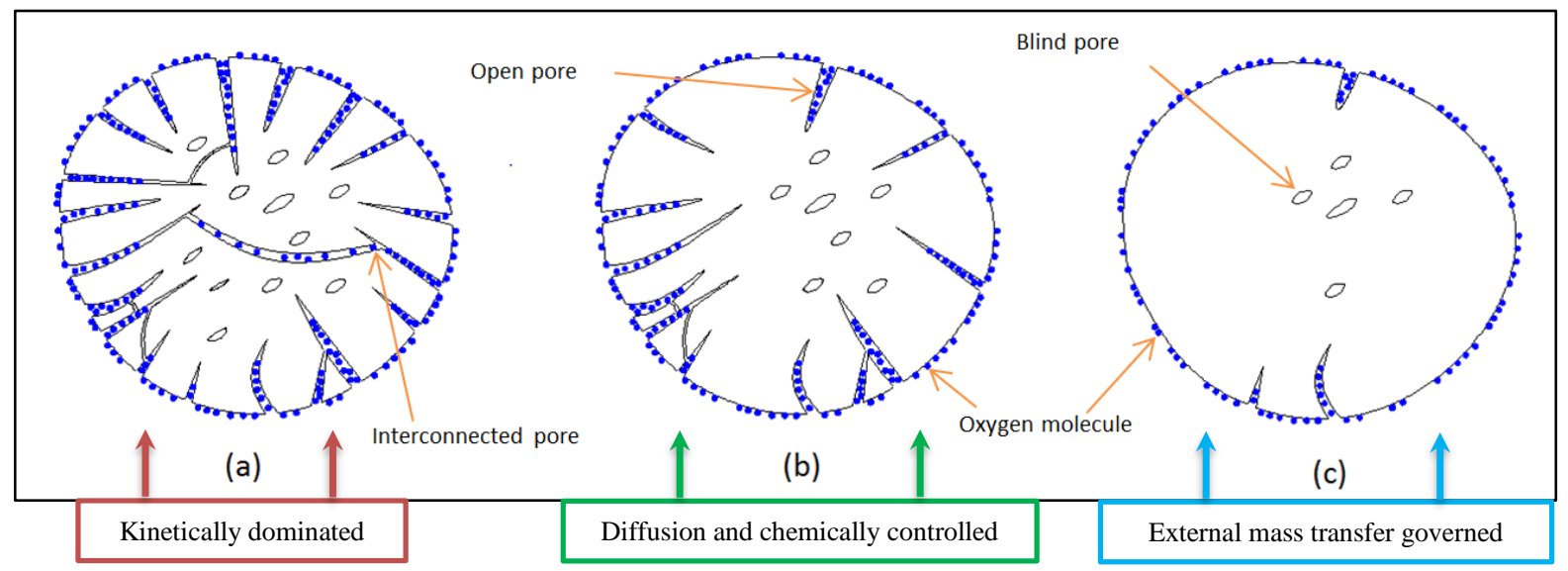

Figure 11 A schematic illustration of three coal oxidation regimes

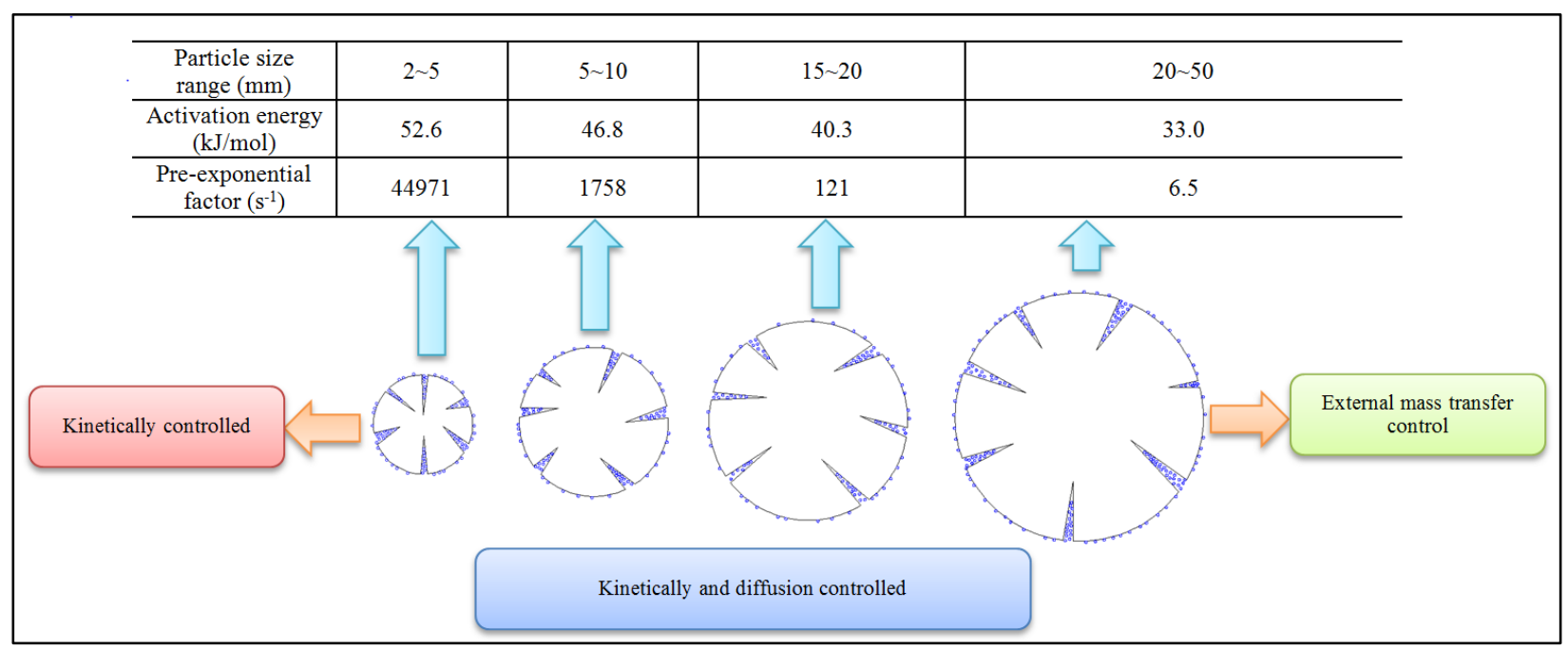

Figure 12 Influence of coal particle size on kinetic constants and oxidation regimes
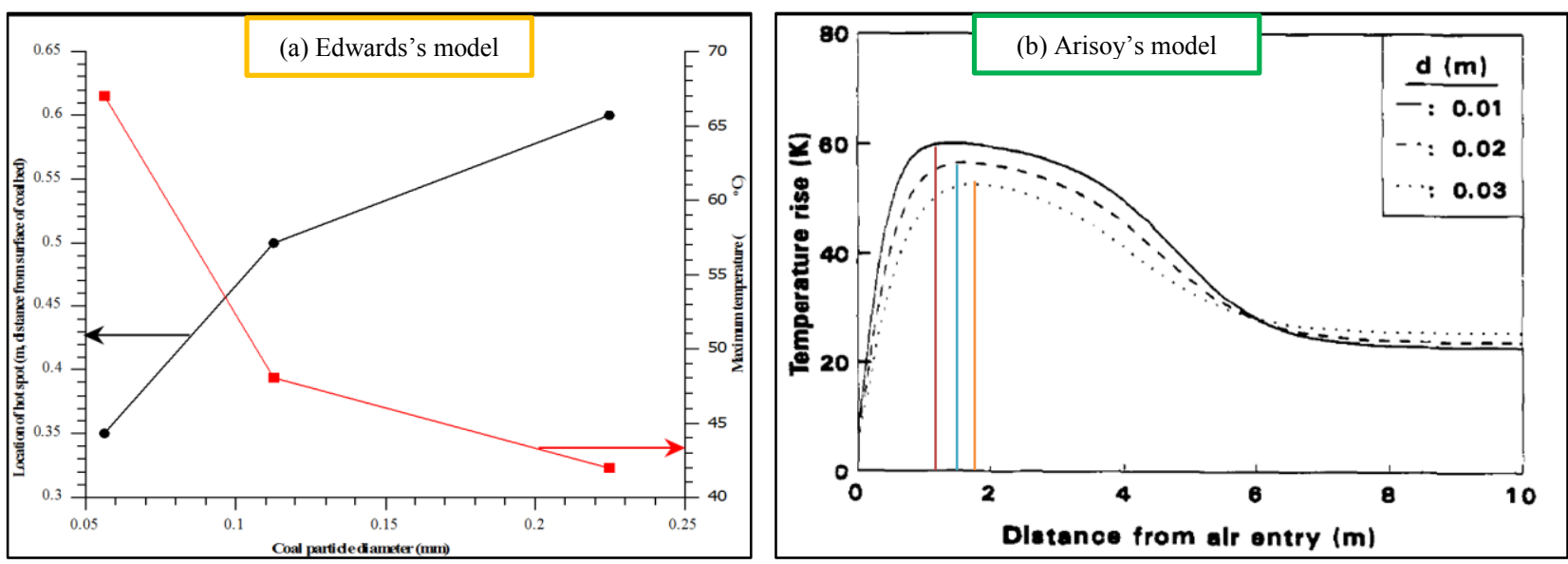

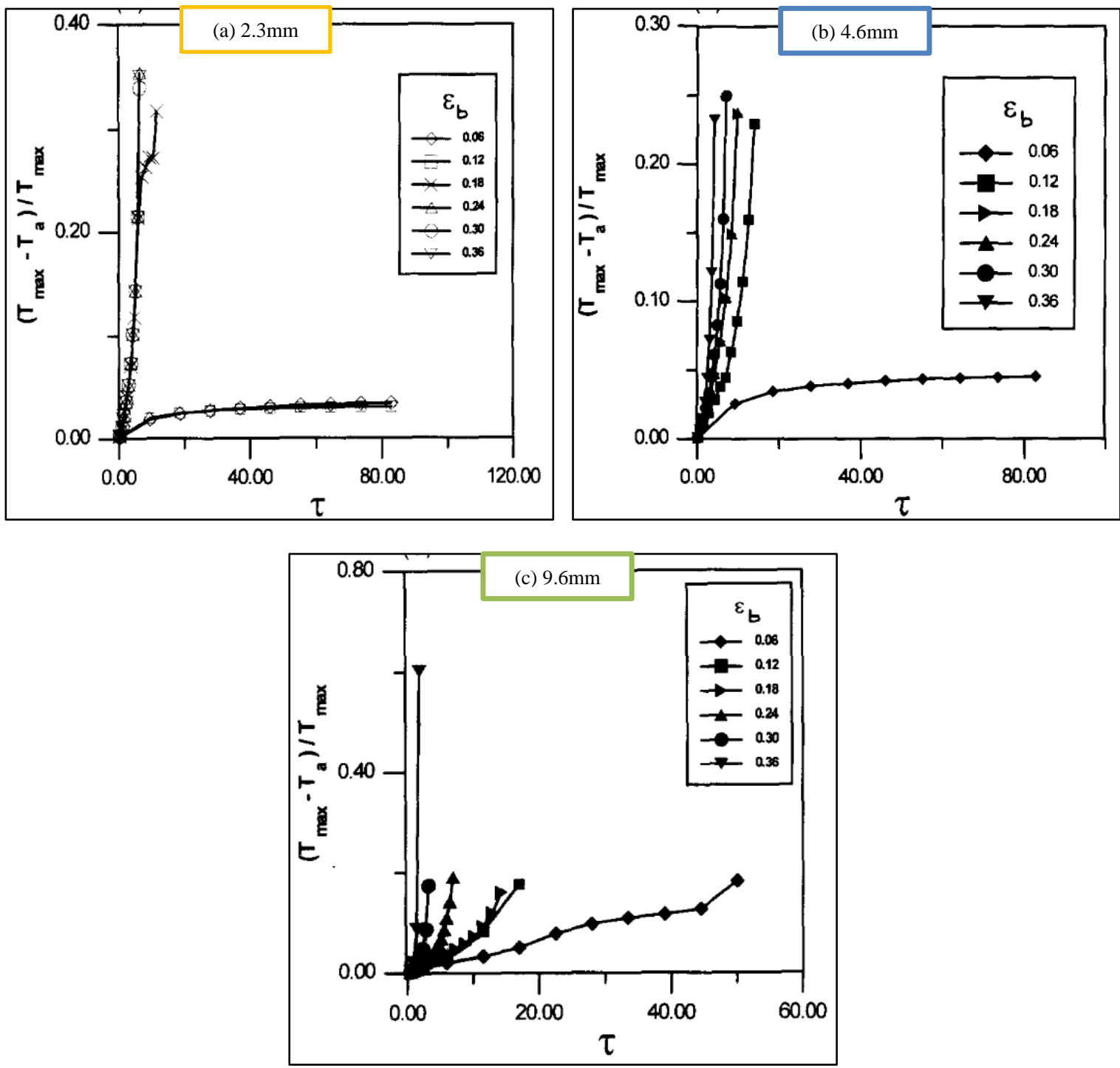

Figure 14 Influence of average particle diameter on temperature rise for various bed porosities [62]
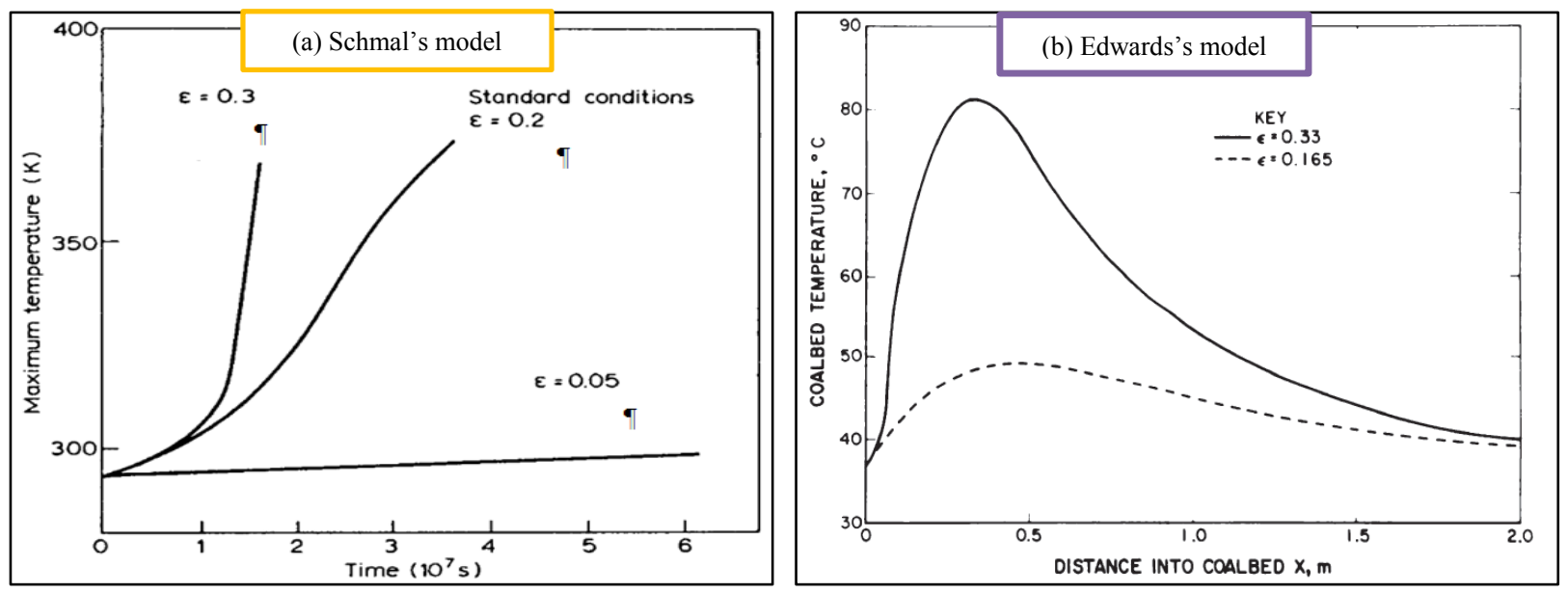

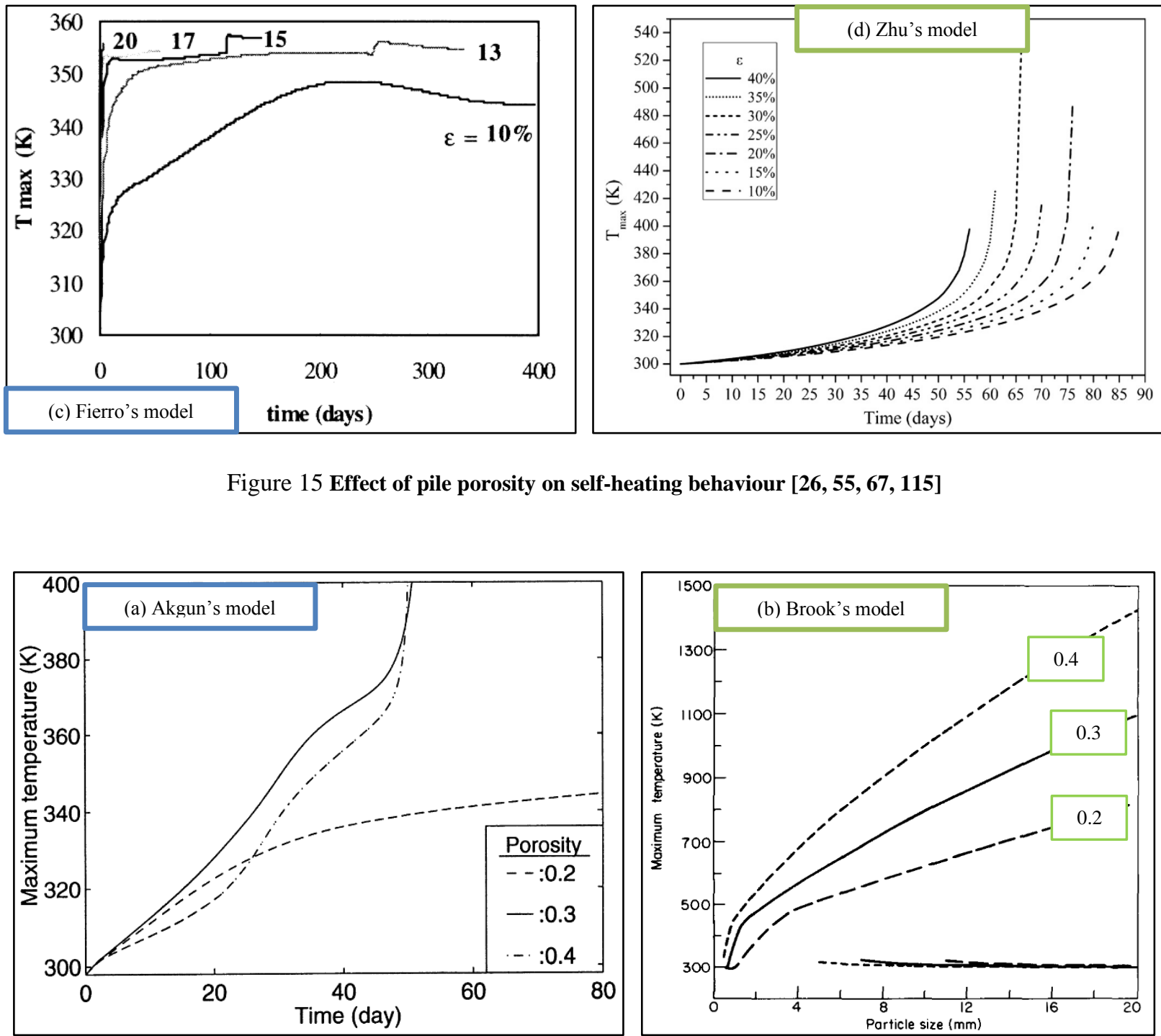

Figure 16 Exceptional findings of effect of pile porosity on self-heating behaviour [58, 64]
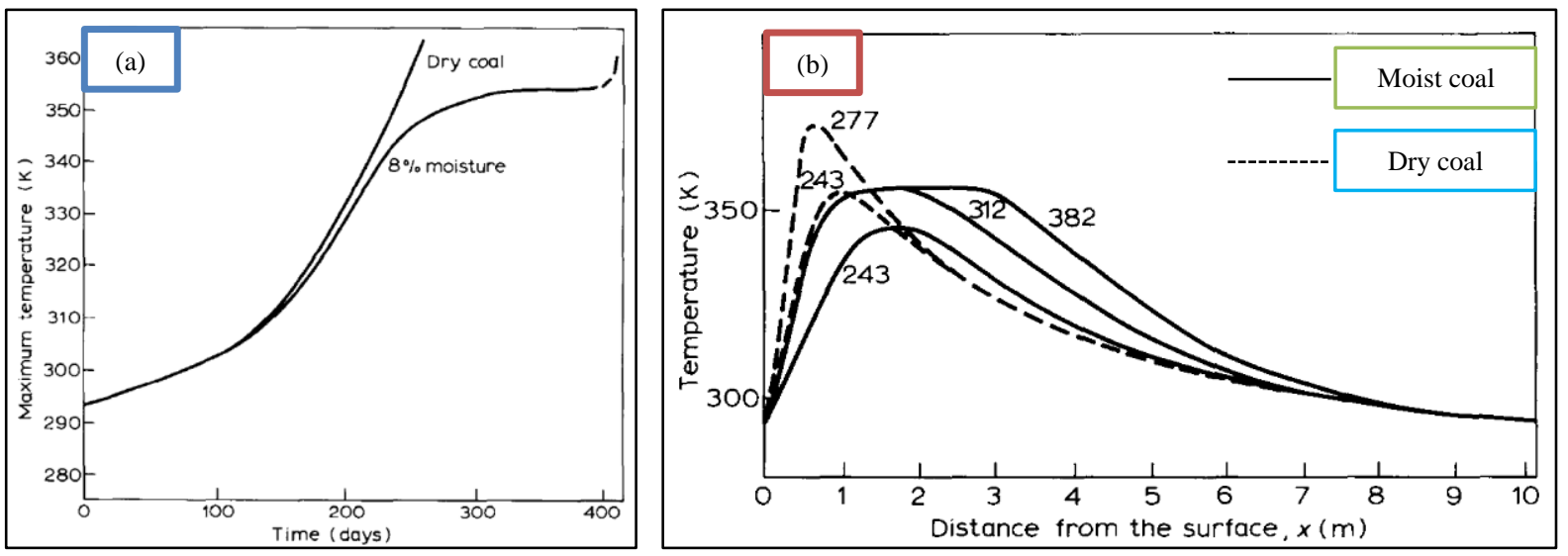


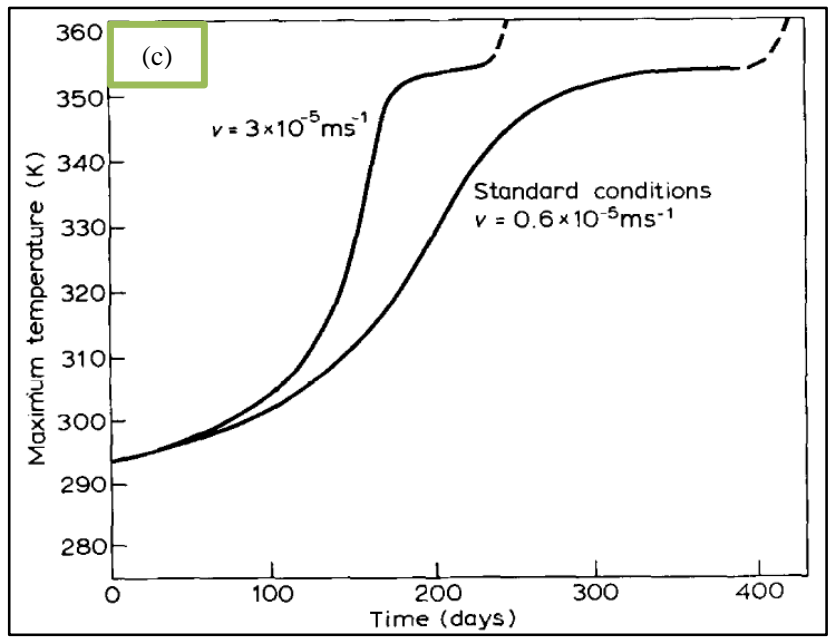

1249
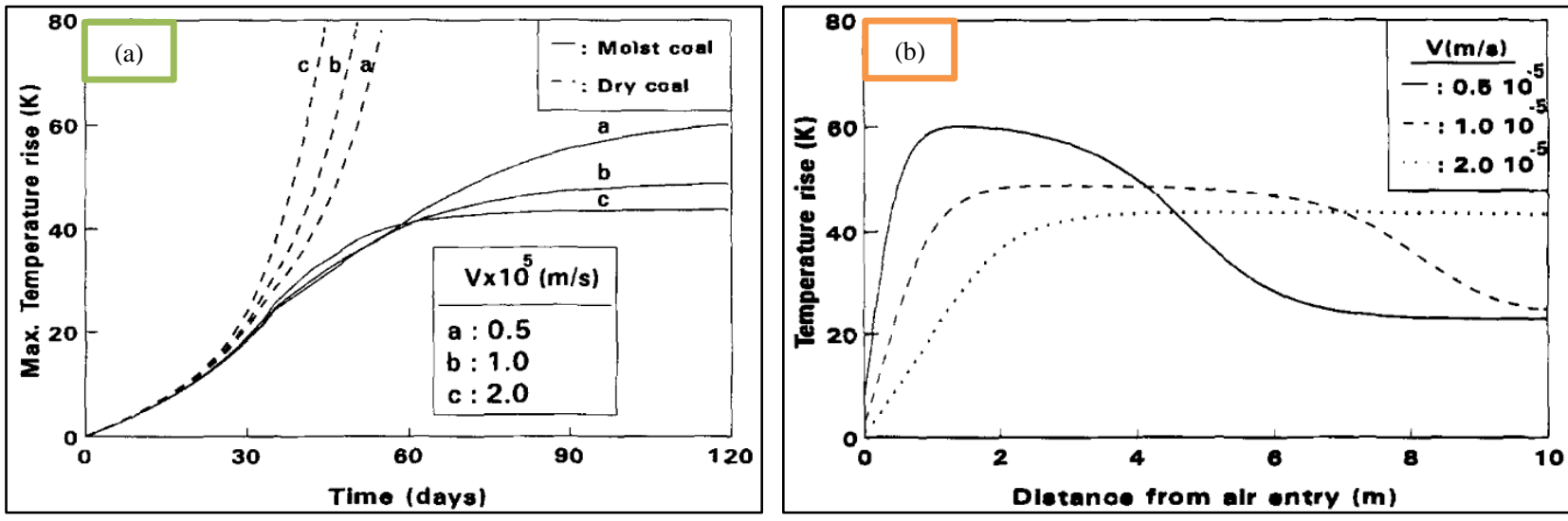

Figure 18 Influence of moisture on self-heating behaviour of a coalbed [65]

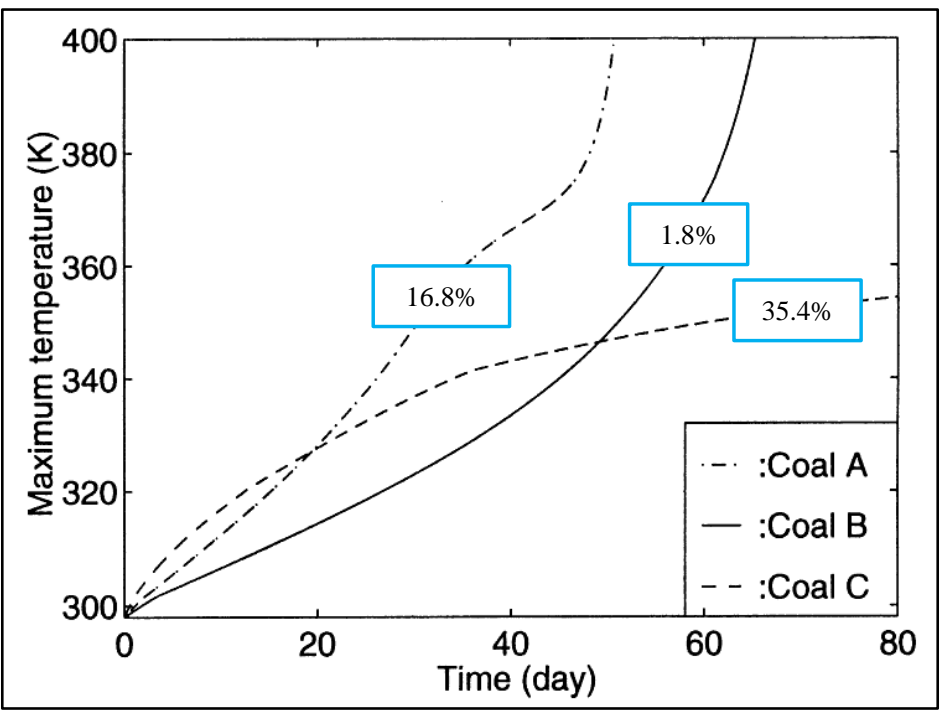

Figure 19 Influence of moisture on self-heating behaviour of three coal stockpiles [64] 

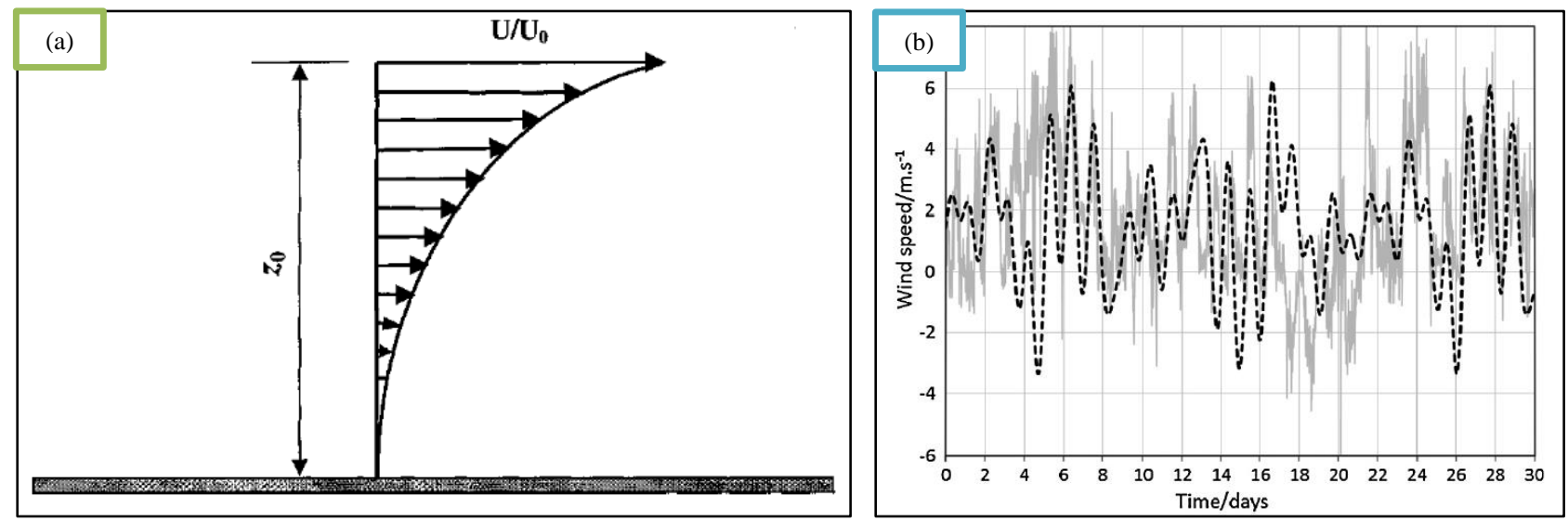

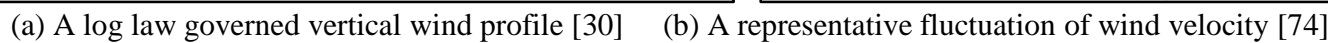
Figure 20 Profile of inlet wind velocity

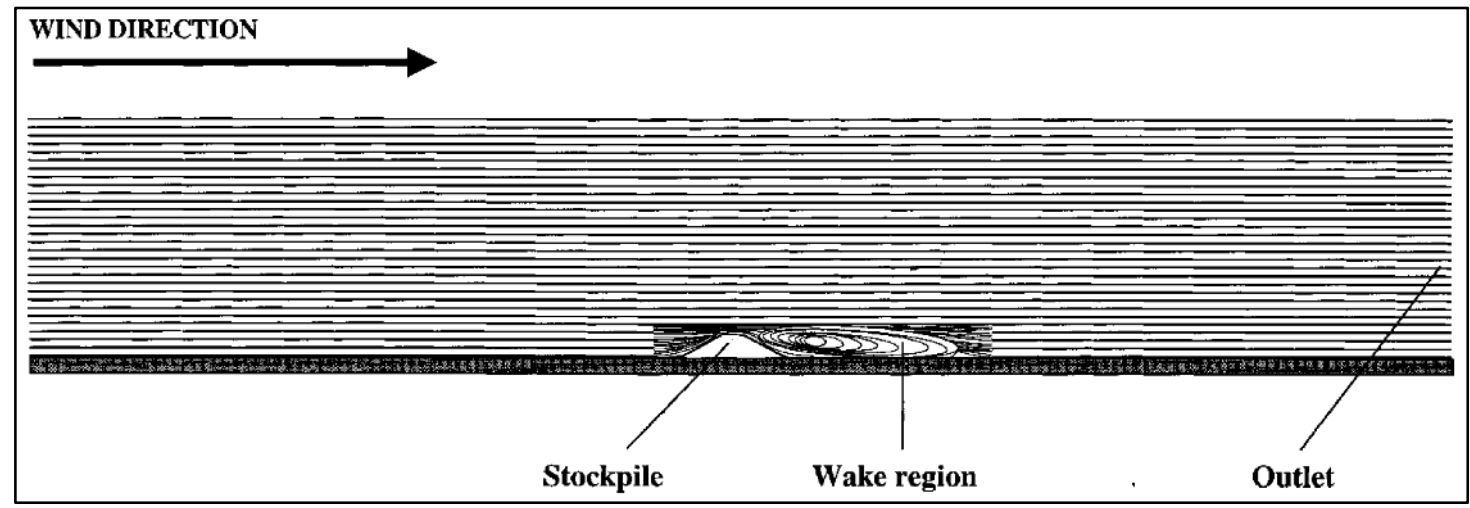

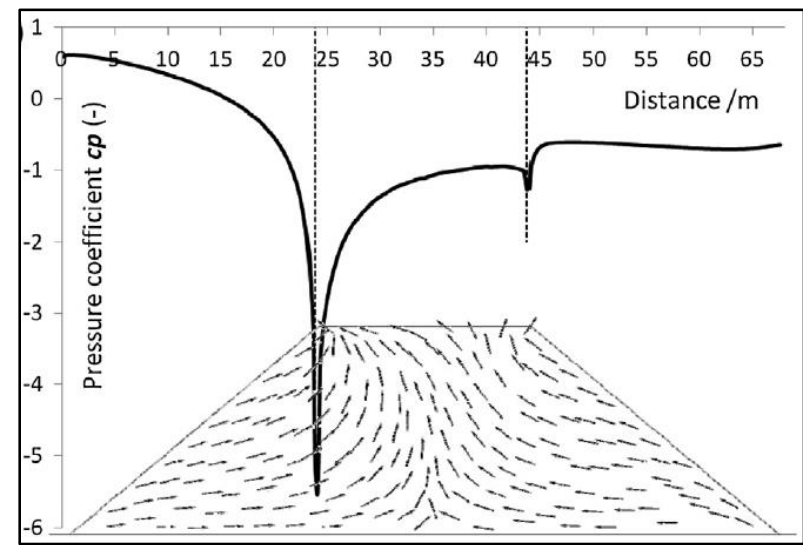

(a) Taraba' model [74]

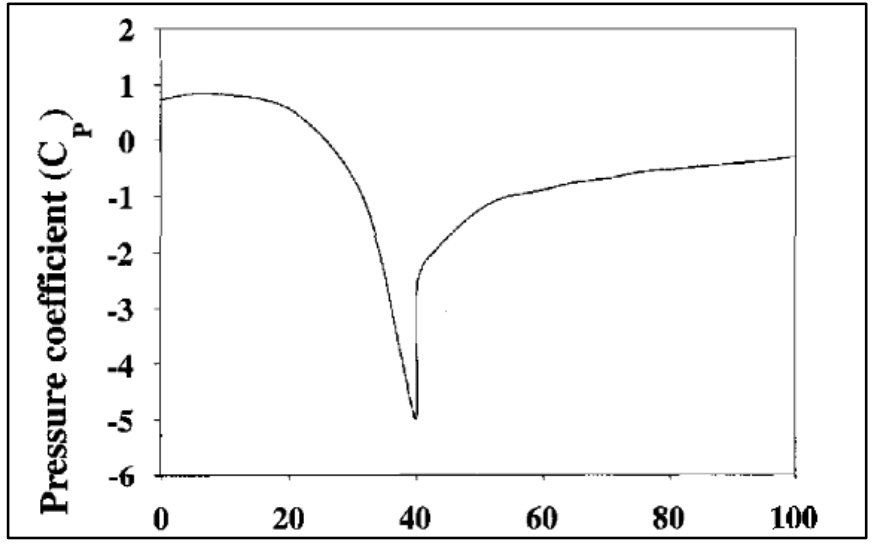

(b) Moghtaderi's model [30] Figure 22 Variation of the pressure coefficient around stockpile 
1266

1267

1268
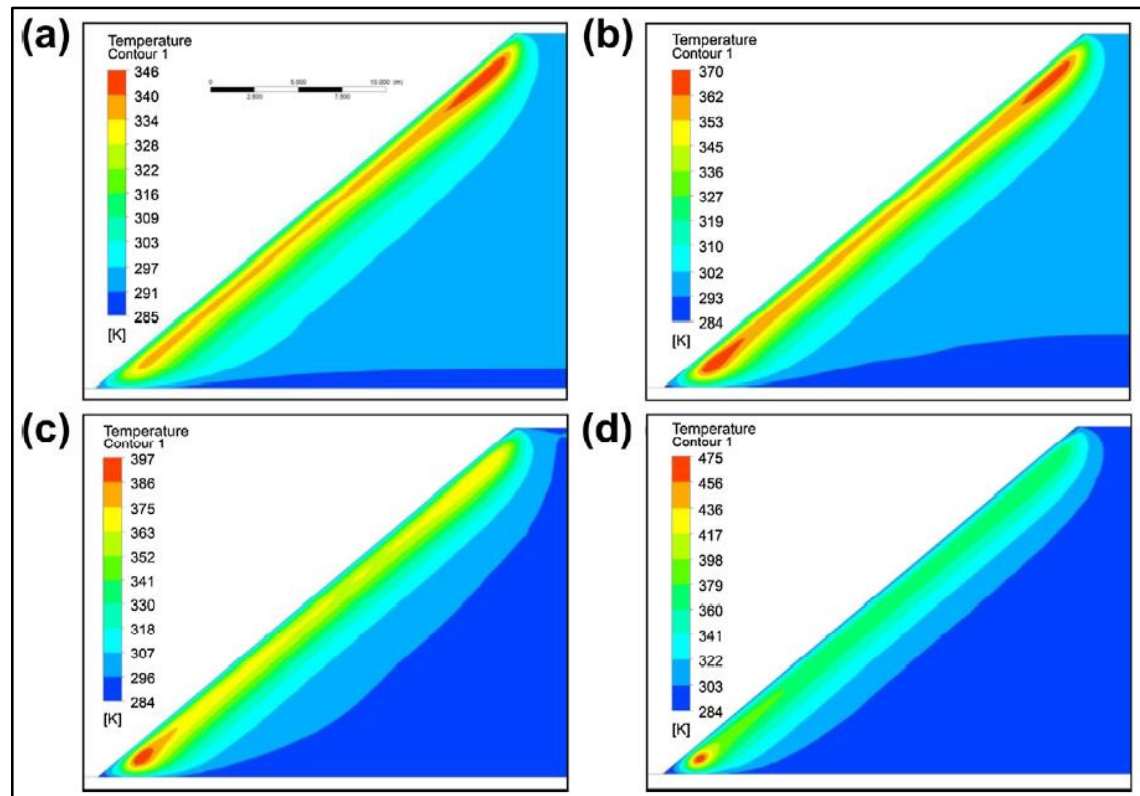

(d)

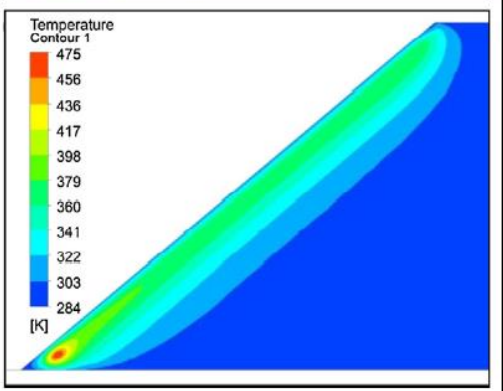

Figure 23 Vertical shift of hot spot at various stages of self-heating: (a) 346 K; (b) $370 \mathrm{~K}$; (c) $397 \mathrm{~K}$; (d) $475 \mathrm{~K}$ [74]

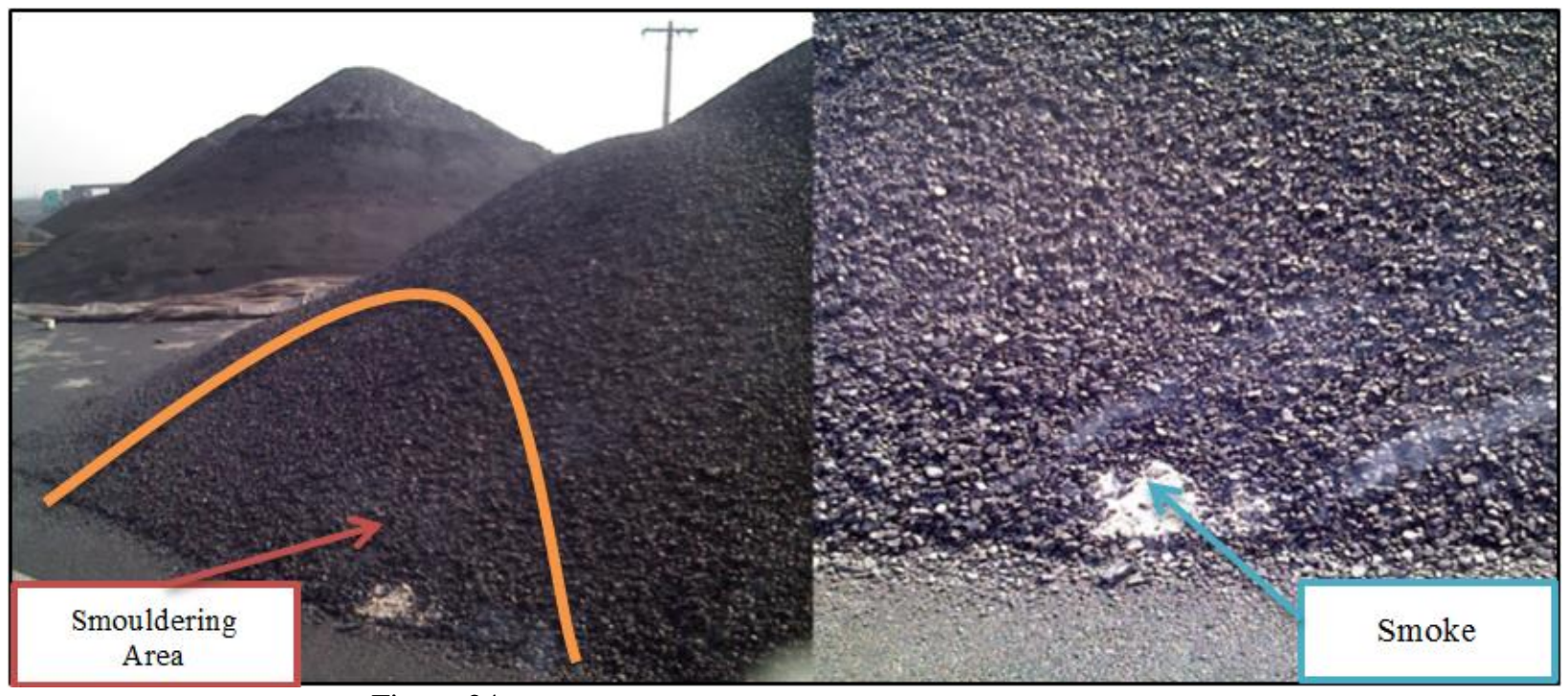

Figure 24 Field observation of self-heating of coal stockpiles [31]

Smoke 


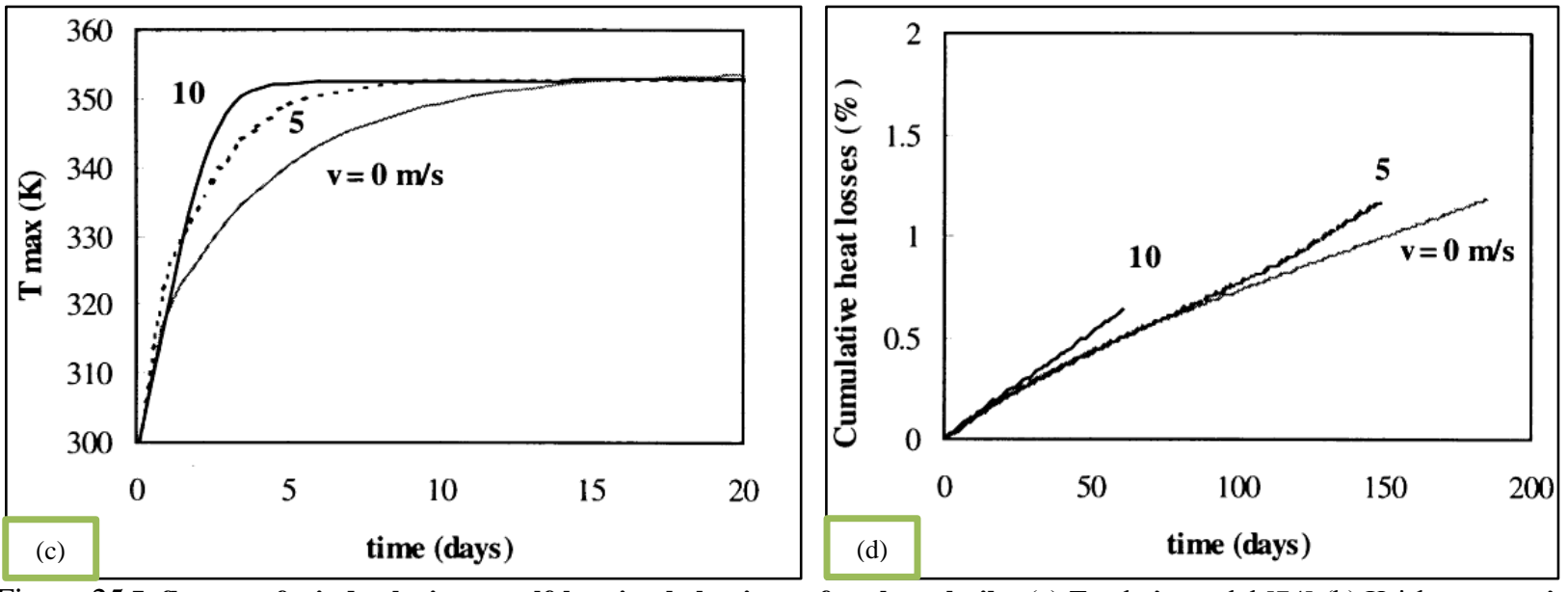

Figure 25 Influence of wind velocity on self-heating behaviour of coal stockpile: (a) Taraba's model [74] (b) Krishnaswamy's model [62] (c, d) Fierro's model [115]
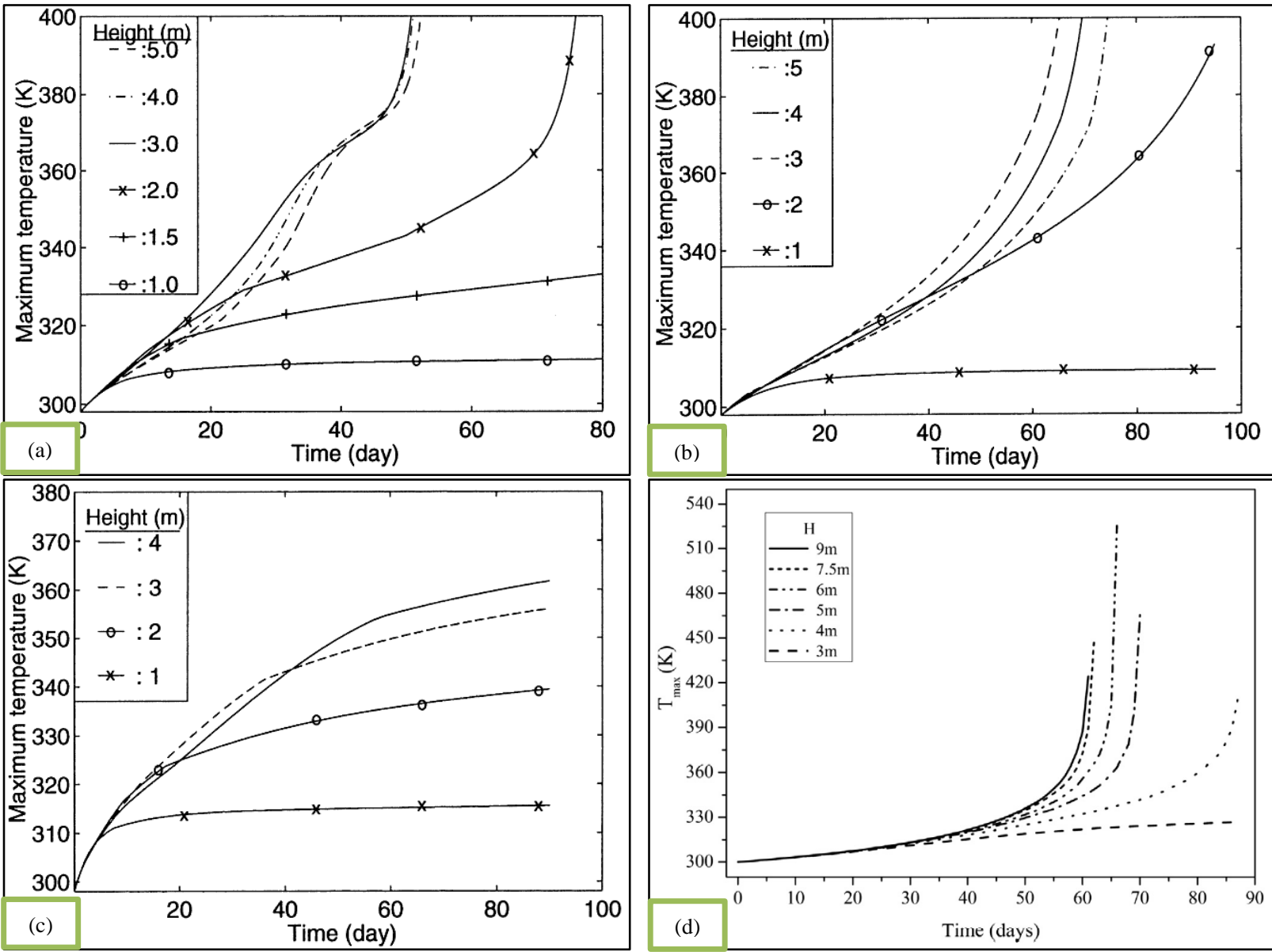

Figure 26 Influence of stockpile height on self-heating behaviour of coal stockpile: (a, b, c) A moderate moist coal, a dry coal, a very damp coal [64] (d) a coarse coal stockpile [26] 


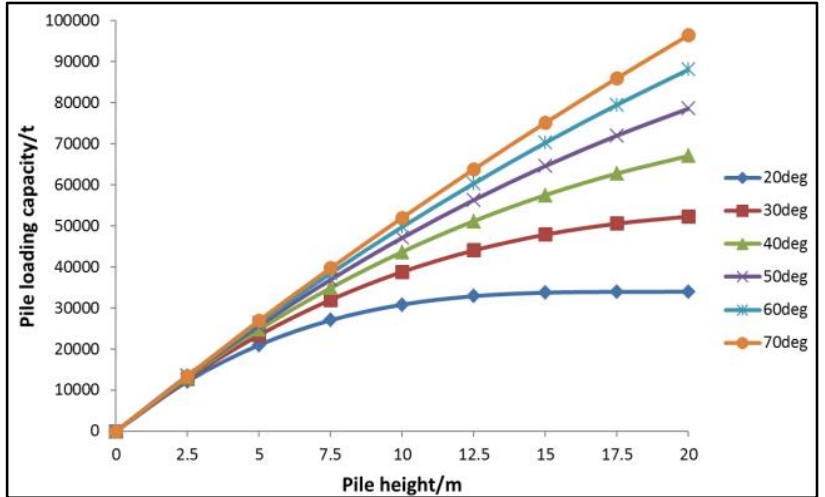

(a) Varied pile height at different side slopes

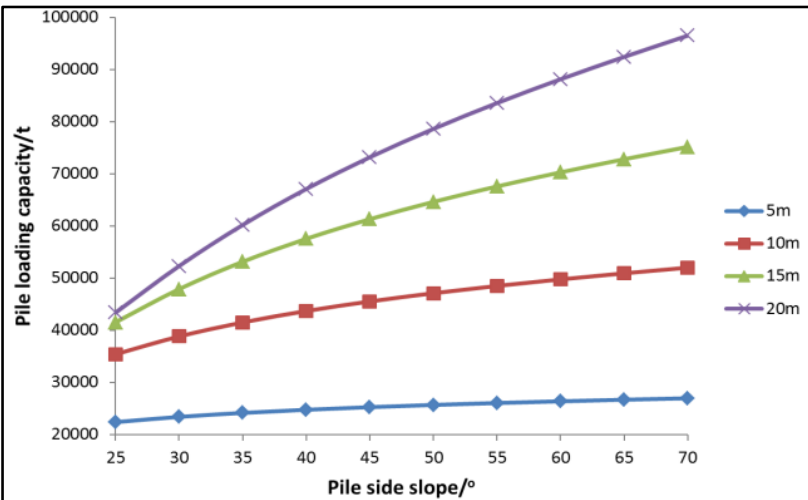

(b) Varied side slope at different heights Figure 27 Storage capacities of stockpiles with different pile heights and side slopes
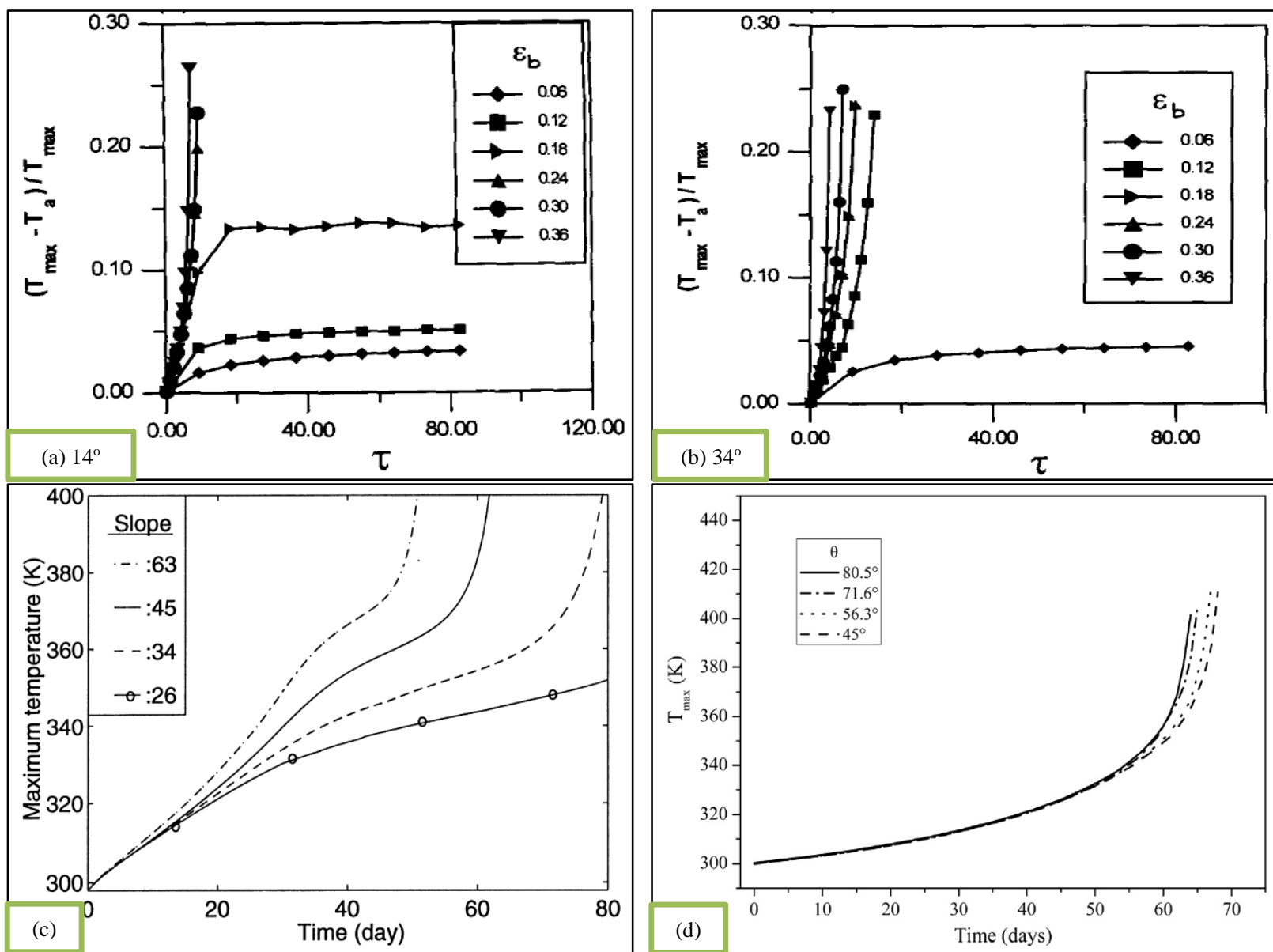

Figure 28 Influence of bed slope on self-heating behaviour of coal stockpile: (a, b) sourced from [62] (c) Akgun's model [64] (d) Zhu's model [26] 
Table 1 Comparisons of kinetic models developed by various investigators [15]

\begin{tabular}{|c|c|c|c|}
\hline Reference & $\begin{array}{l}\text { Temperature } \\
\text { range }\left({ }^{\circ} \mathrm{C}\right) \\
\end{array}$ & Reaction mechanism & Model features \\
\hline$[99,100]$ & $200 \sim 225$ & $\begin{array}{l}>\quad \text { Direct burn-off reaction coal }+\mathrm{O}_{2} \rightarrow \mathrm{CO}_{2}, \\
\text { CO, } \mathrm{H}_{2} \mathrm{O}\end{array}$ & $\begin{array}{l}\text { Prediction of oxygen consumption and } \\
\text { gaseous products }\left(\mathrm{CO}_{2}, \mathrm{CO} \text { and } \mathrm{H}_{2} \mathrm{O}\right) \text {, } \\
\text { Analytical solutions for the reaction rates, as } \\
\text { a sum of constant and exponential decay } \\
\text { terms, } \\
\text { Stoichiometric correlation between the } \\
\text { reactants and the gaseous products }\end{array}$ \\
\hline$[95,96]$ & $150 \sim 160$ & $\begin{array}{l}>\quad \begin{array}{l}\text { Direct burn-off reaction coal }+\mathrm{O}_{2} \rightarrow \mathrm{CO}_{2}, \\
\text { CO }\end{array} \\
>\quad \begin{array}{l}\text { Sorption sequence coal }+\mathrm{O}_{2} \leftrightarrow \text { physisorbed } \\
\mathrm{O}_{2} \rightarrow \text { chemisorbed } \mathrm{O}_{2} \rightarrow \mathrm{CO}_{2}, \mathrm{CO}\end{array} \\
>\quad \begin{array}{l}\text { Separate water production } \\
\text { coal }+\mathrm{O}_{2} \rightarrow \mathrm{H}_{2} \mathrm{O}\end{array}\end{array}$ & $\begin{array}{l}\text { Prediction of oxygen consumption, gaseous } \\
\text { products }\left(\mathrm{CO}_{2}, \mathrm{CO} \text { and } \mathrm{H}_{2} \mathrm{O}\right) \text { and solid } \\
\text { intermediates, } \\
\text { - Site conservation among various active sites, } \\
\text { Numerical solution of the model }\end{array}$ \\
\hline$[8,9]$ & $25 \sim 95$ & $\begin{array}{l}\text { Direct burn-off reaction } \\
\text { coal }+\mathrm{O}_{2} \rightarrow \mathrm{CO}_{2} \\
>\quad \begin{array}{l}\text { Sorption sequence coal }+\mathrm{O}_{2} \rightarrow \text { oxycoal } \\
\rightarrow \mathrm{CO}_{2}\end{array}\end{array}$ & $\begin{array}{l}\text { Prediction of oxygen consumed and carbon } \\
\text { dioxide produced, } \\
\text { Conserved active sites and exponential decay } \\
\text { in the active sites for oxygen adsorption, } \\
\text { Analytical solutions for the rates }\end{array}$ \\
\hline [90] & $60 \sim 90$ & $\begin{array}{l}>\quad \begin{array}{l}\text { Direct burn-off reaction coal }+\mathrm{O}_{2} \rightarrow \mathrm{CO}_{2}, \\
\text { CO, others }\end{array} \\
>\quad \begin{array}{l}\text { Sorption sequence } \\
\text { coal }+\mathrm{O}_{2} \rightarrow \text { carboxyl }+ \text { carbonyl }+\mathrm{CO}_{2}+\text { unre }\end{array} \\
\text { active species, } \\
>\quad \begin{array}{l}\text { Carboxyl species } \rightarrow \mathrm{CO}_{2} \\
\text { Carbonyl species } \rightarrow \mathrm{CO}\end{array}\end{array}$ & $\begin{array}{l}\text { Prediction of oxygen consumed and carbon } \\
\text { oxides produced, } \\
\text { Self-conserved active sites and reduction in } \\
\text { active sites due to the formation of unreactive } \\
\text { species, } \\
\text { Analytical equations for the rates }\end{array}$ \\
\hline
\end{tabular}


Table 2 Main features and parameters of numerical solutions to self-heating of coal (char) mass

\begin{tabular}{|c|c|c|c|c|c|c|c|c|c|c|c|c|c|c|c|c|c|c|}
\hline \multirow{3}{*}{\multicolumn{2}{|c|}{ Reference }} & \multicolumn{6}{|c|}{ Main features } & \multicolumn{5}{|c|}{ Chemical reaction parameters } & \multicolumn{6}{|c|}{ Physical properties of coal (mass) } \\
\hline & & \multirow[b]{2}{*}{$\begin{array}{l}\text { Coal } \\
\text { type }\end{array}$} & \multirow[b]{2}{*}{$\begin{array}{c}\text { Transien } \\
\mathrm{t}(\mathrm{T}) / \text { Stea } \\
\text { dy(S) }\end{array}$} & \multirow{2}{*}{$\begin{array}{c}\text { Spatial } \\
\text { dimens } \\
\text { ionalit } \\
\mathrm{y} \\
\end{array}$} & \multirow{2}{*}{$\begin{array}{c}\text { Moisture( } \\
\text { Y-yes/N- } \\
\text { no) }\end{array}$} & \multicolumn{2}{|c|}{ Transport mechanism } & \multirow[b]{2}{*}{$\begin{array}{l}\text { Reac } \\
\text { tion } \\
\text { order }\end{array}$} & \multicolumn{2}{|c|}{ Arrhenius constants } & \multirow[b]{2}{*}{$\begin{array}{l}\text { Reaction } \\
\text { mechanism }\end{array}$} & \multirow[b]{2}{*}{$\begin{array}{c}\text { Heat of } \\
\text { oxidation }\end{array}$} & \multirow{2}{*}{$\begin{array}{c}\text { Averag } \\
\text { e } \\
\text { particle } \\
\text { diamet } \\
\text { er } \\
\end{array}$} & \multirow[b]{2}{*}{$\begin{array}{l}\text { Poro } \\
\text { sity }\end{array}$} & \multirow[b]{2}{*}{$\begin{array}{c}\text { Dens } \\
\text { ity }\end{array}$} & \multirow{2}{*}{$\begin{array}{c}\text { Specifi } \\
\text { c heat } \\
\text { capacit } \\
y\end{array}$} & \multirow[b]{2}{*}{$\begin{array}{c}\text { Thermal } \\
\text { conductivit } \\
y\end{array}$} & \multirow{2}{*}{$\begin{array}{c}\text { Oxygen } \\
\text { diffusion } \\
\text { coefficient } \\
\text { in gas } \\
\text { phase }\end{array}$} \\
\hline & & & & & & Heat & Oxygen & & $\begin{array}{c}\text { Activat } \\
\text { ion } \\
\text { energy } \\
\end{array}$ & $\begin{array}{c}\text { Pre- } \\
\text { exponenti } \\
\text { al factor } \\
\end{array}$ & & & & & & & & \\
\hline \multicolumn{2}{|c|}{ [23] } & $\begin{array}{l}\text { A U.S. } \\
\text { lignite }\end{array}$ & $\mathrm{T}$ & 1D & $\mathrm{N}$ & Conduction & Forced convection & 1 & 50 & - & $\begin{array}{c}\text { Oxygen } \\
\text { consumptio } \\
\mathrm{n}\end{array}$ & $\begin{array}{c}376 \mathrm{~kJ} / \mathrm{mol} \\
\mathrm{O}_{2}\end{array}$ & - & - & 801 & 2263 & 0.2 & - \\
\hline \multicolumn{2}{|c|}{ [54] } & $\begin{array}{l}\text { Yallourn } \\
\text { briquette } \\
\text { char }\end{array}$ & $\mathrm{T}$ & 1D & $\mathrm{Y}$ & $\begin{array}{c}\text { Conduction \& } \\
\text { convection }\end{array}$ & $\begin{array}{l}\text { Diffusion \& forced } \\
\text { convection }\end{array}$ & 1 & 66 & - & $\begin{array}{c}\text { Oxygen } \\
\text { consumptio } \\
\mathrm{n}\end{array}$ & $\begin{array}{c}300 \mathrm{~kJ} / \mathrm{mol} \\
\mathrm{O}_{2}\end{array}$ & - & - & - & - & - & - \\
\hline [55] & $\begin{array}{c}\text { Dry } \\
\text { coal }\end{array}$ & - & $\mathrm{T}$ & 1D & $\mathrm{Y}$ & $\begin{array}{l}\text { Conduction \& } \\
\text { convection }\end{array}$ & $\begin{array}{l}\text { Diffusion \& forced } \\
\text { convection }\end{array}$ & $\begin{array}{c}1 \\
0.7 \\
\end{array}$ & $\begin{array}{c}7 \\
7.5 \\
\end{array}$ & $\begin{array}{l}4.2 \times 10^{-10} \\
2.1 \times 10^{-10} \\
\end{array}$ & $\begin{array}{c}\text { Oxygen } \\
\text { chemisorpti } \\
\text { on }\end{array}$ & $\begin{array}{c}3 \mathrm{~kJ} / \mathrm{mol} \mathrm{O}_{2} \\
3.7 \mathrm{~kJ} / \mathrm{mol} \\
\mathrm{O}_{2}\end{array}$ & & $\begin{array}{l}0.05, \\
0.2, \\
0.3 \\
\end{array}$ & 1500 & 1000 & 0.12 & $2 \times 10^{-5}$ \\
\hline & 8] & - & $\mathrm{s}$ & 1D & $\mathrm{N}$ & Conduction & Natural convection & 1 & 58.2 & 3600 & $\begin{array}{c}\text { Oxygen } \\
\text { consumptio } \\
n\end{array}$ & $\begin{array}{c}300 \mathrm{~kJ} / \mathrm{mol} \\
\mathrm{O}_{2}\end{array}$ & 0.01 & 0.3 & - & - & 0.2 & $2 \times 10^{-5}$ \\
\hline & 0] & - & $\mathrm{S}$ & $2 \mathrm{D}$ & $\mathrm{N}$ & Conduction & Natural convection & - & - & - & - & $\begin{array}{c}400 \mathrm{~kJ} / \mathrm{mol} \\
\mathrm{O}_{2}\end{array}$ & - & - & - & - & 0.16 & - \\
\hline & 6] & - & $\mathrm{s}$ & $2 \mathrm{D}$ & $\mathrm{N}$ & Conduction & Natural convection & 1 & 58.2 & 3600 & $\begin{array}{c}\text { Oxygen } \\
\text { consumptio } \\
n\end{array}$ & $\begin{array}{c}300 \mathrm{~kJ} / \mathrm{mol} \\
\mathrm{O}_{2}\end{array}$ & 0.01 & 0.3 & - & - & 0.2 & $2 \times 10^{-5}$ \\
\hline & $\begin{array}{c}\text { Force } \\
d \\
\text { conve } \\
\text { ction } \\
\text { model } \\
\end{array}$ & & & $2 \mathrm{D}$ & $\mathrm{N}$ & $\begin{array}{l}\text { Conduction \& } \\
\text { convection }\end{array}$ & $\begin{array}{l}\text { Forced convection \& } \\
\text { diffusion }\end{array}$ & 1 & 90 & $1.23 \times 10^{9}$ & & & 0.076 & 0.33 & & & & \\
\hline [67] & $\begin{array}{c}\text { Buoya } \\
\text { ncy- } \\
\text { driven } \\
\text { model } \\
\end{array}$ & $\begin{array}{c}\text { High- } \\
\text { volatile } \\
\text { C } \\
\text { bitumino }\end{array}$ & $\mathrm{T}$ & $2 \mathrm{D}$ & $\mathrm{N}$ & $\begin{array}{l}\text { Conduction \& } \\
\text { convection }\end{array}$ & $\begin{array}{l}\text { Natural convection } \\
\quad \& \text { diffusion }\end{array}$ & 1 & 90 & $1.23 \times 10^{9}$ & $\begin{array}{c}\text { Oxygen } \\
\text { consumptio } \\
\mathrm{n}\end{array}$ & $\begin{array}{c}300 \mathrm{~kJ} / \mathrm{mol} \\
\mathrm{O}_{2}\end{array}$ & 0.076 & 0.33 & 1300 & 1004 & 0.114 & $1.5 \times 10^{-5}$ \\
\hline & $\begin{array}{l}\text { Wind- } \\
\text { driven } \\
\text { model }\end{array}$ & us coal & & 1D & $\mathrm{N}$ & $\begin{array}{l}\text { Conduction \& } \\
\text { convection }\end{array}$ & $\begin{array}{l}\text { Forced convection \& } \\
\text { diffusion }\end{array}$ & 1 & $\begin{array}{l}90 \\
76.6\end{array}$ & $\begin{array}{l}1.23 \times 10^{9} \\
5.96 \times 10^{7}\end{array}$ & & & $\begin{array}{c}5.625 x \\
10^{-5} \\
1.125 x \\
10^{-4}, \\
2.25 \times 1 \\
0^{-4}\end{array}$ & $\begin{array}{c}0.33, \\
0.16 \\
5\end{array}$ & & & & \\
\hline & $1]$ & - & $\mathrm{S}$ & 3D & $\mathrm{N}$ & $\begin{array}{c}\text { Conduction \& } \\
\text { convection }\end{array}$ & - & 0 & - & - & - & - & - & - & - & - & - & - \\
\hline & 5] & $\begin{array}{c}\text { Turkish } \\
\text { moist } \\
\text { coals } \\
\end{array}$ & $\mathrm{T}$ & 1D & $\mathrm{Y}$ & $\begin{array}{c}\text { Conduction \& } \\
\text { convection }\end{array}$ & $\begin{array}{l}\text { Forced convection \& } \\
\text { diffusion }\end{array}$ & 1 & 70 & $\underset{6}{2.933 \times 10}$ & $\begin{array}{c}\text { Oxygen } \\
\text { adsorption }\end{array}$ & $\begin{array}{c}9375 \mathrm{~kJ} / \mathrm{kg} \\
\mathrm{O}_{2} \\
\end{array}$ & $\begin{array}{l}0.01 \\
0.02 \\
0.03 \\
\end{array}$ & 0.3 & 1100 & 1000 & 0.2 & $2 \times 10^{-5}$ \\
\hline & 9] & - & $\mathrm{s}$ & $2 \mathrm{D}$ & $\mathrm{N}$ & $\begin{array}{c}\text { Conduction \& } \\
\text { convection }\end{array}$ & $\begin{array}{c}\text { Natural convection } \\
\& \text { diffusion }\end{array}$ & 1 & 58.2 & 3600 & $\begin{array}{c}\text { Oxygen } \\
\text { consumptio } \\
\text { n }\end{array}$ & $\begin{array}{c}300 \mathrm{~kJ} / \mathrm{mol} \\
\mathrm{O}_{2} \\
\end{array}$ & 0.01 & 0.4 & - & - & 0.2 & $2 \times 10^{-5}$ \\
\hline & 2] & $\begin{array}{c}\text { Weather } \\
\text { ed } \\
\text { Wyomin } \\
g \\
\text { subbitu } \\
\text { minous } \\
\text { coal }\end{array}$ & $\mathrm{T}$ & $2 \mathrm{D}$ & $\mathrm{N}$ & $\begin{array}{l}\text { Conduction \& } \\
\text { convection }\end{array}$ & $\begin{array}{l}\text { Forced \& natural } \\
\text { convection }\end{array}$ & 1 & 57.5 & $8.83 \times 10^{6}$ & Burn-off & - & 0.023 & $\begin{array}{c}0.09 \\
6\end{array}$ & - & - & - & - \\
\hline & 3] & - & $\mathrm{T}$ & 1D & $\mathrm{N}$ & Conduction & Diffusion & 1 & 57.5 & $8.83 \times 10^{6}$ & $\begin{array}{c}\text { Oxygen } \\
\text { consumptio } \\
n\end{array}$ & $\begin{array}{c}330 \mathrm{~kJ} / \mathrm{mol} \\
\mathrm{O}_{2}\end{array}$ & - & - & - & - & 0.2 & $2 \times 10^{-5}$ \\
\hline
\end{tabular}




\begin{tabular}{|c|c|c|c|c|c|c|c|c|c|c|c|c|c|c|c|c|c|}
\hline$[68]$ & - & $\mathrm{T}$ & 1D & $\mathrm{N}$ & $\begin{array}{l}\text { Conduction \& } \\
\text { radiation }\end{array}$ & Diffusion & 1 & 57.5 & $8.83 \times 10^{6}$ & $\begin{array}{c}\text { Oxygen } \\
\text { consumptio } \\
\text { n }\end{array}$ & $\begin{array}{c}330 \mathrm{~kJ} / \mathrm{mol} \\
\mathrm{O}_{2}\end{array}$ & - & - & - & - & 0.2 & $2 \times 10^{-5}$ \\
\hline$[70]$ & $\begin{array}{c}\text { Wyomin } \\
g \\
\text { subbitu } \\
\text { minous } \\
\text { coal }\end{array}$ & $\mathrm{T}$ & 1D & $\mathrm{Y}$ & $\begin{array}{l}\text { Conduction \& } \\
\text { convection }\end{array}$ & $\begin{array}{l}\text { Natural convection } \\
\& \text { diffusion }\end{array}$ & 1 & 57.5 & $8.83 \times 10^{6}$ & $\begin{array}{c}\text { Oxygen } \\
\text { consumptio } \\
\mathrm{n}\end{array}$ & $\begin{array}{c}330 \mathrm{~kJ} / \mathrm{mol} \\
\mathrm{O}_{2}\end{array}$ & $\begin{array}{c}0.003 \sim \\
0.015\end{array}$ & - & - & - & - & - \\
\hline [30] & $\begin{array}{c}\text { Australi } \\
\text { an } \\
\text { bitumino } \\
\text { us coal }\end{array}$ & $\mathrm{T}$ & $2 \mathrm{D}$ & $\mathrm{Y}$ & $\begin{array}{l}\text { Conduction \& } \\
\text { convection }\end{array}$ & $\begin{array}{l}\text { Forced convection \& } \\
\text { diffusion }\end{array}$ & 0.7 & $\underset{7}{7.5 \times 10^{-}}$ & $2.1 \times 10^{-10}$ & $\begin{array}{c}\text { Oxygen } \\
\text { consumptio } \\
\mathrm{n}\end{array}$ & $\begin{array}{c}11560 \\
\mathrm{~kJ} / \mathrm{kg} \text { coal }\end{array}$ & - & 0.3 & 1260 & 1423 & 0.12 & $1.2 \times 10^{-5}$ \\
\hline [64] & $\begin{array}{l}\text { Turkish } \\
\text { brown } \\
\text { coals }\end{array}$ & $\mathrm{T}$ & $2 \mathrm{D}$ & $\mathrm{Y}$ & $\begin{array}{c}\text { Conduction \& } \\
\text { convection }\end{array}$ & $\begin{array}{l}\text { Forced convection \& } \\
\quad \text { diffusion }\end{array}$ & 1 & $\begin{array}{l}46.81, \\
30.64, \\
21.89\end{array}$ & $\begin{array}{l}1758, \\
1.485, \\
0.424\end{array}$ & $\begin{array}{c}\text { Oxygen } \\
\text { consumptio } \\
n\end{array}$ & - & - & 0.3 & - & - & - & - \\
\hline [143] & $\begin{array}{c}\text { A China } \\
\text { coal }\end{array}$ & $\mathrm{T}$ & 1D & $\mathrm{N}$ & $\begin{array}{l}\text { Conduction \& } \\
\text { convection \& } \\
\text { radiation }\end{array}$ & $\begin{array}{l}\text { Forced convection \& } \\
\quad \text { diffusion }\end{array}$ & 1 & 40 & 10 & $\begin{array}{c}\text { Oxygen } \\
\text { consumptio } \\
\text { n }\end{array}$ & - & - & 0.5 & - & 1500 & 3.4 & $2 \times 10^{-5}$ \\
\hline [115] & $\begin{array}{l}\text { A Spain } \\
\text { coal }\end{array}$ & $\mathrm{T}$ & 1D & $\mathrm{N}$ & $\begin{array}{l}\text { Conduction \& } \\
\text { convection }\end{array}$ & $\begin{array}{l}\text { Forced convection \& } \\
\text { diffusion }\end{array}$ & 0.52 & 42 & $2.8 \times 10^{-8}$ & $\begin{array}{c}\text { Oxygen } \\
\text { consumptio } \\
\mathrm{n}\end{array}$ & $\begin{array}{c}380 \mathrm{~kJ} / \mathrm{mol} \\
\mathrm{O}_{2}\end{array}$ & - & $\begin{array}{c}0.1, \\
0.13, \\
0.15, \\
0.17, \\
0.2, \\
0.25, \\
0.3\end{array}$ & 1566 & 1132 & 0.113 & - \\
\hline [78] & $\begin{array}{l}\text { Four } \\
\text { coals }\end{array}$ & $\mathrm{T}$ & $2 \mathrm{D}$ & $\mathrm{N}$ & $\begin{array}{l}\text { Conduction \& } \\
\text { radiation }\end{array}$ & Diffusion & 1 & $\begin{array}{c}40, \\
26.88 \\
58, \\
30.64\end{array}$ & $\begin{array}{c}10, \\
6, \\
8.83 \times 10^{6}, \\
1485\end{array}$ & $\begin{array}{c}\text { Oxygen } \\
\text { consumptio } \\
\mathrm{n}\end{array}$ & - & - & - & - & 1500 & 3.4 & $2 \times 10^{-5}$ \\
\hline [75] & $\begin{array}{l}\text { Three } \\
\text { U.S. } \\
\text { coals }\end{array}$ & $\mathrm{T}$ & $3 \mathrm{D}$ & $\mathrm{N}$ & $\begin{array}{l}\text { Conduction \& } \\
\text { convection }\end{array}$ & $\begin{array}{l}\text { Forced convection \& } \\
\quad \text { diffusion }\end{array}$ & 0.61 & $\begin{array}{l}66.5 \\
73.6 \\
88.3\end{array}$ & $\begin{array}{l}1.9 \times 10^{6} \\
1.1 \times 10^{7} \\
4.4 \times 10^{8}\end{array}$ & $\begin{array}{c}\mathrm{Coal}+\mathrm{O}_{2} \rightarrow \\
\mathrm{CO}_{2}+0.1 \mathrm{C} \\
\mathrm{O}\end{array}$ & $\begin{array}{c}300 \mathrm{~kJ} / \mathrm{mol} \\
\mathrm{O}_{2}\end{array}$ & - & - & 1300 & 1003.2 & 0.1998 & $1.5 \times 10^{-5}$ \\
\hline [24] & $\begin{array}{c}\text { A U.S. } \\
\text { High } \\
\text { volatile } \\
\text { bitumino } \\
\text { us coal }\end{array}$ & $\mathrm{T}$ & $3 \mathrm{D}$ & $\mathrm{N}$ & $\begin{array}{l}\text { Conduction \& } \\
\text { convection }\end{array}$ & $\begin{array}{c}\text { Forced convection \& } \\
\text { diffusion }\end{array}$ & 0.61 & 66.5 & $1.9 \times 10^{6}$ & $\begin{array}{c}\mathrm{Coal}+\mathrm{O}_{2} \rightarrow \\
\mathrm{CO}_{2}+0.1 \mathrm{C} \\
\mathrm{O}\end{array}$ & $\begin{array}{c}300 \mathrm{~kJ} / \mathrm{mol} \\
\mathrm{O}_{2}\end{array}$ & 0.02 & 0.3 & 1240 & 1003.2 & 0.1998 & - \\
\hline [73] & $\begin{array}{l}\text { A Czech } \\
\text { bitumino } \\
\text { us coal }\end{array}$ & $\mathrm{T}$ & $3 \mathrm{D}$ & $\mathrm{N}$ & $\begin{array}{l}\text { Conduction \& } \\
\text { convection }\end{array}$ & $\begin{array}{l}\text { Forced convection \& } \\
\text { diffusion }\end{array}$ & 1 & $\begin{array}{c}23.5 \\
\text { (subcri } \\
\text { tical), } \\
51 \\
\text { (superc } \\
\text { ritical) }\end{array}$ & $\begin{array}{c}1.85 \\
\text { (subcritic } \\
\text { al) } \\
13700 \\
\text { (supercrit } \\
\text { ical) }\end{array}$ & $\begin{array}{c}\text { Oxygen } \\
\text { consumptio } \\
\mathrm{n}\end{array}$ & $\begin{array}{c}250 \mathrm{~kJ} / \mathrm{mol} \\
\mathrm{O}_{2}\end{array}$ & - & - & - & - & - & - \\
\hline [77] & A lignite & $\mathrm{T}$ & $2 \mathrm{D}$ & $\mathrm{Y}$ & $\begin{array}{l}\text { Conduction \& } \\
\text { convection }\end{array}$ & $\begin{array}{l}\text { Forced convection \& } \\
\text { diffusion }\end{array}$ & 1 & 55 & 1000 & $\begin{array}{c}\text { Oxygen } \\
\text { consumptio } \\
\text { n }\end{array}$ & $\begin{array}{c}22000 \\
\mathrm{~kJ} / \mathrm{kg} \text { coal }\end{array}$ & - & - & - & 1500 & 0.12 & - \\
\hline [72] & - & $\mathrm{T}$ & $2 \mathrm{D}$ & $\mathrm{N}$ & $\begin{array}{c}\text { Conduction \& } \\
\text { convection }\end{array}$ & $\begin{array}{l}\text { Forced convection } \\
\& \text { diffusion }\end{array}$ & 0 & 0.75 & $2.1 \times 10^{-10}$ & $\begin{array}{c}\mathrm{Coal}+\mathrm{O}_{2} \rightarrow \\
\mathrm{CO}_{2}\end{array}$ & - & - & - & 1200 & 1050 & 0.12 & - \\
\hline [26] & $\begin{array}{l}\text { A China } \\
\text { coal }\end{array}$ & $\mathrm{T}$ & $2 \mathrm{D}$ & $\mathrm{N}$ & $\begin{array}{l}\text { Conduction \& } \\
\text { convection }\end{array}$ & $\begin{array}{l}\text { Forced and natural } \\
\text { convection \& } \\
\text { diffusion }\end{array}$ & 1 & 50 & 180 & $\begin{array}{c}\text { Oxygen } \\
\text { consumptio } \\
\mathrm{n}\end{array}$ & $\begin{array}{c}400 \mathrm{~kJ} / \mathrm{mol} \\
\mathrm{O}_{2}\end{array}$ & - & $\begin{array}{c}0.1, \\
0.15, \\
0.2, \\
0.25, \\
0.3, \\
0.35, \\
0.4\end{array}$ & - & 1003.2 & 0.2 & $2 \times 10^{-5}$ \\
\hline [74] & $\begin{array}{c}\text { A } \\
\text { bitumino } \\
\text { us coal }\end{array}$ & $\mathrm{T}$ & $2 \mathrm{D}$ & $\mathrm{N}$ & $\begin{array}{l}\text { Conduction \& } \\
\text { convection }\end{array}$ & $\begin{array}{l}\text { Forced \& natural } \\
\text { convection \& } \\
\text { diffusion }\end{array}$ & 1 & $\begin{array}{c}22 \\
\text { (subcri } \\
\text { tical), } \\
50.5\end{array}$ & $\begin{array}{c}1.85 \\
\text { (subcritic } \\
\text { al), } \\
13500\end{array}$ & $\begin{array}{c}\mathrm{Coal}+\mathrm{O}_{2} \rightarrow \\
0.1 \mathrm{CO}_{2}+0.4 \\
\mathrm{H}_{2} \mathrm{O}+1.4 \mathrm{O}- \\
\text { Coal }\end{array}$ & $\begin{array}{c}270 \mathrm{~kJ} / \mathrm{mol} \\
\mathrm{O}_{2}\end{array}$ & 0.01 & - & - & - & - & - \\
\hline
\end{tabular}




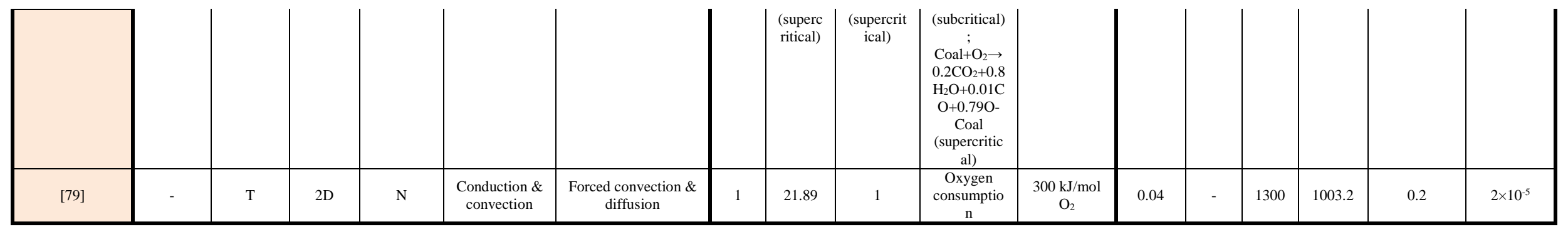


Table 3 Different compaction degree of coal stockpile and according value of porosity

\begin{tabular}{|c|c|c|c|}
\hline Porosity & $\sim 0.1$ & $\sim 0.2$ & $\sim 0.3$ \\
\hline Compaction degree & Densely Compacted & Loosely compacted & Uncompacted \\
\hline
\end{tabular}

1313

Table 4 Generalised effects of moisture in coal oxidation and self-heating

\begin{tabular}{|c|c|c|}
\hline Literatures & Promotion of coal oxidation and self-heating & Numerical solution \\
\hline$[22,144]$ & Heat gain in adsorption of water & $\mathrm{N}$ \\
\hline- & Heat gain from vapour condensation & $\mathrm{Y}$ \\
\hline$[2,15,145,146]$ & Drying can free more active surface & $\mathrm{N}$ \\
\hline$[145]$ & Water is a critical element in oxidation of pyritic sulphur & $\mathrm{N}$ \\
\hline$[15,131]$ & Facilitate the formation of unstable intermediates at the early & $\mathrm{N}$ \\
\hline$[147]$ & Tightly bound moisture generates radical sites & $\mathrm{Numerical} \mathrm{solution}$ \\
\hline Literatures & Inhibition of coal oxidation and self-heating & $\mathrm{N}$ \\
\hline$[15,131,145]$ & Water can occupy active sites in coal surface and block pores & $\mathrm{N}$ \\
\hline$[148]$ & Vapour pressure in pores blocks access for oxygen & $\mathrm{Y}$ \\
\hline
\end{tabular}

Table 5 Reported critical water contents for different coals

\begin{tabular}{|c|c|c|}
\hline Literatures & Coal type & Critical moisture content/\% \\
\hline$[146]$ & A New Zealand subbituminous coal & 8.1 \\
\hline \multirow{2}{*}[145]{} & Brown coals & $5 \sim 10$ \\
\cline { 2 - 3 } & Two lignites & $\sim 7$ \\
\cline { 2 - 4 } & A sub-bituminous coal & $\sim 20$ \\
\hline$[23]$ & A U.S. lignite & $5 \sim 8$ \\
\hline \multirow{2}{*}[151]{} & Brown coals & $1.5 \sim 2$ \\
\hline & Subbituminous coals & $0.5 \sim 0.7$ \\
\hline & Bituminous coals to anthracites & 8.3 \\
\hline
\end{tabular}


Appendix A-Parametric studies conducted by various investigators

\begin{tabular}{|c|c|c|c|c|c|c|c|c|c|c|c|}
\hline \multirow[b]{2}{*}{ Reference } & \multicolumn{11}{|c|}{ Examined variables and assigned values } \\
\hline & Coal reactivity & Particle size $(\mathrm{m})$ & $\begin{array}{c}\text { Moisture } \\
\text { content (\% by } \\
\text { mass) }\end{array}$ & $\begin{array}{l}\text { Stockpile } \\
\text { height }(\mathrm{m})\end{array}$ & $\begin{array}{l}\text { Stockpile } \\
\text { slope (o) }\end{array}$ & $\begin{array}{l}\text { Packing } \\
\text { porosity }\end{array}$ & Airflow velocity (m/s) & $\begin{array}{l}\text { Bed } \\
\text { length } \\
(\mathrm{m})\end{array}$ & $\begin{array}{l}\text { Thermal } \\
\text { conductivity(W m-1 } \\
\text { K-1) }\end{array}$ & $\begin{array}{l}\text { Initial } \\
\text { temperature } \\
\text { (K) }\end{array}$ & $\begin{array}{c}\text { Oxygen } \\
\text { concentration } \\
(\%)\end{array}$ \\
\hline [23] & - & - & - & - & - & $\begin{array}{l}0.1,0.125, \\
0.15,0.175 \\
\end{array}$ & - & - & - & - & - \\
\hline [54] & $\begin{array}{c}\text { Various values of } \\
\text { activation energy }(8, \\
20,40,60) \text { and rate } \\
\text { constants, Elovich } \\
\text { effect }\end{array}$ & - & - & - & - & . & $\begin{array}{c}0,1 \times 10^{-5}, 2 \times 10^{-5}, 5 \times 10^{-5}, \\
2 \times 10^{-4}\end{array}$ & $\begin{array}{l}3.4,4.5 \\
4.6,8\end{array}$ & - & - & - \\
\hline [55] & $\begin{array}{c}\text { Various values of } \\
\text { pre-exponential } \\
\text { factor }(1.2 \times 10-10, \\
4.2 \times 10-10,1.2 \times 10- \\
\text { 9), deterioration } \\
\text { effect }\end{array}$ & - & 0,8 & - & - & $0.05,0.2,0.3$ & $\begin{array}{c}2 \times 10^{-7}, 2 \times 10^{-6}, 6 \times 10^{-6}, 2 \times 10^{-} \\
5,2 \times 10^{-4}\end{array}$ & - & $0.12,0.2$ & 283,293 & - \\
\hline [58] & $\begin{array}{c}\text { Various values of } \\
\text { activation energy } \\
(53,62,71) \text { and pre- } \\
\text { exponential factor } \\
(1,10,100)\end{array}$ & - & - & - & - & $0.2,0.3,0.4$ & - & $1,5,10$ & - & - & - \\
\hline [67] & - & $\begin{array}{l}5.625 \times 10^{-5} \\
1.125 \times 10^{-4}, \\
2.25 \times 10^{-4}\end{array}$ & - & - & - & $0.165,0.33$ & $2.2,4.4$ & - & - & - & - \\
\hline [65] & - & $0.01,0.02,0.03$ & Dry, moist & - & - & - & $0.5 \times 10^{-5}, 1 \times 10^{-5}, 2 \times 10^{-5}$ & - & - & - & - \\
\hline [62] & $\begin{array}{l}\text { Two values of pre- } \\
\text { exponential factors } \\
\left(8.83 \times 10^{7}, 8.83 \times 10^{5}\right)\end{array}$ & $0.0023,0.0096$ & - & - & $\begin{array}{c}11.3,14,18.4, \\
20,21.8,26.6, \\
39.8\end{array}$ & $\begin{array}{c}0.06,0.12, \\
0.18,0.24, \\
0.3,0.36\end{array}$ & $0.45,2.23,4.46,6.69,8.93$ & - & - & - & - \\
\hline [70] & $\begin{array}{l}\text { Varying values of } \\
\text { pre-exponential } \\
\text { factors }\end{array}$ & $0.003 \sim 0.015$ & $0 \sim 30$ & - & - & - & - & - & - & 293 333 & - \\
\hline [32] & - & - & - & $\begin{array}{l}0.85,1,1.2, \\
1.8,2.4, \\
\text { infinite }\end{array}$ & - & - & - & - & - & - & - \\
\hline [64] & $\begin{array}{c}\text { Three coals with } \\
\text { different Arrhenius } \\
\text { constants }\end{array}$ & - & $\begin{array}{l}16.81,1.81 \\
35.4\end{array}$ & $\begin{array}{c}1,1.5,2,3,4 \\
5\end{array}$ & $26,34,45,63$ & $0.2,0.3,0.4$ & - & - & - & - & - \\
\hline [78] & $\begin{array}{c}\text { Various values of } \\
\text { activation energy } \\
(40,26.88,58 \\
30.64) \text { and pre- } \\
\text { exponential factor } \\
\left(10,6,8.83 \times 10^{6}\right. \\
1485) \\
\end{array}$ & - & - & - & - & $\begin{array}{l}0.2,0.3 \\
0.35,0.4\end{array}$ & - & - & - & - & - \\
\hline [115] & - & - & - & - & - & $\begin{array}{c}0.1,0.13 \\
0.15,0.17 \\
0.2,0.25,0.3\end{array}$ & $0,5,10$ & - & - & - & - \\
\hline [26] & - & & & $\begin{array}{c}3,4,5,6,7.5 \\
9\end{array}$ & $\begin{array}{c}45,56.3,71.6 \\
80.5\end{array}$ & $\begin{array}{c}0.1,0.15 \\
0.2,0.25 \\
0.3,0.35,0.4 \\
\end{array}$ & $0.001,0.05,0.5,1$ & - & - & - & $\begin{array}{c}5,8,10,15,18 \\
21\end{array}$ \\
\hline [74] & - & - & - & - & - & - & $1,2,3,4,6,10$ & - & - & - & - \\
\hline
\end{tabular}


